Portland State University

PDXScholar

Civil and Environmental Engineering Faculty

Publications and Presentations

Civil and Environmental Engineering

$8-2000$

\title{
Theoretical Basis for the CE-QUAL-W2 River Basin Model
}

\author{
Scott A. Wells \\ Portland State University \\ Thomas M. Cole \\ U.S. Army Engineer Research and Development Center
}

Follow this and additional works at: https://pdxscholar.library.pdx.edu/cengin_fac

Part of the Fresh Water Studies Commons, Hydrology Commons, and the Water Resource Management Commons

Let us know how access to this document benefits you.

\section{Citation Details}

Wells, S. A., and Cole, T. M. (2000). "Theoretical basis for the CE-QUAL-W2 river basin model," ERDC/EL TR-00-7, U.S. Army Engineer Research and Development Center, Vicksburg, MS.

This Article is brought to you for free and open access. It has been accepted for inclusion in Civil and Environmental Engineering Faculty Publications and Presentations by an authorized administrator of PDXScholar. Please contact us if we can make this document more accessible: pdxscholar@pdx.edu. 


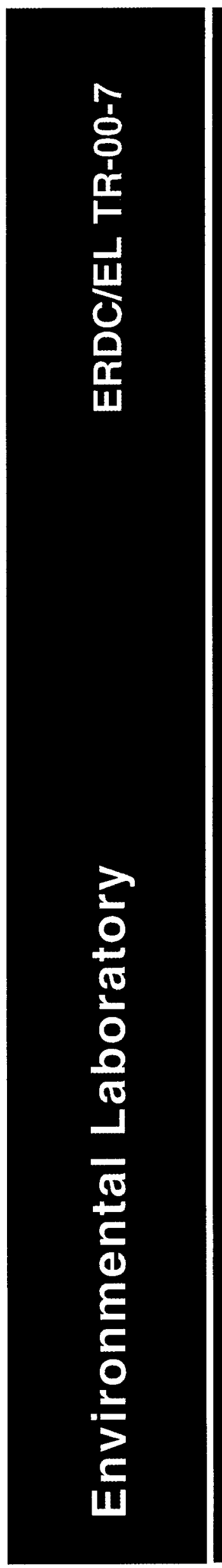

Water Quality Research Program

Theoretical Basis for the CE-QUAL-W2 River Basin Model

Scott A. Wells and Thomas M. Cole

August 2000

US Army Corps

of Engineers $S_{\circledast}$

Engineer Research and Development Center



Approved for public release; distribution is unlimited. 
The contents of this report are not to be used for advertising, publication, or promotional purposes. Citation of trade names does not constitute an official endorsement or approval of the use of such commercial products.

The findings of this report are not to be construed as an official Department of the Army position, unless so designated by other authorized documents. 


\section{Theoretical Basis for the CE-QUAL-W2 River Basin Model}

by Scott A. Wells

Department of Civil Engineering

Portland State University

Portland, OR 97207-0751

Thomas M. Cole

Environmental Laboratory

U.S. Army Engineer Research and Development Center 3909 Halls Ferry Road

Vicksburg, MS 39180-6199

Final report

Approved for public release; distribution is unlimited 


\section{Engineer Research and Development Center Cataloging-in-Publication Data}

\section{Wells, Scott A.}

Theoretical basis for the CE-QUAL-W2 River Basin Model / by Scott A. Wells, Thomas M. Cole ; prepared for U.S. Army Corps of Engineers.

62 p. : ill. ; $28 \mathrm{~cm}$.- (ERDC/EL ; TR-00-7)

Includes bibliographic references.

1. CE-QUAL-W2 (Computer program) 2. Watersheds -- Computer programs. 3. Water quality -Computer programs. I. Cole, Thomas M. II. United States. Army. Corps of Engineers. III. U.S. Army Engineer Research and Development Center. IV. Environmental Laboratory (U.S.) V. Water Quality Research Program (U.S.) VI. Title. VII. Series: ERDC/EL TR; 00-7. TA7 E8 no.ERDC/EL TR-00-7 


\section{Table of Contents}

Preface

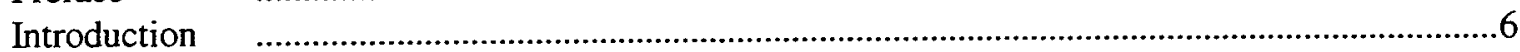

River Basin Model Development Rationale ……...........................................................................

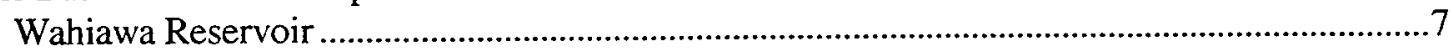

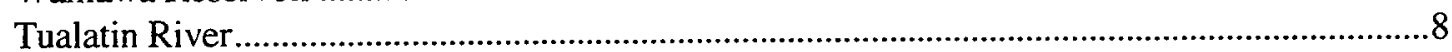

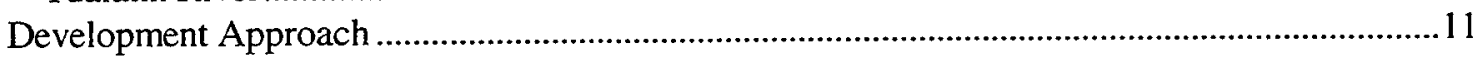



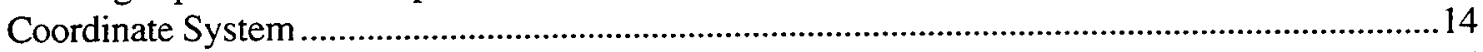

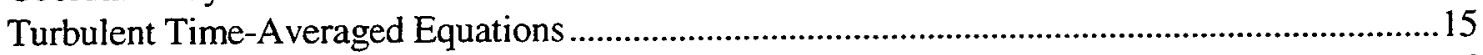

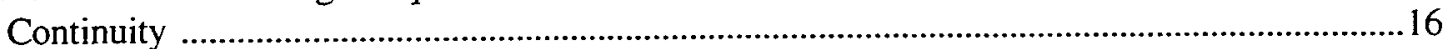

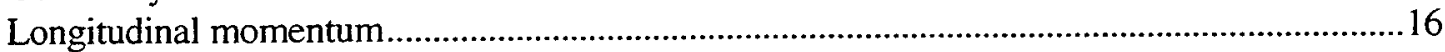

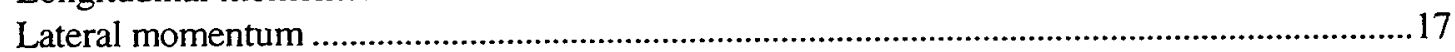



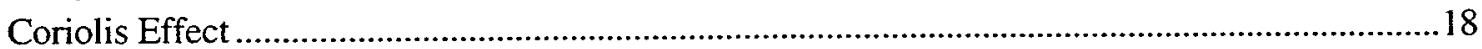

Coordinate System Transformation...................................................................................19

Governing Equations for General Coordinate System............................................................21

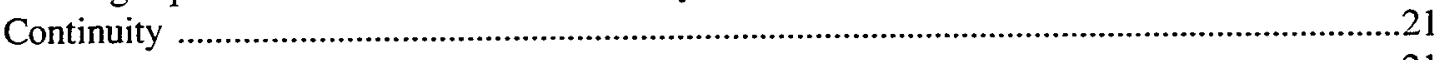

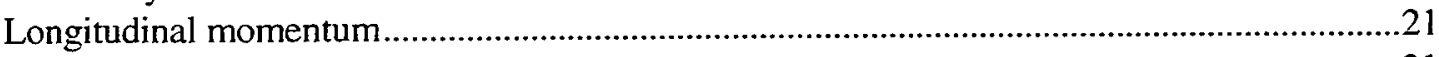

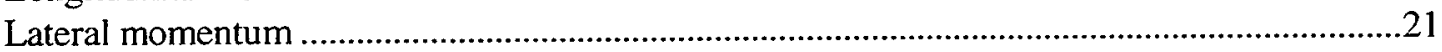

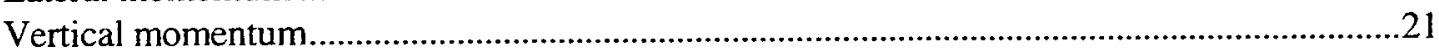



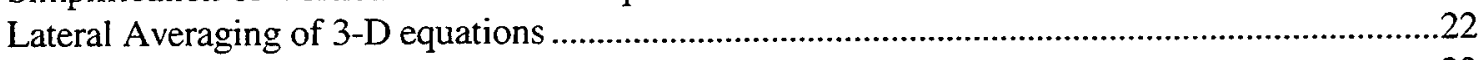



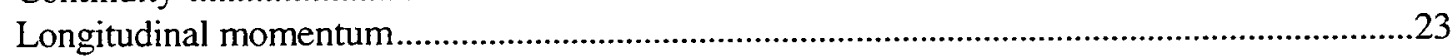

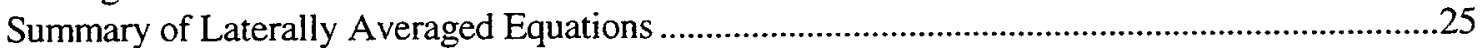

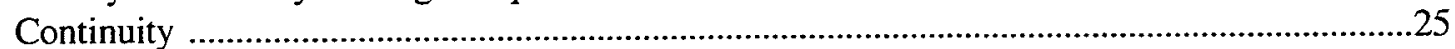

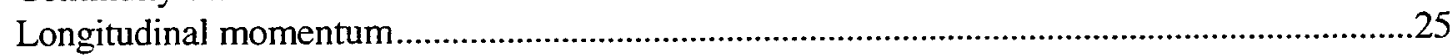

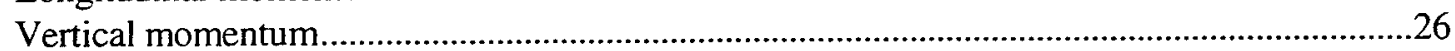

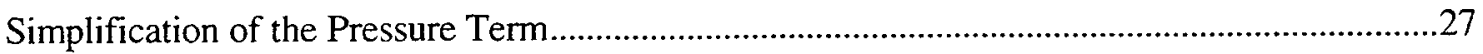

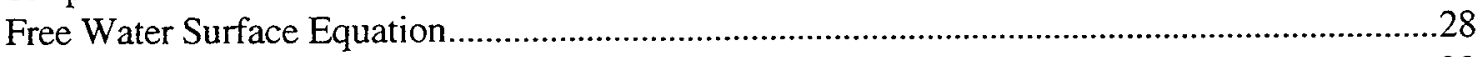

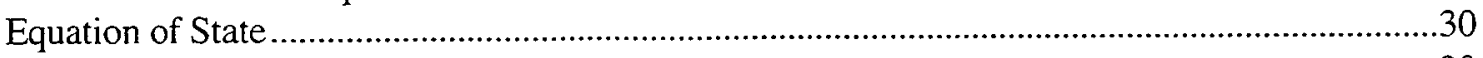

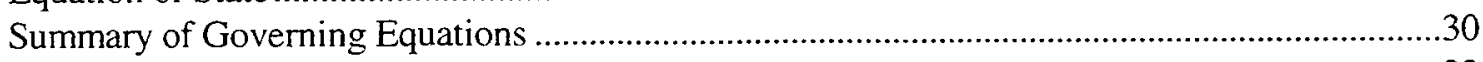

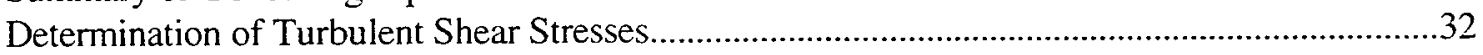





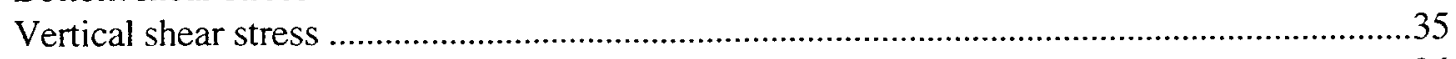

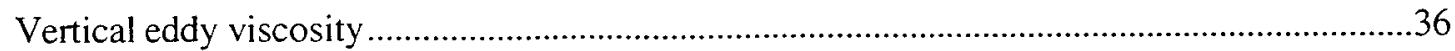

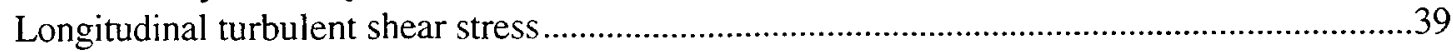


Validation of Velocity Field

Variability in Meteorological Forcing..

Air temperature

Dew-point temperature

Alternative solar radiation calculation....

Variability in Reaeration Formulae

Theoretical reaeration formulae as function of wind speed

Theoretical formulae as a function of boundary shear.

Temperature dependence of reaeration formulae

Linkage of Branches with Internal Head Boundary Conditions

Linkage of mainstem branches

Linkage of tributary branches

Longitudinal momentum.

Cross-shear of tributary inflow

Additional River Basin Model Issues

References 


\section{List of Figures}

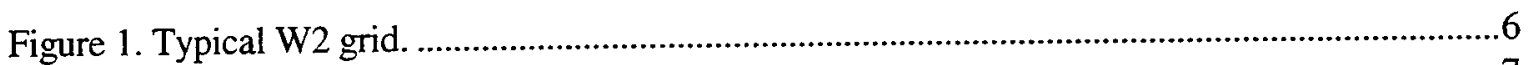

Figure 2. Wahiawa Reservoir, Oahu, Hawaii. ……..............................................................................

Figure 3 Comparison of WQRSS and W2 schematization for Wahiawa Reservoir. ........................9

Figure 4. Schematic of river-reservoir linkage where $\alpha$ is the slope of the channel bottom..............10

Figure 5. Tualatin River channel bottom elevations as a function of River mile. Channel slope from

RM 68 to 62 is about $0.003\left(\alpha=0.2^{\circ}\right)$ and the slope from RM 62 to RM 32 is about

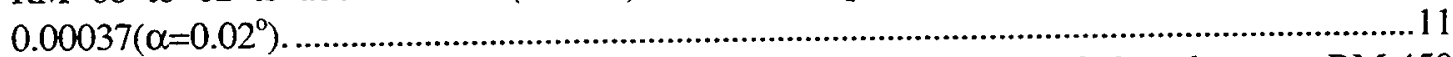

Figure 6. Snake River channel bottom elevation versus River mile. Channel slope between RM 450

and 385 was about $2.5 \mathrm{E}-4$. The slope between RM 385 and 335 was about $4.3 \mathrm{E}-4$.................12

Figure 7. Coordinate system for governing equations ( $x$ is oriented $\mathrm{E}, \mathrm{y}$ is oriented $\mathrm{N}$, and $\mathrm{z}$ is



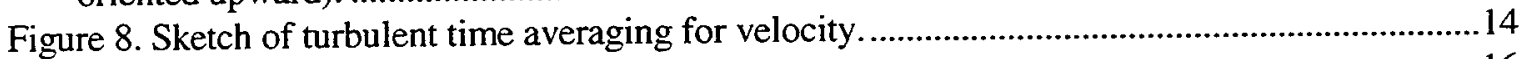

Figure 9. Sketch of turbulent shear stresses in $\mathrm{x}$-direction.................................................................16

Figure 10. Sketch of turbulent shear stresses in $y$-direction...........................................................17

Figure 11. Sketch of turbulent shear stresses in $y$-direction.............................................................. 17

Figure 12. General coordinate system with $z$-axis compatible with

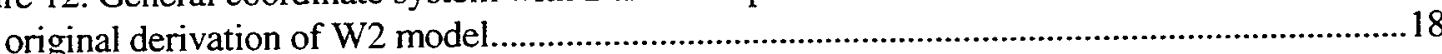

Figure 13. Sketch of channel slope and coordinate system for W2 where the $\mathrm{x}$-axis is

oriented along the channel slope..............................................................................................19

Figure 14. Lateral average and deviation from lateral average components of

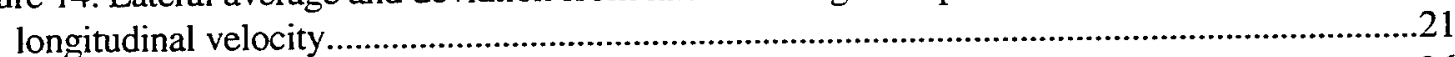

Figure 15. Illustration of layout for simplification of pressure term..............................................26

Figure 16. W2 coordinate system with no channel slope...............................................................27

Figure 17. W2 coordinate system with finite channel slope. ...........................................................28

Figure 18. Definition sketch for channel slope (exaggerated slope) .................................................30

Figure 19. Wind stress on the water surface...................................................................................31

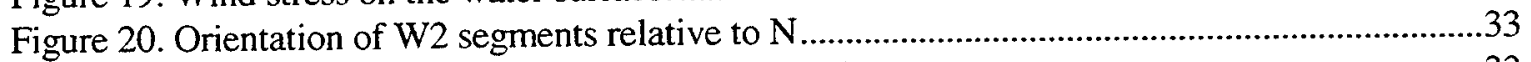

Figure 21. Orientation of wind velocity relative to North ............................................................33

Figure 22. Decay of wind shear with depth. ................................................................................35

Figure 23. Comparison of solar radiation formulae for daily average clear-sky

conditions using current W2 model equation and those used in QUAL2E

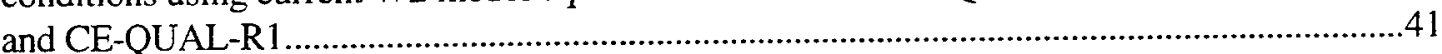

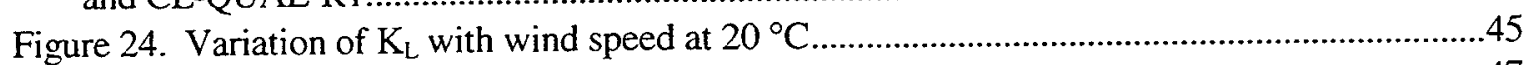

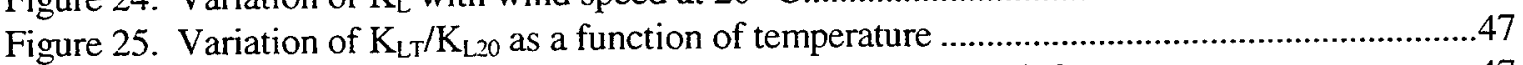

Figure 26. Variable definitions for W2 model with arbitrary channel slope. .....................................47

Figure 27. Branch transition vertically .......................................................................................4

Figure 28. Variation of longitudinal velocity between segments.................................................48

Figure 29. Illustration of branch transition. ..................................................................................48

Figure 30. Transfer of mass and momentum between main stem branches with unequal



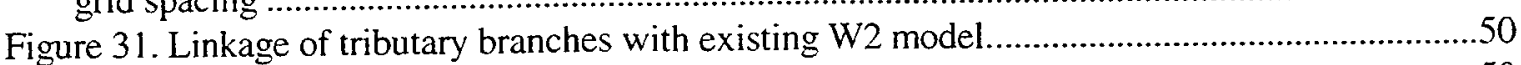

Figure 32. Linkage of tributary branch coming in at an angle to main branch.................................50 
Figure 33. Schematic of branch connection.

\section{List of Tables}

Table 1. Comparison of governing equations for CE-QUAL-W2 with and without channel slope...31 Table 2. Typical vertical eddy viscosity $\left(A_{v}\right)$ formulations for shallow systems that are vertically well-mixed where $\tau_{z}=A_{v} \frac{\partial u}{\partial z}$

Table 3. Typical vertical eddy viscosity $\left(A_{v}\right)$ formulations for systems that are continuously stratified where $\tau_{z}=A_{v} \frac{\partial u}{\partial z}$ 


\section{Preface}

The work reported herein was conducted as part of the Water Quality Research Program (WQRP), Work Unit Number 33251. The WQRP is sponsored by Headquarters, U.S. Army Corps of Engineers (HQUSACE), and is assigned to the U.S. Army Engineer Research and Development Center (ERDC) under the purview of the Environmental Laboratory (EL), Vicksburg, MS. Dr. John W. Barko was Program Manager for the WQRP, and Mr. Robert C. Gunkel, Jr., was Assistant Manager. Program Monitor during this study was Mr. Frederick B. Juhle, HQUSACE.

This report presents the theoretical basis for the extension of CE-QUAL-W2 to model entire river basins including steeply sloping rivers, reservoirs, and estuaries.

The study was conducted and the report written by Dr. Scott A. Wells of the Department of Civil Engineering, Portland State University, Portland, OR, and Mr. Thomas M. Cole of the Water Quality and Contaminant Modeling Branch (WQCMB), Environmental Processes and Effects Division (EPED), EL. Technical review by Dr. Mark S. Dortch, Chief, WQCMB, and Ms. Lillian T. Schneider, WQCMB, is gratefully acknowledged.

This investigation was conducted under the general supervision of Dr. John Keeley, Acting Director, EL, and Dr. Richard E. Price, Chief, EPED, and under the direct supervision of Dr. Dortch.

At the time of publication of this report, Dr. James R. Houston was Director of ERDC, and COL James S. Weller, EN, was Commander.

This report should be cited as follows:

Wells, S. A., and Cole, T. M. (2000). "Theoretical basis for the CE-QUAL-W2 river basin model," ERDC/EL TR-00-7, U.S. Army Engineer Research and Development Center, Vicksburg, MS. 


\section{Introduction}

CE-QUAL-W2 (W2) is a two-dimensional (2-D) water quality and hydrodynamic code supported by the USACE Waterways Experiments Station (Cole and Buchak, 1995). The model has been widely applied to surface water systems such as lakes, reservoirs, and estuaries. W2 predicts water levels, horizontal/vertical velocities, temperature, and 21 other water quality parameters. A typical grid for this model is shown in Figure 1 where the vertical axis is aligned with gravity.

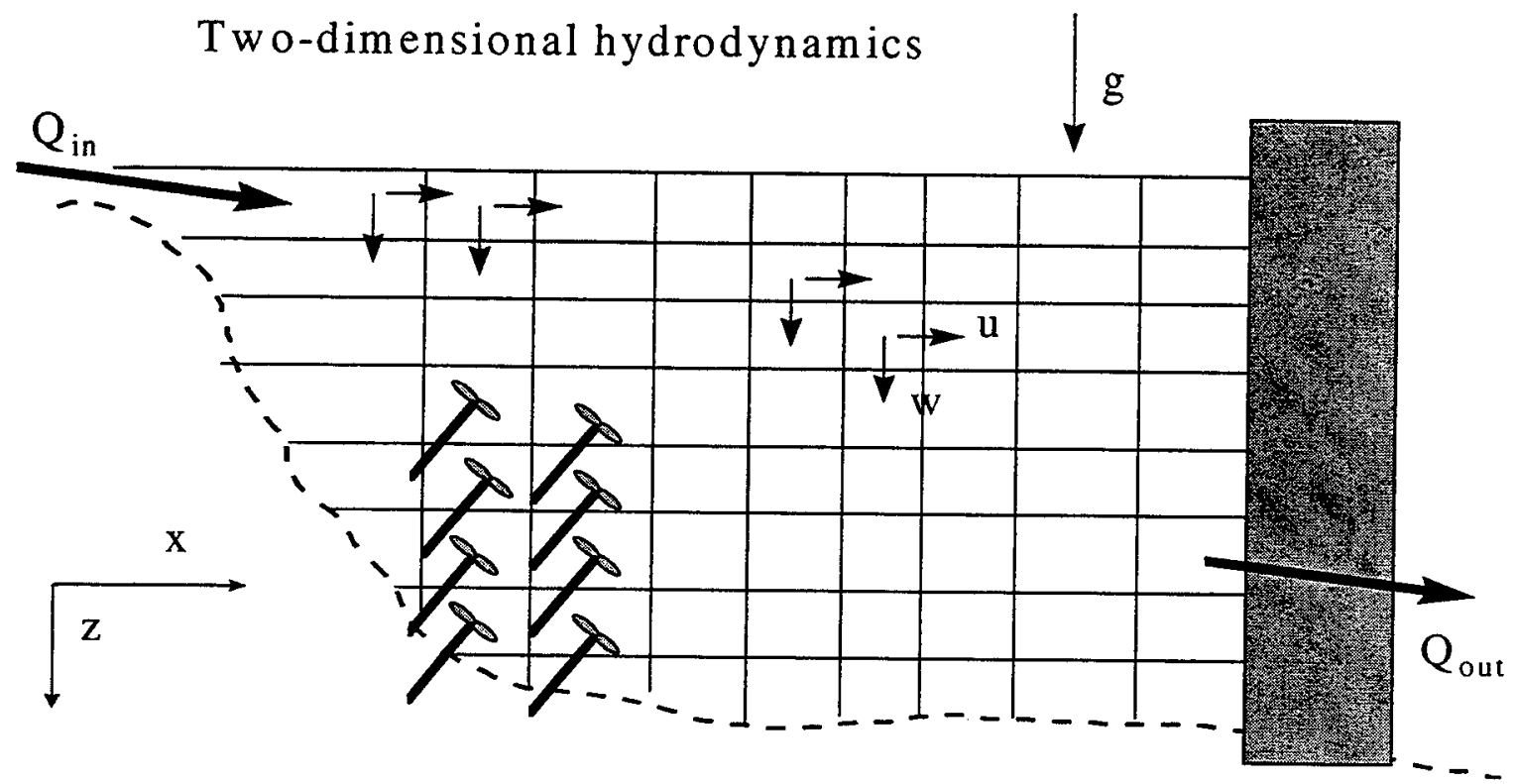

Figure 1. Typical W2 grid.

The primary objective of this research is to integrate a riverine model into the existing W2 code that would provide the capability for modeling entire watersheds. This task was accomplished by the following steps:

- Formal derivation of governing equations and solution algorithm with general channel slope

- Detailed analysis of algorithm for linking branches and smooth implementation of boundary conditions between branches

- Algorithm development and changes to basic model code (including branch definitions with slope, slope correction to solution algorithm, transfer of momentum between internal branches)

These tasks were performed with the following constraints and initiatives:

- Utilize the same solution algorithms as the existing code for hydrodynamics and water quality for the riverine system 
- Allow momentum transfer between adjacent branches for internal head boundary conditions

- Refine the turbulence closure hypothesis for riverine sections

\section{River Basin Model Development Rationale}

W2 has been in use for the last several decades as a tool for water quality managers to assess the impacts of management strategies on river, reservoir, lake, and estuarine systems. A predominant feature of the model is its ability to compute the 2-D velocity field for narrow systems that stratify. In contrast to many reservoir models that are zero-dimensional hydrodynamic models, an understanding of the fluid mechanical transport can be as important as the reaction kinetics in the water column.

One limitation of W2 is its inability to model steeply sloping river stretches and hence an entire water basin. Models, such as WQRSS, HEC-5Q, and HSPF have been developed for water basin modeling but have serious limitations. The most serious limitation is that the HEC-5Q (similar to WQRSS) and HSPF models incorporate a one-dimensional (1-D) longitudinal river model with a one-dimensional vertical reservoir model (1-D in water quality and $0-D$ in hydrodynamics). The modeler must choose the location of the transition from 1-D longitudinal to 1-D vertical. Besides the problem of not solving for the velocity field in the stratified, reservoir system, any point source inputs to the reservoir section are spread over the entire longitudinal distribution of the reservoir cell. This has created problems in the following two WQRSS water quality modeling studies.

\section{Wahiawa Reservoir}

Wahiawa Reservoir (a narrow, 5 mile long reservoir with $100 \mathrm{ft}$ depth at the dam). The HEC WQRSS model was initially applied to this two-fork reservoir system. The system is shown in Figure 2. 


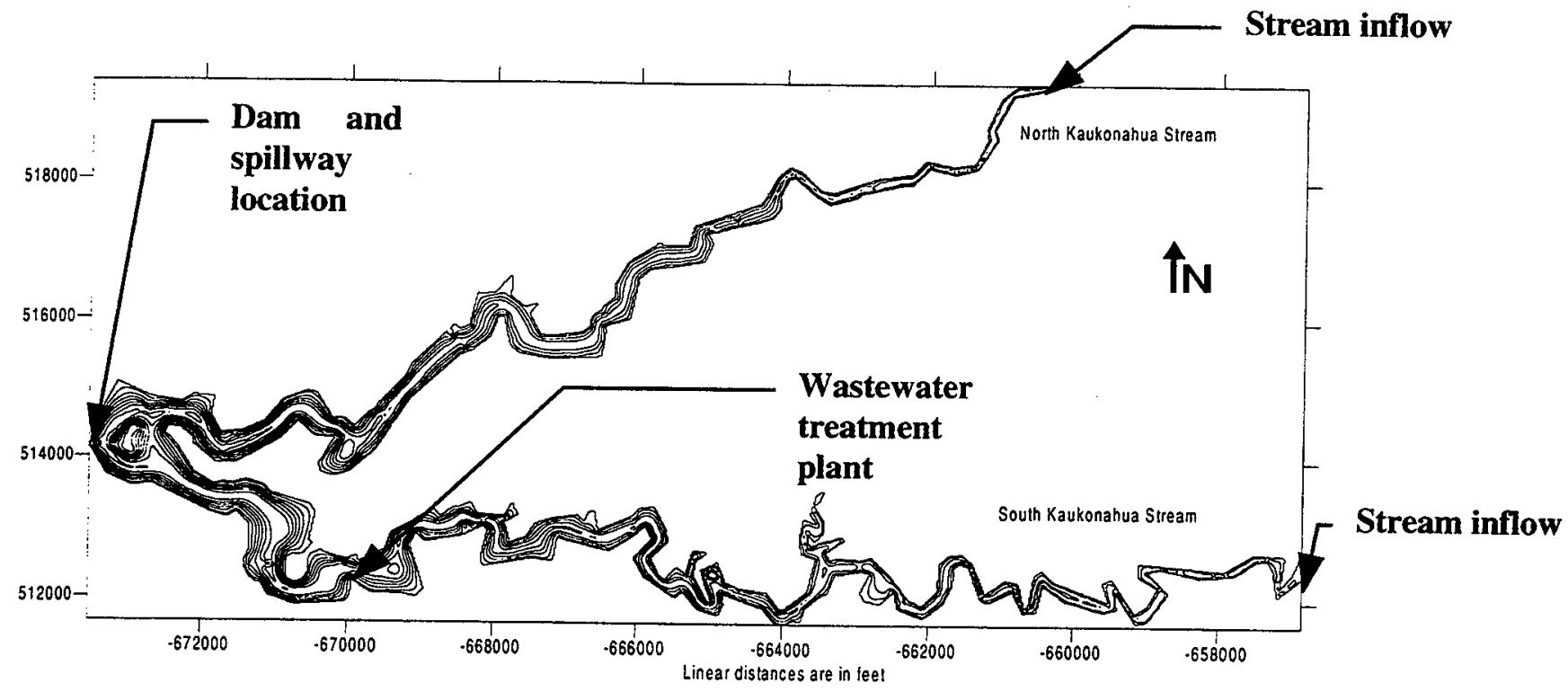

Uppermost contour level is $850 \mathrm{ft}$ MSL with a $10 \mathrm{ft}$ contour interval

Figure 2. Wahiawa Reservoir, Oahu, Hawaii.

The WQRRS model schematization is contrasted to the W2 schematization for Wahiawa Reservoir in Figure 3. The initial reservoir study using WQRRS produced poor results even after expending large resources to "make" the model work. The modeling effort did not provide a management tool for water quality managers because of gross errors in setting up the model, i.e., combining the two forks and spreading the discharge from the wastewater treatment plant throughout the length of the reservoir.

\section{Tualatin River}

The Tualatin River, located in Oregon, is a 32-mile long, narrow, stratified system, with pools 25$30 \mathrm{ft}$ deep. The WQRSS model was applied to this system incorrectly because the modelers decided to break the system from a river to a reservoir at the location of a wastewater treatment plant discharge. Hence, a large section of the Tualatin that stratified was modeled as completely mixed because the modelers knew it would be inappropriate to spread a point source over 32 miles if this section was chosen as a stratified system. A later application of W2 (Berger and Wells, 1995) correctly represented the physics of the system.

In these two cases, the application of WQRSS had serious limitations for the reservoir section. W2 was subsequently applied to these cases and was able to be used effectively because of its 2-D hydrodynamics and water quality.

Other hydraulic and water quality models in common use for unsteady flow include the 1-D dynamic EPA model DYNHYD (Ambrose, et al., 1988), used together with the multidimensional water quality model WASP. WASP relies on DYNHYD for the 1-D hydrodynamics. If WASP is used in a multi-dimensional schematization, the modeler must supply dispersion coefficients to allow transport in the vertical or lateral directions. In addition, the Corps model, CE-QUAL-RIV 1 (Environmental Laboratory, 1995), is a one-dimensional dynamic flow and water quality model used for one-dimensional river or stream sections. Each of these models does not have the ability to characterize adequately the hydraulics or water quality of deeper reservoir systems or deep river pools that stratify. 
W2, even though able to handle narrow systems that stratify, is not well-suited for one-dimensional river channels. In the development of $\mathrm{W} 2$, vertical accelerations were considered negligible compared to gravity forces. This assumption lead to the hydrostatic pressure approximation for the $z$-momentum equation. In sloping channels, this assumption is not always valid because the vertical accelerations cannot be neglected if the $x$ and $z$ axes are aligned with an elevation datum and gravity, respectively. In addition, the current W2 algorithm does not allow the upstream bed elevation to be above the downstream water surface elevation. If one wanted to use the existing model for sloping channels, one would have to break the sloping section into multiple small branches. Because water basin modeling is becoming more and more essential for water quality managers, providing the capability for W2 to be used as a complete tool for water basin modeling is an essential step in upgrading the state-of-the-art in modeling river basins. 


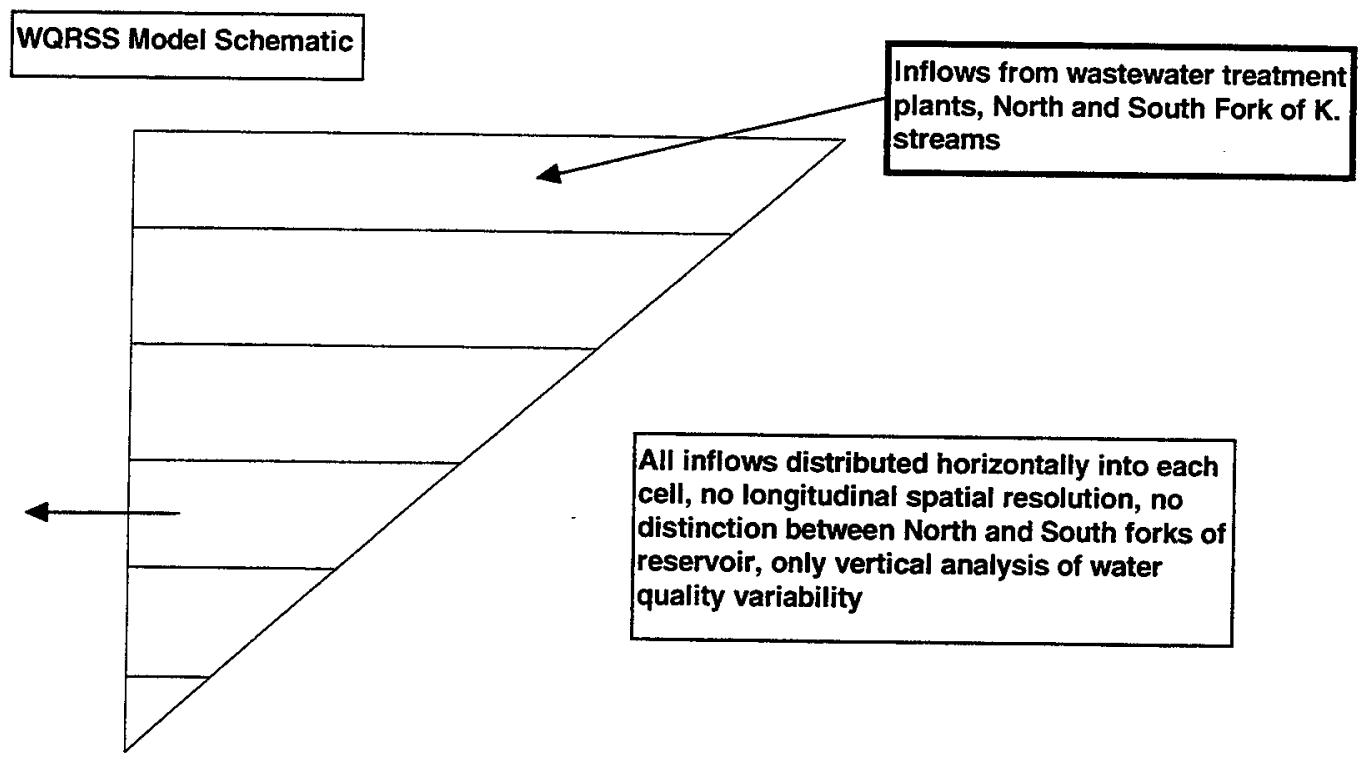

\section{CE-QUAL-W2 Schematic}

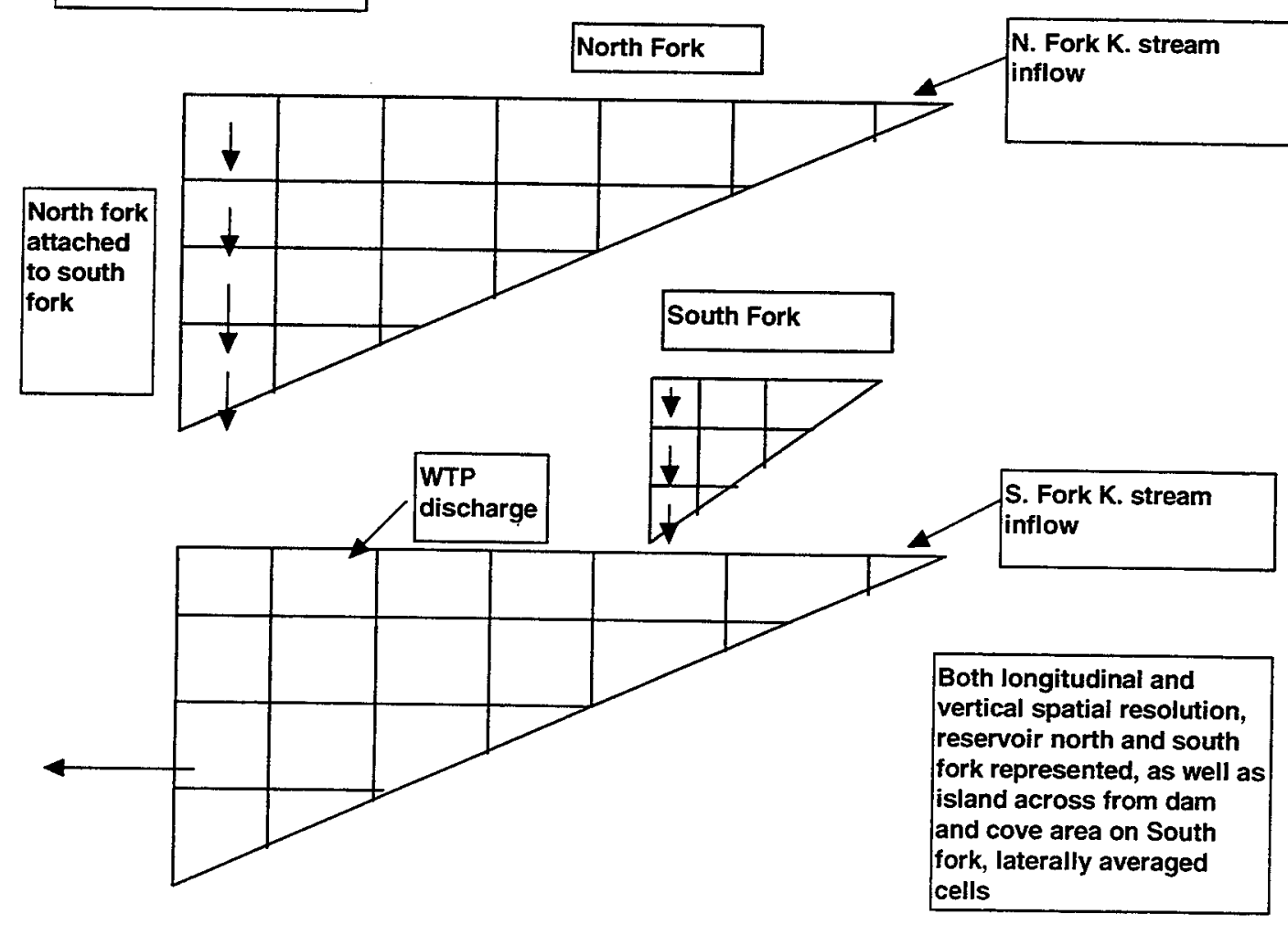

Figure 3. Comparison of WQRSS and W2 schematization for Wahiawa Reservoir. 


\section{Development Approach}

There are many approaches that could be implemented within W2 for riverine branches. By choosing a theoretical basis for the riverine branches that uses the existing 2-D computational scheme for hydraulics and water quality, the following benefits accrue:

- code updates in the computational scheme will affect the entire model rather than just one of the computational schemes for either the riverine or the reservoir sections leading to easier code maintenance

- no changes would be made to the temperature or water quality solution algorithms

- by using the two-dimensional framework, the riverine branches would also have the ability to predict the velocity and water quality field in two dimensions. This has advantages in modeling the following processes: sediment deposition and scour, particulate (algae, detritus, suspended solids) sedimentation, and sediment flux processes.

- since the entire watershed model has the same theoretical basis, setting up branches and interfacing branches involves the same process whether for reservoir or riverine sections, thus making code maintenance and model set-up easier.

The theoretical approach will be to allow each branch segment to have a channel slope. The governing equations will then be re-derived assuming that the gravity force in the $\mathrm{x}$ and $\mathrm{z}$ momentum equations is adjusted by the channel slope. This is shown schematically in Figure 3.

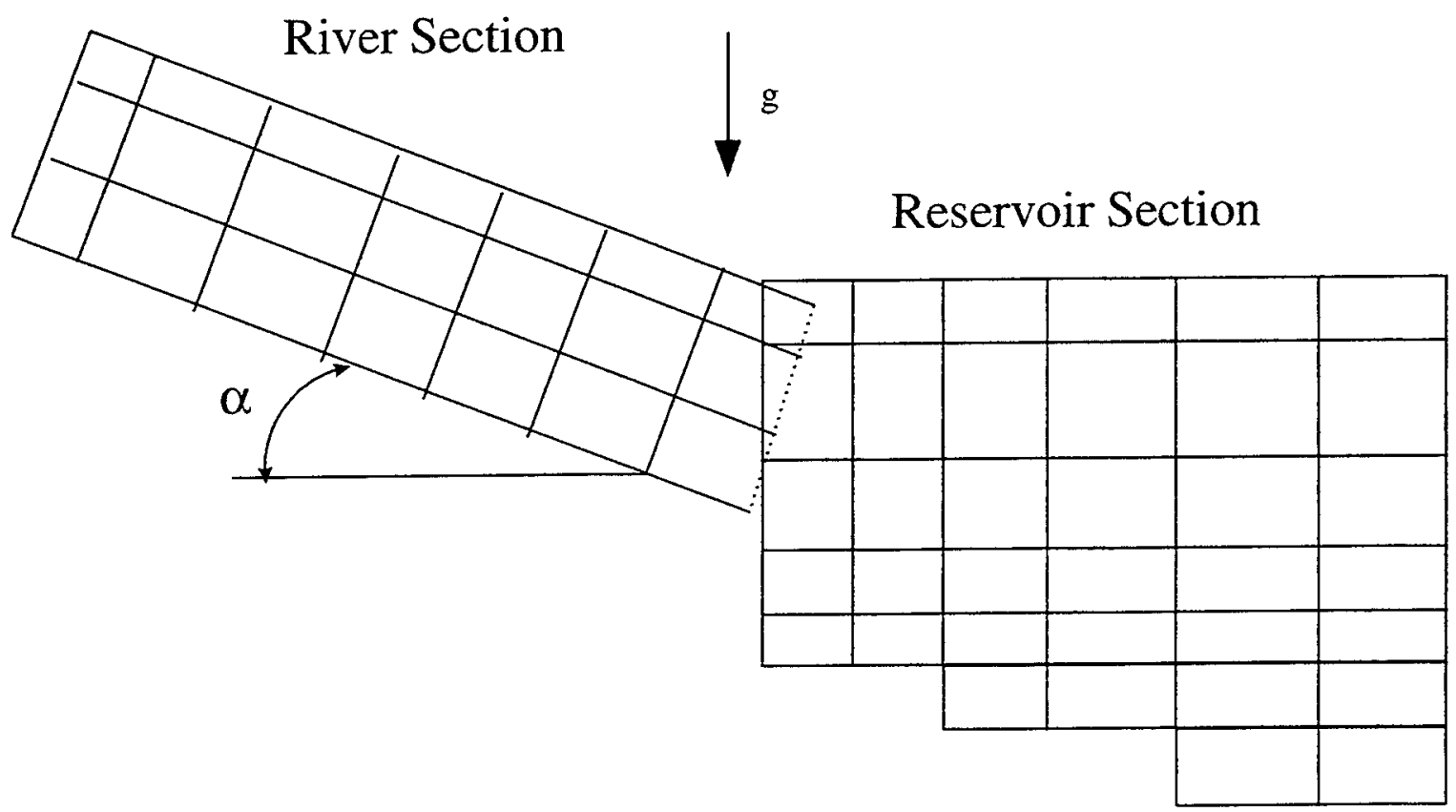

Figure 4. Schematic of river-reservoir linkage where $\alpha$ is the slope of the channel bottom.

The turbulence closure hypothesis used in the reservoir sections may not be completely adequate in the riverine branches. Various turbulence closure hypotheses will be explored. 
At the interface between the two branches (a riverine and a reservoir branch), an internal head boundary condition would be specified. In the present model configuration, momentum is not transferred between branches if an internal head boundary condition is specified. The existing code would then be altered to allow momentum transfer between adjacent branches based on the angle between the branches.

As a test case, the Tualatin River upper reaches will be used with the new algorithm. Figure 5 shows the river bottom elevations as a function of river mile. Prior modeling of the pool section was reported in Berger and Wells (1995).

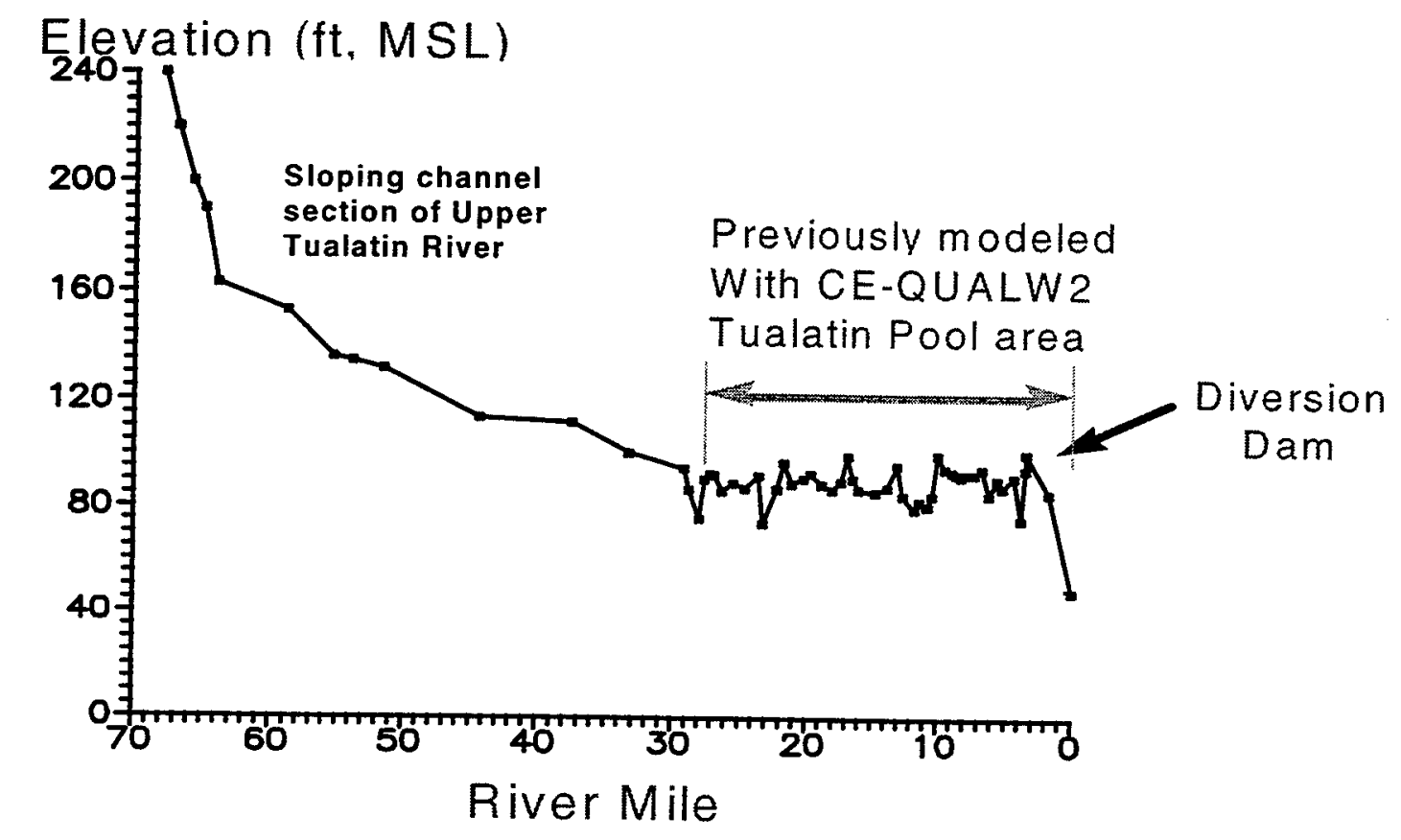

Figure 5. Tualatin River channel bottom elevations as a function of River mile. Channel slope from RM 68 to 62 is about $0.003\left(\alpha=0.2^{\circ}\right)$ and the slope from RM 62 to RM 32 is about $0.00037\left(\alpha=0.02^{\circ}\right)$.

The Snake River in Idaho will be used as another test case of the river basin model. Figure 6 shows the bottom channel elevation as a function of river mile between C. J. Strike Reservoir and Brownlee Reservoir. Recent work by Wells and Berger has taken the original W2 code and adapted it to this river system. However, this implementation required dividing up a 110 mile section of the Lower Snake River system into 91 branches and performing significant code alterations. Results of the new code development will be applied to this Lower Snake River stretch also and compared to results using the existing $\mathrm{W} 2$ formulation. 




Figure 6. Snake River channel bottom elevation versus River mile. Channel slope between RM 450 and 385 was about 2.5E-4. The slope between RM 385 and 335 was about 4.3E-4. 


\section{Governing Equations Development}

This section will formally derive the governing equations for W2 highlighting assumptions and limitations of the model equations.

\section{Coordinate System}

The general coordinate system that will be used is shown in Figure 7.

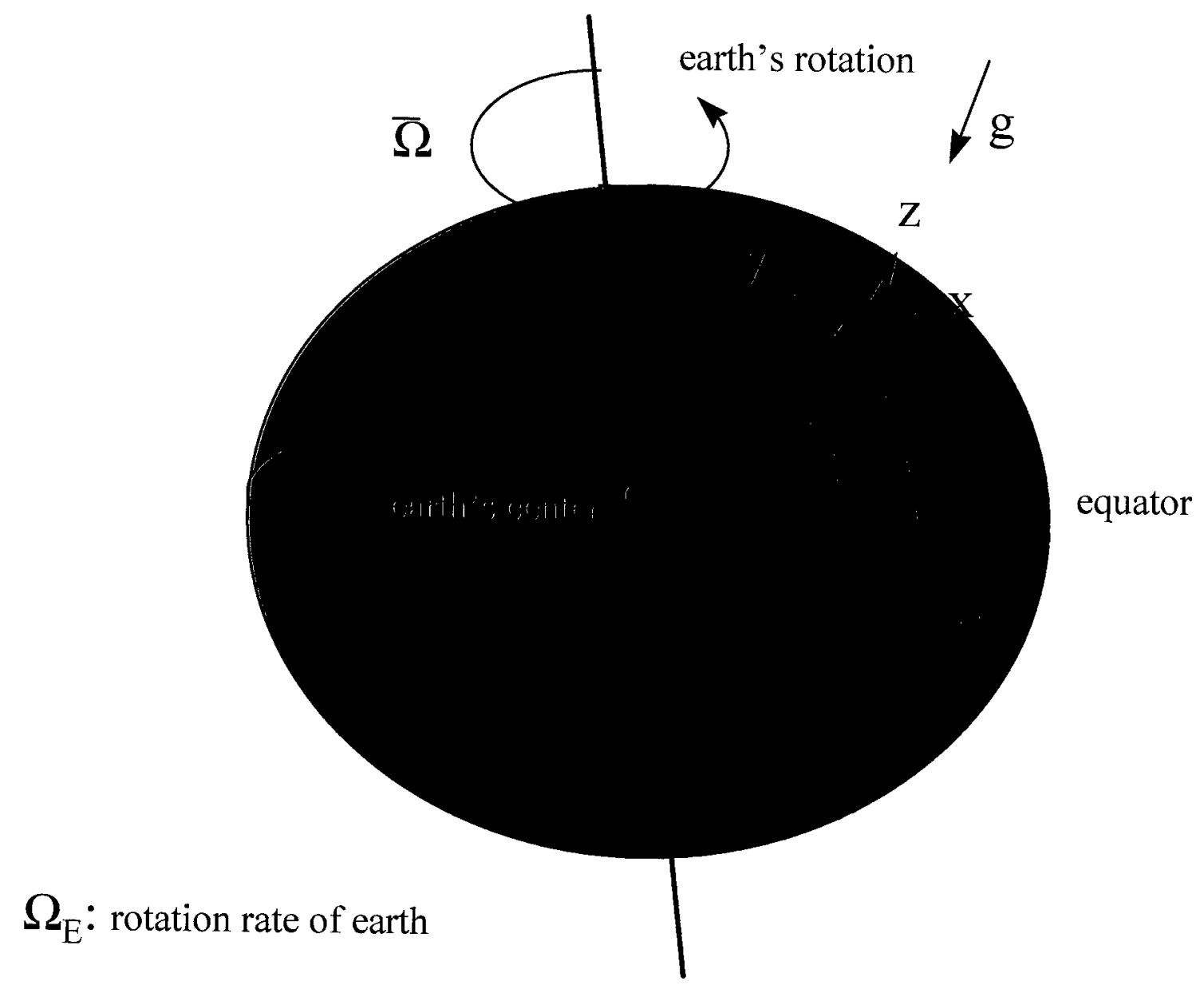

Figure 7. Coordinate system for governing equations ( $\mathrm{x}$ is oriented $\mathrm{E}, \mathrm{y}$ is oriented $\mathrm{N}$, and $\mathrm{z}$ is oriented upward). 
Note that $\Omega$ is a vector that represents the angular velocity of the earth spinning on its axis. The rotation of our coordinate system can result in significant horizontal accelerations of fluids. This is usually restricted to large water bodies, such as large lakes and ocean systems. The force that causes horizontal accelerations as a result of the spinning coordinate system is termed the Coriolis force.

\section{Turbulent Time-Averaged Equations}

The governing equations are obtained by performing a mass and a momentum balance of the fluid phase about a control volume. The resulting equations are the continuity (or conservation of fluid mass) and the conservation of momentum equations for a rotating coordinate system (Sabersky et al., 1989; Cushman-Roisin, 1994; Batchelor, 1967). After using the coordinate system in Figure 7, applying the following assumptions:

- incompressible fluid

- centripetal acceleration is a minor correction to gravity

- Boussinesq approximation

$\frac{1}{\rho}=\frac{1}{\rho_{o}+\Delta \rho} \approx \frac{1}{\rho_{o}}$ where $\rho=\rho_{o}+\Delta \rho$ where $\rho_{o}$ is a base value and $\Delta \rho$ has all variations in $\rho$

and substituting the turbulent time averages of velocity and pressure as defined below

- all velocities and pressure are considered the sum of turbulent time averages and deviations from that average, i.e., $u=\bar{u}+u^{\prime}$, where $\bar{u}=\frac{1}{T} \int_{1}^{t+T} u d t$ as shown in Figure

8. The other terms are $v=\bar{v}+v^{\prime} ; w=\bar{w}+w^{\prime}$ and $p=\bar{p}+p^{\prime}$ where the overbar represents time averaged and the prime represents deviation from the temporal average;

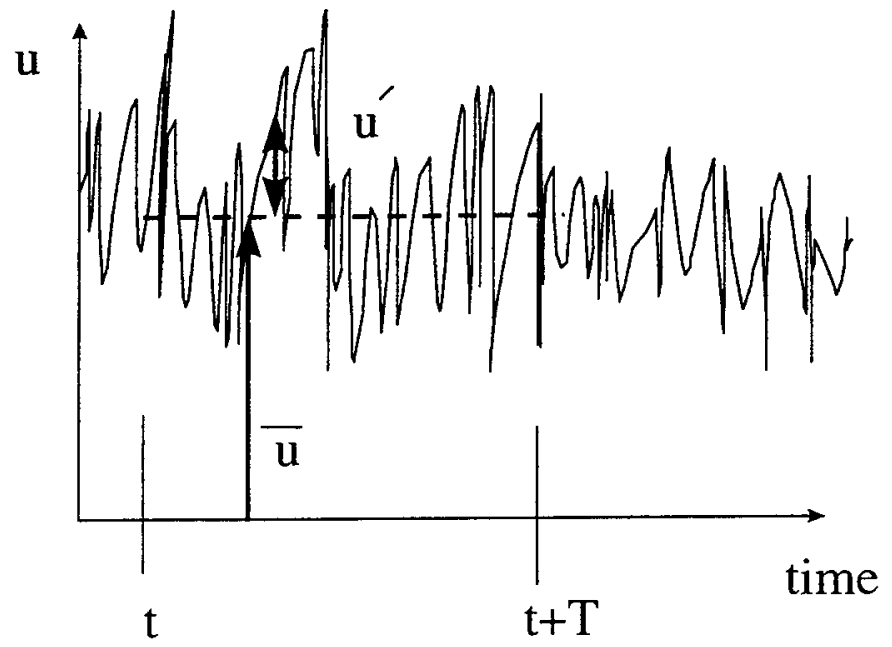

Figure 8. Sketch of turbulent time averaging for velocity. 
the governing equations become after simplification:

\section{Continuity}

$\frac{\partial \bar{u}}{\partial x}+\frac{\partial \bar{v}}{\partial y}+\frac{\partial \bar{w}}{\partial z}=0$

where $\mathrm{u}, \mathrm{v}, \mathrm{w}$ are the velocities in the $\mathrm{x}, \mathrm{y}$, and $\mathrm{z}$ axes, respectively;

\section{Longitudinal momentum}

$$
\begin{gathered}
\underbrace{\frac{\partial \bar{u}}{\partial t}}_{\text {unsteady acceleration }}+\underbrace{\bar{u} \frac{\partial \bar{u}}{\partial x}+\bar{v} \frac{\partial \bar{u}}{\partial y}+\bar{w} \frac{\partial \bar{u}}{\partial z}}_{\text {convective acceleration }} \underbrace{2 \Omega_{z} \bar{v}+2 \Omega_{y} \bar{w}}_{\text {Coriolis acceleration }}= \\
-\frac{1}{\rho \frac{\partial \bar{p}}{\partial x}}+\underbrace{\frac{\mu}{\rho}\left(\frac{\partial^{2} \bar{u}}{\partial x^{2}}+\frac{\partial^{2} \bar{u}}{\partial y^{2}}+\frac{\partial^{2} \bar{u}}{\partial z^{2}}\right)}_{\text {pressure gradient }}+\underbrace{\frac{1}{\rho} \underbrace{\left(\frac{\partial \tau_{x x}}{\partial x}+\frac{\partial \tau_{x y}}{\partial y}+\frac{\partial \tau_{x z}}{\partial z}\right)}_{\text {turbulent stresses }}}_{\text {viscous stresses }}
\end{gathered}
$$

where $\tau_{x x}$ : turbulent shear stress acting in $x$ direction on the $x$-face of control volume (see Fig. 9) $\tau_{x y}$ : turbulent shear stress acting in $x$ direction on the $y$-face of control volume (see Fig. 9) $\tau_{x z}$ : turbulent shear stress acting in $x$ direction on the $z$-face of control volume (see Fig. 9) $\mu$ : dynamic viscosity

$\Omega$ : component of Coriolis acceleration where

$\Omega_{\mathrm{z}}: \Omega_{E} \sin \phi$

$\Omega_{\mathrm{y}}: \Omega_{E} \cos \phi$

$\phi$ : latitude of the earth

$\Omega_{\mathrm{E}}$ : rotation rate of the earth 

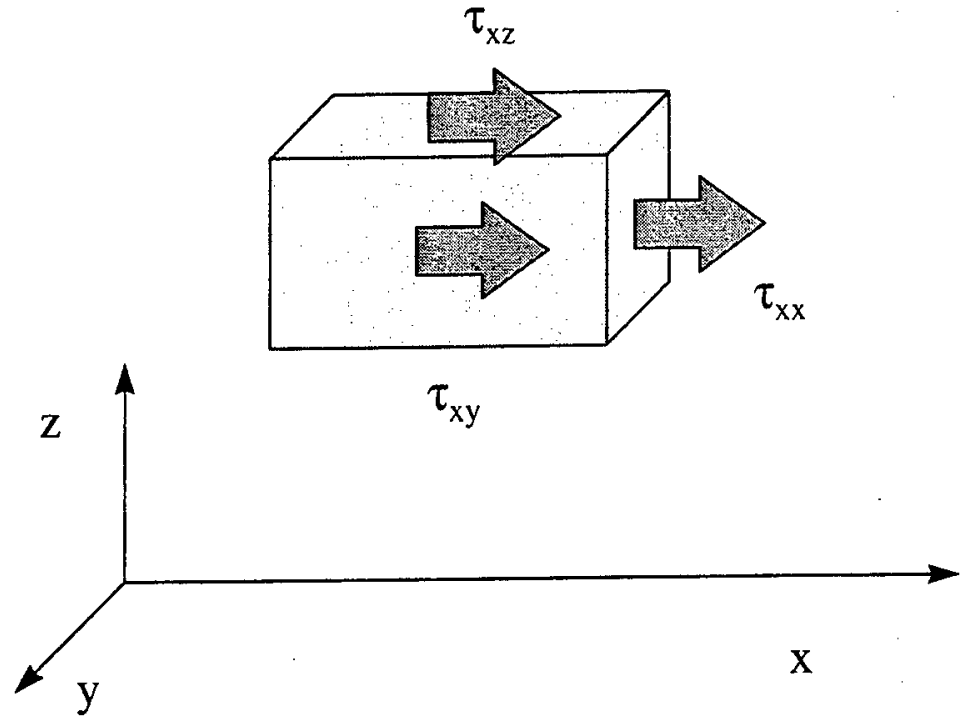

Figure 9. Sketch of turbulent shear stresses in $\mathrm{x}$-direction.

\section{Lateral momentum}

$$
\begin{aligned}
& \frac{\partial \bar{v}}{\partial t}+\bar{u} \frac{\partial \bar{v}}{\partial x}+\bar{v} \frac{\partial \bar{v}}{\partial y}+\bar{w} \frac{\partial \bar{v}}{\partial z}+2 \Omega_{z} \bar{u}-2 \Omega_{x} \bar{w}= \\
& -\frac{1}{\rho} \frac{\partial \bar{p}}{\partial y}+\frac{\mu}{\rho}\left(\frac{\partial^{2} \bar{v}}{\partial x^{2}}+\frac{\partial^{2} \bar{v}}{\partial y^{2}}+\frac{\partial^{2} \bar{v}}{\partial z^{2}}\right)+\frac{1}{\rho}\left(\frac{\partial \tau_{y x}}{\partial x}+\frac{\partial \tau_{y y}}{\partial y}+\frac{\partial \tau_{y z}}{\partial z}\right)
\end{aligned}
$$

where: $\tau_{\mathrm{yx}}$ : turbulent shear stress acting in $\mathrm{y}$ direction on the $\mathrm{x}$-face of control volume (see Fig. 10) $\tau_{\mathrm{yy}}$ : turbulent shear stress acting in $y$ direction on the $y$-face of control volume (see Fig. 10) $\tau_{\mathrm{yz}}$ : turbulent shear stress acting in $y$ direction on the $\mathrm{z}$-face of control volume (see Fig. 10) $\Omega_{\mathrm{x}}=0$

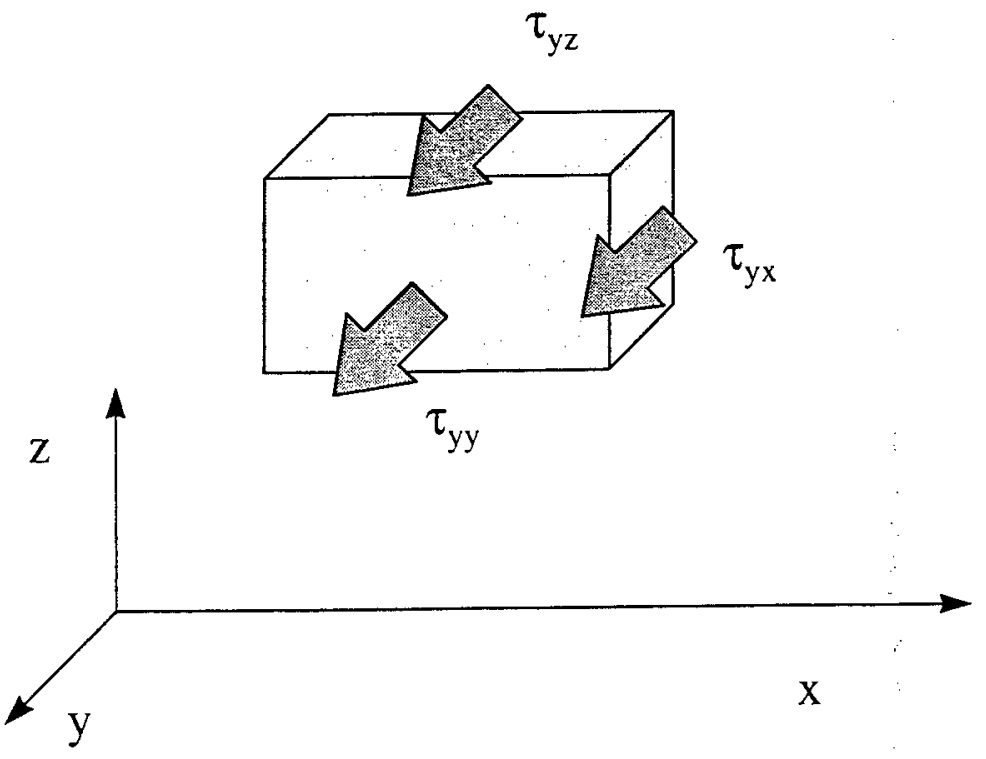


Figure 10. Sketch of turbulent shear stresses in y-direction.

\section{Vertical momentum}

$$
\begin{aligned}
& \frac{\partial \bar{w}}{\partial t}+\bar{u} \frac{\partial \bar{w}}{\partial x}+\bar{v} \frac{\partial \bar{w}}{\partial y}+\bar{w} \frac{\partial \bar{w}}{\partial z}-2 \Omega_{y} \bar{u}+2 \Omega_{x} \bar{v}=-g \\
& -\frac{1}{\rho} \frac{\partial \bar{p}}{\partial z}+\frac{\mu}{\rho}\left(\frac{\partial^{2} \bar{w}}{\partial x^{2}}+\frac{\partial^{2} \bar{w}}{\partial y^{2}}+\frac{\partial^{2} \bar{w}}{\partial z^{2}}\right)+\frac{1}{\rho}\left(\frac{\partial \tau_{z x}}{\partial x}+\frac{\partial \tau_{z y}}{\partial y}+\frac{\partial \tau_{z z}}{\partial z}\right)
\end{aligned}
$$

where: $\tau_{\mathrm{zx}}$ : turbulent shear stress acting in $\mathrm{z}$ direction on the $\mathrm{x}$-face of control volume (see Fig. 11) $\tau_{z y}:$ turbulent shear stress acting in $z$ direction on the $y$-face of control volume (see Fig. 11) $\tau_{z z}$ : turbulent shear stress acting in $\mathrm{z}$ direction on the $\mathrm{z}$-face of control volume (see Fig. 11) $\Omega_{\mathrm{x}}=0$

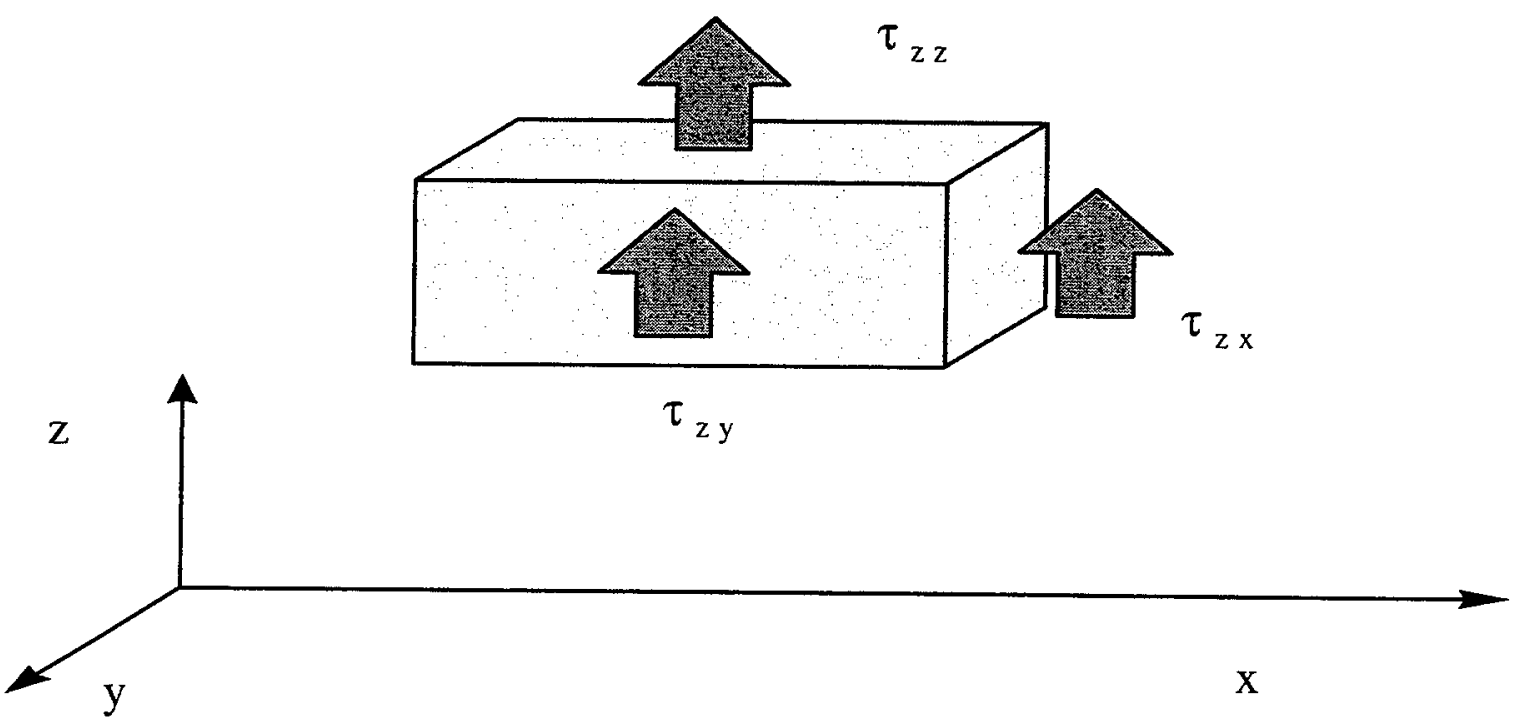

Figure 11. Sketch of turbulent shear stresses in y-direction.

Note that the turbulent shear stresses are defined as follows:

$\tau_{x x}=\rho \overline{u^{\prime} u^{\prime}}$

$\tau_{x y}=\rho \overline{u^{\prime} v^{\prime}}$ is the same as $\tau_{y x}=\rho \overline{v^{\prime} u^{\prime}}$

$\tau_{x=}=\rho \overline{u^{\prime} w^{\prime}}$ is the same as $\tau_{z x}=\rho \overline{w^{\prime} u^{\prime}}$

$\tau_{y y}=\rho \overline{v^{\prime} v^{\prime}}$

$\tau_{y z}=\rho \overline{v^{\prime} w^{\prime}}$ is the same as $\tau_{z y}=\rho \overline{w^{\prime} v^{\prime}}$

$\tau_{z:=}=\rho \overline{w^{\prime} w^{\prime}}$

\section{Coriolis Effect}


As noted above, all the $\Omega_{\mathrm{x}}$ terms are zero and can be eliminated from the $\mathrm{y}$ and $\mathrm{z}$-momentum equations. If one integrates over the $y$-direction (therefore assuming the net velocity in $y$ is zero) and assumes that the horizontal length scale is much greater than vertical length scale, it can be shown by using scaling arguments that the Coriolis acceleration forces are negligible (CushmanRoisin, 1994). Hence, prior to lateral averaging, the Coriolis acceleration terms will be neglected.

\section{Coordinate System Transformation}

The coordinate system will be transformed into a form compatible with the original W2 development where the vertical axis is in the direction of gravity. In addition, as shown in Figure 12 , the coordinate system will be oriented along an arbitrary slope.

\section{Coordinate System}

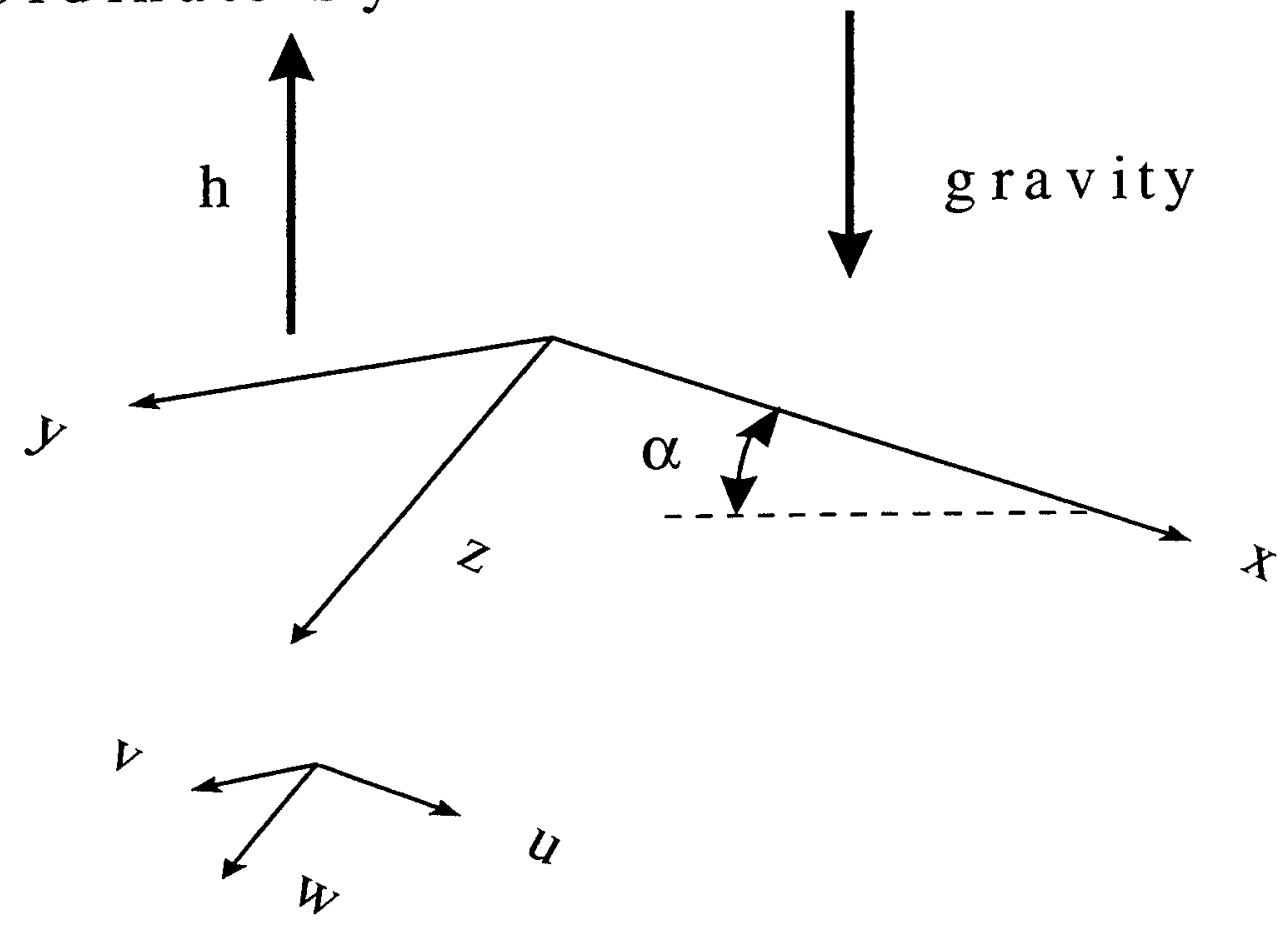

Figure 12. General coordinate system with z-axis compatible with original derivation of W2 model.

The gravity acceleration is a body force that is then represented by a vector:

$\bar{g}=-g \bar{\nabla} h$

where $h$ is the surface normal from the earth's surface ( $h$ is an elevation in the opposite direction to the acceleration of gravity vector) and $g$ is the acceleration constant $\left(9.8 \mathrm{~m} / \mathrm{s}^{2}\right)$.

This term can be written as three vector components: 


$$
\begin{aligned}
& g_{x}=-g \frac{\partial h}{\partial x} \\
& g_{y}=-g \frac{\partial h}{\partial y} \\
& g_{z}=-g \frac{\partial h}{\partial z}
\end{aligned}
$$

These gravity components can be applied to an arbitrary channel slope as shown in Figure 13.

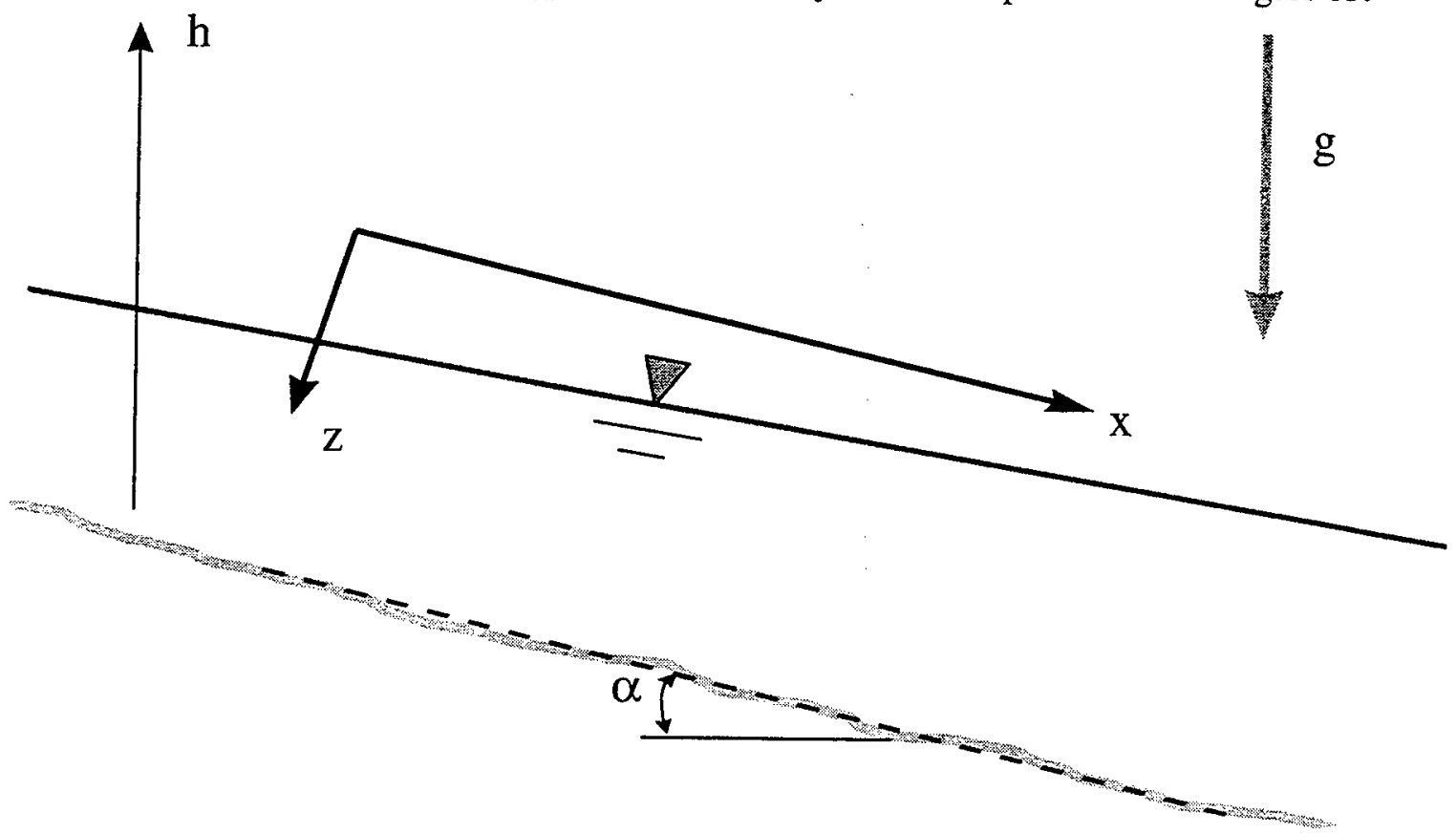

Figure 13. Sketch of channel slope and coordinate system for W2 where the $\mathrm{x}$-axis is oriented along the channel slope.

The channel slope can also be incorporated into the definition of the gravity vector if the $x$-axis is chosen parallel to the channel slope as:

The channel slope is defined as $S_{o}=\sin \alpha=-\frac{\partial h}{\partial x}$

And hence,

$$
\begin{aligned}
& g_{x}=-g \frac{\partial h}{\partial x}=g \sin \alpha \\
& g_{z}=-g \frac{\partial h}{\partial z}=g \cos \alpha
\end{aligned}
$$

The gravity acceleration in $y$ is assumed to be negligible since $\frac{\partial h}{\partial y}=0$ in the lateral direction of the channel. 


\section{Governing Equations for General Coordinate System}

After making the following simplifications:

- redefine coordinate system

- eliminate Coriolis effects

- neglect viscous shear stresses

The governing equations become:

\section{Continuity}

$$
\frac{\partial \bar{u}}{\partial x}+\frac{\partial \bar{v}}{\partial y}+\frac{\partial \bar{w}}{\partial z}=0
$$

\section{Longitudinal momentum}

$$
\underbrace{\frac{\partial \bar{u}}{\partial t}}_{\text {unsteady acceleration }}+\underbrace{\bar{u} \frac{\partial \bar{u}}{\partial x}+\bar{v} \frac{\partial \bar{u}}{\partial y}+\bar{w} \frac{\partial \bar{u}}{\partial z}}_{\text {convective acceleration }}=\underbrace{g \sin \alpha}_{\text {gravity }} \underbrace{-\frac{1}{\rho} \frac{\partial \bar{p}}{\partial x}}_{\text {pressure gradient }}+\frac{1}{\rho} \underbrace{\left(\frac{\partial \tau_{x x}}{\partial x}+\frac{\partial \tau_{x y}}{\partial y}+\frac{\partial \tau_{x z}}{\partial z}\right)}_{\text {turbulent shear stresses }}
$$

\section{Lateral momentum}

$$
\frac{\partial \bar{v}}{\partial t}+\bar{u} \frac{\partial \bar{v}}{\partial x}+\bar{v} \frac{\partial \bar{v}}{\partial y}+\bar{w} \frac{\partial \bar{v}}{\partial z}=-\frac{1}{\rho} \frac{\partial \bar{p}}{\partial y}+\frac{1}{\rho}\left(\frac{\partial \tau_{v x}}{\partial x}+\frac{\partial \tau_{w w}}{\partial y}+\frac{\partial \tau_{1 z}}{\partial z}\right)
$$

\section{Vertical momentum}

$$
\frac{\partial \bar{w}}{\partial t}+\bar{u} \frac{\partial \bar{w}}{\partial x}+\bar{v} \frac{\partial \bar{w}}{\partial y}+\bar{w} \frac{\partial \bar{w}}{\partial z}=g \cos \alpha-\frac{1}{\rho} \frac{\partial \bar{p}}{\partial z}+\frac{1}{\rho}\left(\frac{\partial \tau_{z x}}{\partial x}+\frac{\partial \tau_{z y}}{\partial y}+\frac{\partial \tau_{z z}}{\partial z}\right)
$$

\section{Simplification of Vertical Momentum Equation}

Assuming that the longitudinal length scale is much greater than the vertical length scale, then the vertical velocities $<<$ horizontal velocities. A result of this assumption is that vertical velocities are very small such that the z-momentum equation becomes the hydrostatic equation:

$$
\frac{1}{\rho} \frac{\partial \bar{p}}{\partial z}=g \cos \alpha
$$


This assumption prevents the model from accurately modeling vertical accelerations of the fluid as a result of convective cooling at night and other such vertical accelerations.

\section{Lateral Averaging of 3-D equations}

The governing equations above will be laterally averaged after decomposing all velocities and pressure into a lateral average and a deviation from the lateral average. The vertical and longitudinal velocities and pressure are defined as follows:

$$
\begin{aligned}
& \bar{u}=\overline{\bar{u}}+u^{\prime \prime} \text { where } \overline{\bar{u}}=\frac{1}{B} \int_{y_{1}}^{y_{2}} \bar{u} d y \text { and } \mathrm{B} \text { is the width of the control volume } \\
& \bar{w}=\overline{\bar{w}}+w^{\prime \prime} \\
& \bar{v}=\overline{\bar{v}}+v^{\prime \prime} \\
& \bar{p}=\overline{\bar{p}}+p^{\prime \prime}
\end{aligned}
$$

The double overbars represent the spatial average of the temporal average quantity. The double prime represents the deviation from the lateral average and is a function of $y$. This is shown in Figure 14.

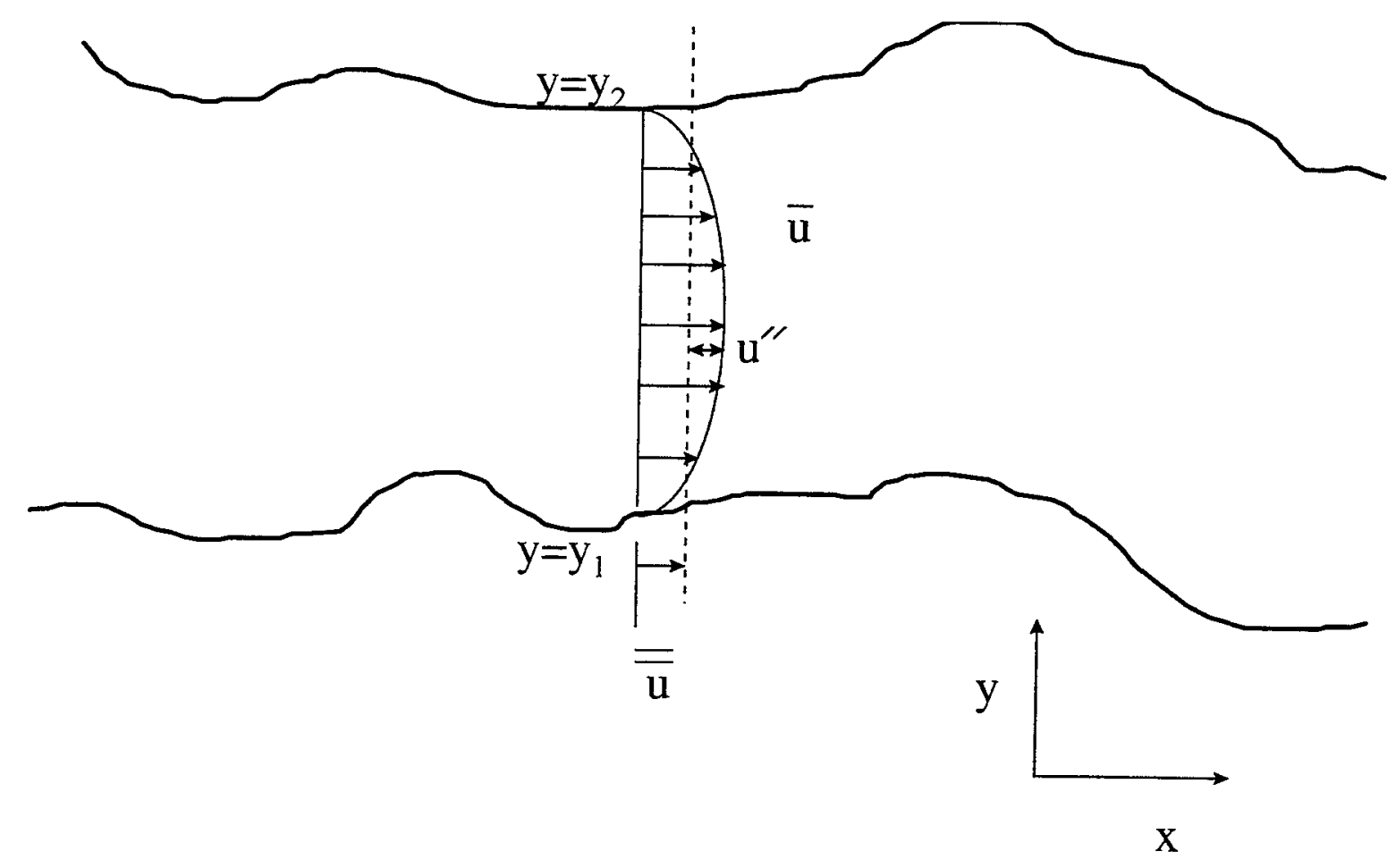

Figure 14. Lateral average and deviation from lateral average components of longitudinal velocity.

These definitions are substituted into the turbulent time-average governing equations and then laterally averaged. The $y$-momentum equation is neglected since the average lateral velocities are zero, i.e., $\overline{\bar{v}}=0$., and cross shear stresses that contribute to vertical mixing will be computed from 
the analysis of wind stress. The equations that remain are the continuity, $x$-momentum, and $z-$ momentum equations.

\section{Continuity}

The continuity equation becomes after substituting the above velocity components and laterally averaging

$$
\overline{\overline{\frac{\partial\left(\overline{\bar{u}}+u^{\prime \prime}\right)}{\partial x}}}+\overline{\overline{\frac{\partial\left(\overline{\bar{v}}+v^{\prime \prime}\right)}{\partial y}}}+\overline{\overline{\frac{\partial\left(\overline{\bar{w}}+w^{\prime \prime}\right)}{\partial z}}}=0
$$

The lateral average of a double primed variable is by definition zero, i.e.,

$$
\overline{\overline{u^{\prime \prime}}}=\frac{1}{B} \int_{y=1}^{y^{2}} u^{\prime \prime} d y=0
$$

Also, note that:

$$
\overline{\overline{\frac{\partial\left(\overline{\bar{v}}+v^{\prime \prime}\right)}{\partial y}}}=\frac{1}{B} \int_{y=1}^{y 2} \frac{\partial\left(\overline{\bar{v}}+v^{\prime \prime}\right)}{\partial y} d y=\left.\frac{\left(\overline{\bar{v}}+v^{\prime \prime}\right)}{B}\right|_{y=1} ^{y 2}=\left.\frac{v^{\prime \prime}}{B}\right|_{y=1} ^{y 2}=q
$$

where $\mathrm{q}$ is defined as the net lateral inflow per unit volume of cell $\left[\mathrm{T}^{-1}\right]$

$$
\overline{\overline{\frac{\partial\left(\overline{\bar{u}}+u^{\prime \prime}\right)}{\partial x}}}=\frac{1}{B} \int_{y=1}^{y \cdot 2} \frac{\partial\left(\overline{\bar{u}}+u^{\prime \prime}\right)}{\partial x} d y=\frac{1}{B} \int_{y=1}^{y 2} \frac{\partial \overline{\bar{u}}}{\partial x} d y+\frac{1}{B} \int_{y=1}^{y 2} \frac{\partial u^{\prime \prime}}{\partial x} d y=\frac{1}{B} \frac{\partial}{\partial x} \int_{y=1}^{y 2} \overline{\bar{u}} d y=\frac{1}{B} \frac{\partial B \overline{\bar{u}}}{\partial x}
$$

and

$$
\frac{\overline{\overline{\partial\left(\overline{\bar{w}}+w^{\prime \prime}\right)}}}{\partial z}=\frac{1}{B} \int_{y=1}^{y 2} \frac{\partial\left(\overline{\bar{w}}+w^{\prime \prime}\right)}{\partial z} d y=\frac{1}{B} \int_{y=1}^{y 2} \frac{\partial \overline{\bar{w}}}{\partial z} d y+\frac{1}{B} \int_{y=1}^{y 2} \frac{\partial w^{\prime \prime}}{\partial z} d y=\frac{1}{B} \frac{\partial}{\partial z} \int_{y=1}^{y 2} \overline{\bar{w}} d y=\frac{1}{B} \frac{\partial B \overline{\bar{w}}}{\partial z}
$$

Combining terms, the continuity equation becomes

$$
\frac{\partial B \overline{\bar{u}}}{\partial x}+\frac{\partial B \overline{\bar{w}}}{\partial z}=q B
$$

\section{Longitudinal momentum}

The laterally averaged $x$-momentum equation is more easily simplified by writing it in conservation form (this can be verified by using the continuity equation with the $x$-momentum equation), 


$$
\begin{aligned}
& \overline{\overline{\frac{\partial\left(\overline{\bar{u}}+u^{\prime \prime}\right)}{\partial t}}}+\overline{\overline{\frac{\partial\left(\overline{\bar{u}}+u^{\prime \prime}\right)\left(\overline{\bar{u}}+u^{\prime \prime}\right)}{\partial x}}}+\overline{\overline{\frac{\partial\left(\overline{\bar{v}}+v^{\prime \prime}\right)\left(\overline{\bar{u}}+u^{\prime \prime}\right)}{\partial y}}}+\frac{\overline{\overline{\partial\left(\overline{\bar{w}}+w^{\prime \prime}\right)\left(\overline{\bar{u}}+u^{\prime \prime}\right)}}}{\partial z}= \\
& \overline{\overline{g \sin \alpha}}-\overline{\overline{\frac{1}{\rho} \frac{\partial\left(\overline{\bar{p}}+p^{\prime \prime}\right)}{\partial x}}}+\overline{\overline{\frac{1}{\rho}\left(\frac{\partial \tau_{x x}}{\partial x}+\frac{\partial \tau_{x y}}{\partial y}+\frac{\partial \tau_{x z}}{\partial z}\right)}}
\end{aligned}
$$

Each term in this equation can be simplified as follows (note that the spatial average of any double primed variable goes to zero by definition):

\section{Unsteady acceleration term}

$$
\frac{\partial \overline{\left.\overline{\bar{u}}+u^{\prime \prime}\right)}}{\partial t}=\frac{1}{B} \int_{y=1}^{y 2} \frac{\partial\left(\overline{\bar{u}}+u^{\prime \prime}\right)}{\partial t} d y=\frac{1}{B} \int_{y=1}^{y 2} \frac{\partial \overline{\bar{u}}}{\partial t} d y+\frac{1}{B} \int_{y=1}^{y 2} \frac{\partial u^{\prime \prime}}{\partial t} d y=\frac{1}{B} \frac{\partial}{\partial t} \int_{y=1}^{y 2} \overline{\bar{u}} d y+\frac{1}{B} \frac{\partial}{\partial t} \int_{y=1}^{y 2} u^{\prime \prime} d y=\frac{1}{B} \frac{\partial B \overline{\bar{u}}}{\partial t}
$$

\section{Convective acceleration term}

$$
\begin{aligned}
& \frac{\overline{\frac{\partial\left(\overline{\bar{u}}+u^{\prime \prime}\right)\left(\overline{\bar{u}}+u^{\prime \prime}\right)}{\partial x}}}{\partial x} \frac{1}{B} \int_{y=1}^{y 2} \frac{\partial\left(\overline{\bar{u}}+u^{\prime \prime}\right)\left(\overline{\bar{u}}+u^{\prime \prime}\right)}{\partial x} d y=\frac{1}{B} \int_{y=1}^{y 2} \frac{\partial \overline{\bar{u}} \overline{\bar{u}}}{\partial x} d y+\frac{1}{B} \int_{y=1}^{y 2} \frac{2 \partial \overline{\bar{u}} u^{\prime \prime}}{\partial x} d y+\frac{1}{B} \int_{y=1}^{y 2} \frac{\partial u^{\prime \prime} u^{\prime \prime}}{\partial x} d y= \\
& \frac{1}{B} \frac{\partial}{\partial x} \int_{y=1}^{y 2} \overline{\bar{u} \bar{u}} d y+\frac{1}{B} \frac{\partial}{\partial x} \int_{y=1}^{y 2} u^{\prime \prime} u^{\prime \prime} d y=\frac{1}{B} \frac{\partial B \overline{\bar{u}} \overline{\bar{u}}}{\partial x}+\underbrace{\frac{1}{B} \frac{\partial}{\partial x} \int_{y=1}^{y 2} u^{\prime \prime} u^{\prime \prime} d y}_{\text {dispersion term }}
\end{aligned}
$$

Similarly for the other two terms:

$$
\begin{aligned}
& \frac{\overline{\overline{\partial\left(\overline{\bar{u}}+u^{\prime \prime}\right)\left(\overline{\bar{w}}+w^{\prime \prime}\right)}}}{\partial z}=\frac{1}{B} \frac{\partial B \overline{\bar{u} \overline{\bar{w}}}}{\partial z}+\underbrace{\frac{1}{B} \frac{\partial}{\partial z} \int_{y=1}^{y 2} u^{\prime \prime} w^{\prime \prime} d y}_{\text {dispersien term }} \\
& \overline{\overline{\frac{\partial\left(\overline{\bar{u}}+u^{\prime \prime}\right)\left(\overline{\bar{v}}+v^{\prime \prime}\right)}{\partial y}}}=\left.u^{\prime \prime} v^{\prime \prime}\right|_{y 2}-\left.u^{\prime \prime} v^{\prime \prime}\right|_{y, 1}=0
\end{aligned}
$$

\section{Gravity term}

$\overline{\overline{g \sin \alpha}}=\frac{1}{B} \int_{y=1}^{y 2} g \sin \alpha d y=\frac{1}{B}(g \sin \alpha) \int_{y=1}^{y 2} d y=g \sin \alpha$ 
Pressure gradient term

$$
\frac{\overline{\overline{\partial\left(\overline{\bar{p}}+p^{\prime \prime}\right)}}}{\partial x}=\frac{1}{B} \int_{y=1}^{y \cdot 2} \frac{\partial\left(\overline{\bar{p}}+p^{\prime \prime}\right)}{\partial x} d y=\frac{1}{B} \int_{y=1}^{y 2} \frac{\partial \overline{\bar{p}}}{\partial x} d y+\frac{1}{B} \int_{y=1}^{y 2} \frac{\partial p^{\prime \prime}}{\partial x} d y=\frac{1}{B} \frac{\partial}{\partial x} \int_{y=1}^{y 2} \overline{\bar{p}} d y+\frac{1}{B} \frac{\partial}{\partial x} \int_{y=1}^{y 2} p^{\prime \prime} d y=\frac{1}{B} \frac{\partial B \overline{\bar{p}}}{\partial x}
$$

or the above equation can be written, assuming that the derivative of the lateral average pressure gradient in the $\mathrm{x}$-direction is not a function of $\mathrm{y}$ :

$\frac{\overline{\partial\left(\overline{\bar{p}}+p^{\prime \prime}\right)}}{\partial x}=\frac{1}{B} \int_{y=1}^{y 2} \frac{\partial\left(\overline{\bar{p}}+p^{\prime \prime}\right)}{\partial x} d y=\frac{1}{B} \frac{\partial \overline{\bar{p}}}{\partial x} \int_{y=1}^{y 2} d y+\frac{1}{B} \int_{y=1}^{y 2} \frac{\partial p^{\prime \prime}}{\partial x} d y=\frac{1}{B} \frac{\partial \overline{\bar{p}}}{\partial x} B+\frac{1}{B} \frac{\partial}{\partial x} \int_{y=1}^{y 2} p^{\prime \prime} d y=\frac{\partial \overline{\bar{p}}}{\partial x}$

Shear stress term

$$
\begin{aligned}
& \overline{\overline{\left(\frac{\partial \tau_{x x}}{\partial x}+\frac{\partial \tau_{x y}}{\partial y}+\frac{\partial \tau_{x z}}{\partial z}\right)}}=\frac{1}{B} \int_{y=1}^{y \cdot 2} \frac{\partial \tau_{x x}}{\partial x} d y+\frac{1}{B} \int_{y=1}^{y 2} \frac{\partial \tau_{x y}}{\partial y} d y+\frac{1}{B} \int_{y=1}^{y 2} \frac{\partial \tau_{x z}}{\partial z} d y=\frac{1}{B} \frac{\partial}{\partial x} \int_{y=1}^{y 2} \tau_{x x} d y+ \\
& \frac{1}{B} \frac{\partial}{y x} \int_{y=1}^{y \cdot 2} \tau_{x y} d y+\frac{1}{B} \frac{\partial}{\partial z} \int_{y=1}^{y 2} \tau_{x z} d y=\frac{1}{B}\left(\frac{\partial B \overline{\tau_{x x}}}{\partial x}+\frac{\partial B \overline{\tau_{x y}}}{\partial y}+\frac{\partial B \overline{\tau_{x z}}}{\partial z}\right)=\frac{1}{B}\left(\frac{\partial B \overline{\tau_{x x}}}{\partial x}+\frac{\partial B \overline{\overline{\tau_{x z}}}}{\partial z}\right)
\end{aligned}
$$

Then collecting all terms and neglecting all dispersion terms, the final $\mathrm{x}$-momentum equation is then after simplification:

$$
\frac{\partial B \overline{\bar{u}}}{\partial t}+\frac{\partial B \overline{\bar{u} \bar{u}}}{\partial x}+\frac{\partial B \overline{\bar{u}} \bar{w}}{\partial z}=B g \sin \alpha-\frac{B}{\rho} \frac{\partial \overline{\bar{p}}}{\partial x}+\frac{1}{\rho}\left(\frac{\partial B \overline{\overline{\tau_{x x}}}}{\partial x}+\frac{\partial B \overline{\overline{\tau_{x z}}}}{\partial z}\right)
$$

\section{Summary of Laterally Averaged Equations}

In the development of W2 in Cole and Buchak (1995), the lateral average terms were represented by uppercase characters, such that $\overline{\bar{u}}=U, \overline{\bar{w}}=W$, and $\overline{\bar{p}}=P$. The shear stress terms will be assumed to be lateral averages and the double overbars will be dropped for convenience. Making these simplifications, the governing equations become

\section{Continuity}

$$
\frac{\partial U B}{\partial x}+\frac{\partial W B}{\partial z}=q B
$$

\section{Longitudinal momentum}




$$
\frac{\partial \mathrm{UB}}{\partial \mathrm{t}}+\frac{\partial \mathrm{UUB}}{\partial \mathrm{x}}+\frac{\partial \mathrm{WUB}}{\partial \mathrm{z}}=g B \sin \alpha-\frac{B}{\rho} \frac{\partial \mathrm{P}}{\partial \mathrm{x}}+\frac{1}{\rho} \frac{\partial B \tau_{x x}}{\partial \mathrm{x}}+\frac{1}{\rho} \frac{\partial \mathrm{B} \tau_{\mathrm{xz}}}{\partial \mathrm{z}}
$$

\section{Vertical momentum}

$$
\frac{1}{\rho} \frac{\partial P}{\partial z}=g \cos \alpha
$$

Now we have three equations and three unknowns: $U, W$, and $P$. 


\section{Simplification of the Pressure Term}

The z-momentum equation reduces to $\mathrm{P}=P_{a}+g \cos \alpha \int_{\eta}^{z} \rho d z$ after integration from a depth $\mathrm{z}$ to the water surface defined as $z=\eta . P_{a}$ is the atmospheric pressure at the water surface (see Figure 15).
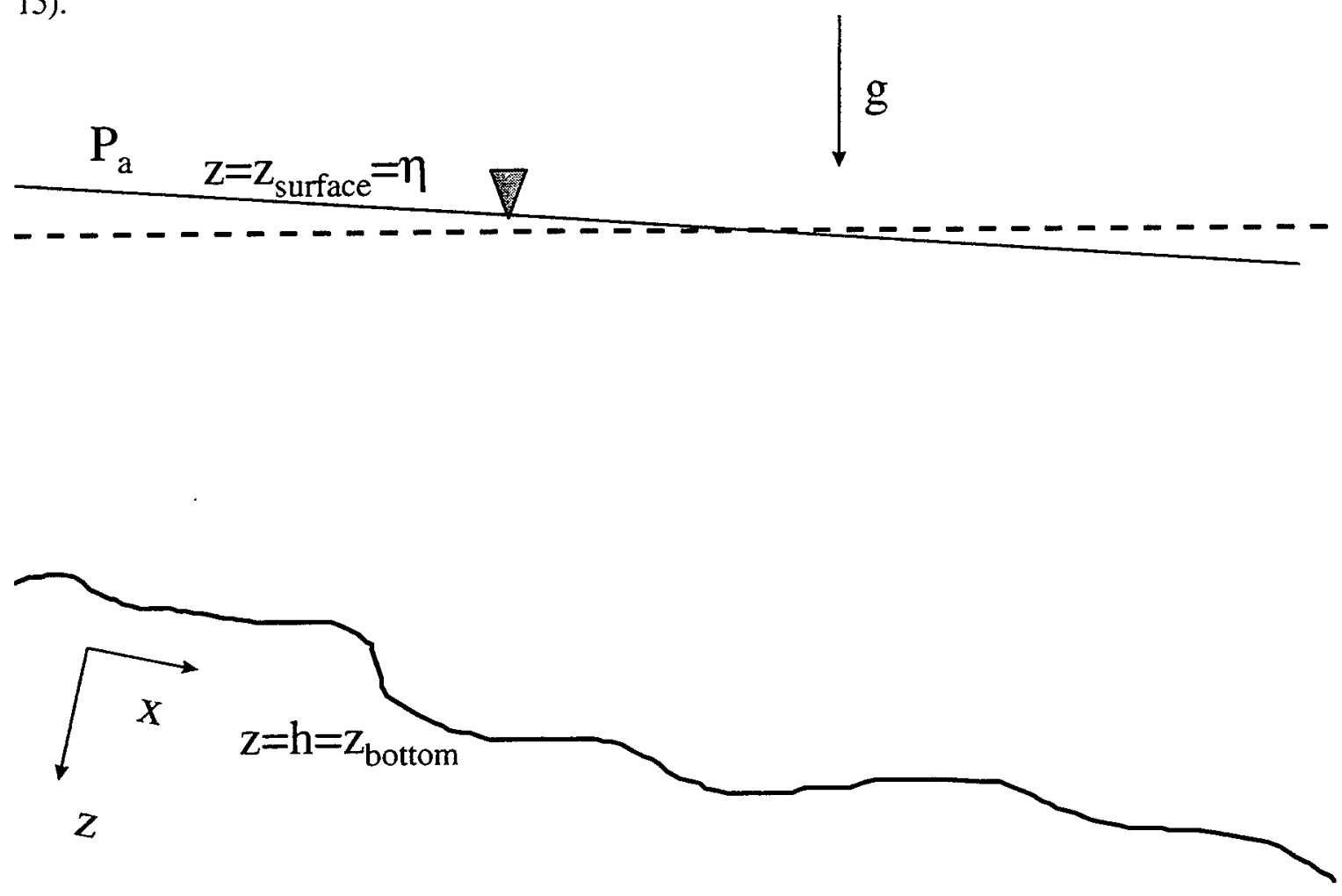

Figure 15. Illustration of layout for simplification of pressure term.

This equation for pressure is now substituted into the $x$-momentum equation and simplified using Leibnitz rule. The pressure gradient term in the $\mathrm{x}$-momentum equation then becomes:

$-\frac{1}{\rho} \frac{\partial P}{\partial x}=-\frac{1}{\rho} \frac{\partial P_{a}}{\partial x}+g \cos \alpha \frac{\partial \eta}{\partial x}-\frac{g \cos \alpha}{\rho} \int_{\eta}^{z} \frac{\partial \rho}{\partial x} d z$

The first term on the RHS is the atmospheric pressure term that accounts for accelerations due to atmospheric pressure changes over the water surface. The second is the barotropic pressure term that accounts for accelerations due to water surface slopes, and the third is the baroclinic pressure term that accounts for accelerations due to density differences.

In W2, the atmospheric pressure term is assumed to be zero and is neglected. This implies that for long systems during severe storms the model will not be able to account for accelerations on account of atmospheric changes. For a large physical domain, variations in meteorological forcing 
may be significant. This is discussed in Variability in Meteorological Forcing. The pressure term then becomes with this simplification:

$$
-\frac{1}{\rho} \frac{\partial P}{\partial x}=g \cos \alpha \frac{\partial \eta}{\partial x}-\frac{g \cos \alpha}{\rho} \int_{\eta}^{z} \frac{\partial \rho}{\partial x} d z
$$

The revised form of the $\mathrm{x}$-momentum equation is then:

$$
\begin{aligned}
& \frac{\partial \mathrm{UB}}{\partial \mathrm{t}}+\frac{\partial \mathrm{UUB}}{\partial \mathrm{x}}+\frac{\partial \mathrm{WUB}}{\partial \mathrm{z}}= \\
& g B \sin \alpha+g \cos \alpha B \frac{\partial \eta}{\partial x}-\frac{g \cos \alpha B}{\rho} \int_{\eta}^{z} \frac{\partial \rho}{\partial x} d z+\frac{1}{\rho} \frac{\partial B \tau_{x x}}{\partial \mathrm{x}}+\frac{1}{\rho} \frac{\partial \mathrm{B} \tau_{\mathrm{xz}}}{\partial \mathrm{z}}
\end{aligned}
$$

Effectively, pressure has been removed from the unknowns by combining the $z$-momentum and $x-$ momentum equations, but we have added $\eta$ as an unknown.

\section{Free Water Surface Equation}

This equation is a simplification of the continuity equation. The continuity equation integrated over the depth from the water surface to the bottom is called the free water surface equation. Figure 15 and Figure 16 are definition sketches for the W2 cell layout without and with a channel slope, respectively.

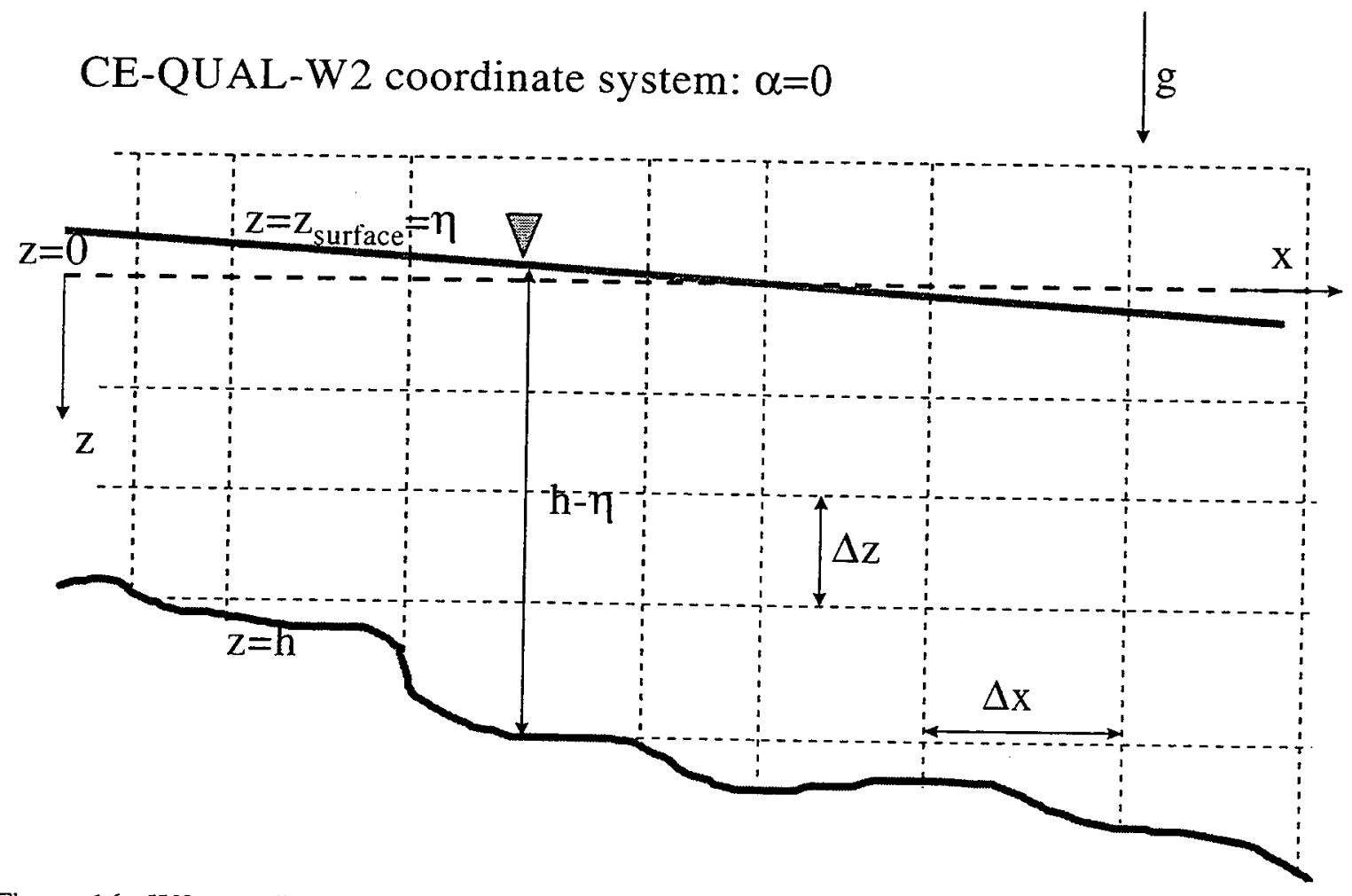

Figure 16. W2 coordinate system with no channel slope. 


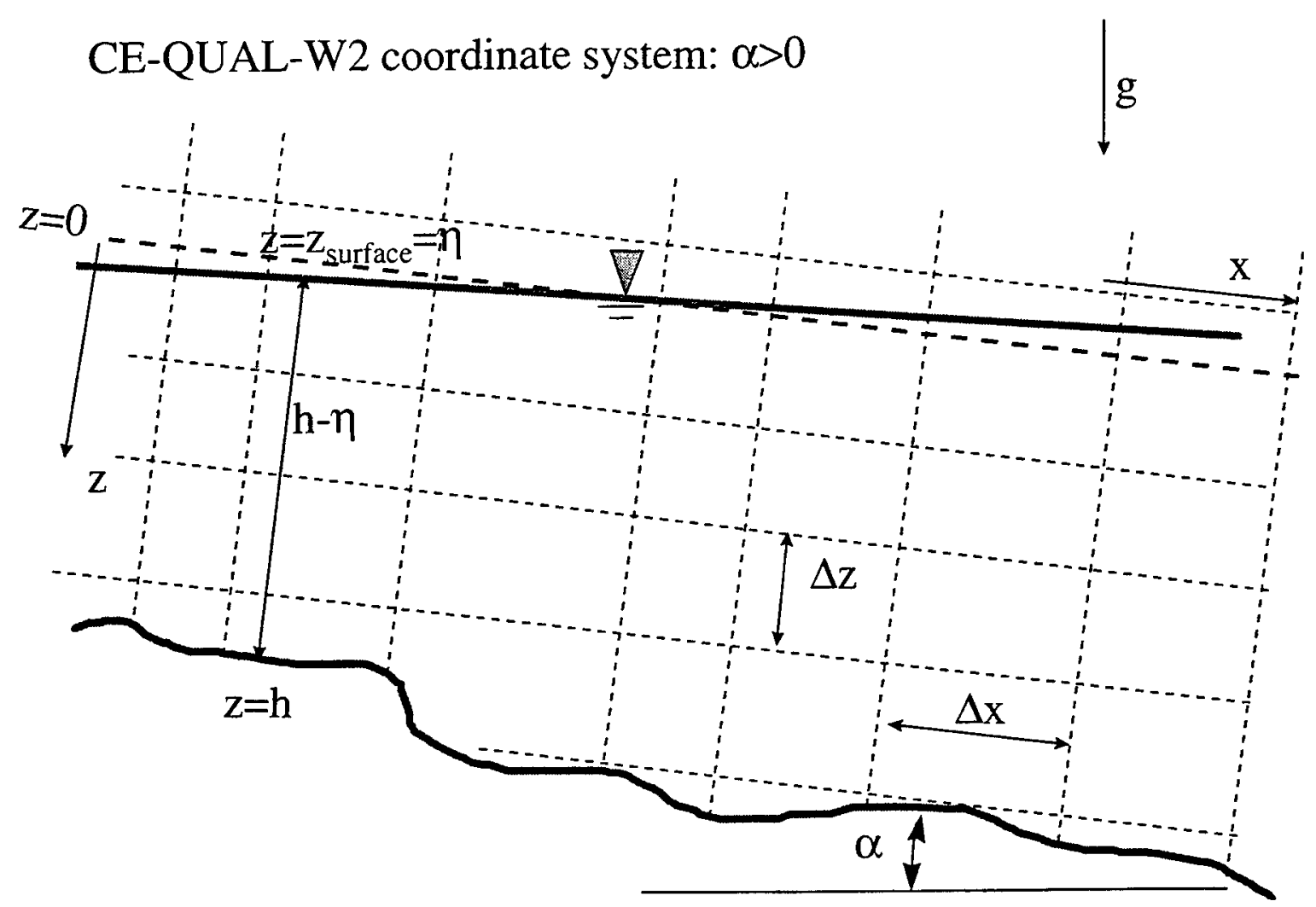

Figure 17. W2 coordinate system with finite channel slope.

The continuity equation is integrated over the depth as follows:

$$
\int_{\eta}^{h} \frac{\partial \mathrm{UB}}{\partial \mathrm{x}} d z+\int_{\eta}^{h} \frac{\partial \mathrm{WB}}{\partial \mathrm{z}} d z=\int_{\eta}^{h} \mathrm{qB} d z
$$

The first term can be expanded as follows using Leibnitz's rule:

$$
\int_{\eta}^{h} \frac{\partial \mathrm{UB}}{\partial \mathrm{x}} d z=\frac{\partial}{\partial x} \int_{\eta}^{h} U B d z-\left.\frac{\partial h}{\partial x} U B\right|_{h}+\left.\frac{\partial \eta}{\partial x} U B\right|_{\eta}
$$

The integral of the vertical flow rate over $\mathrm{z}$ relates to changes in water surface elevation as shown below:

$$
\int_{\eta}^{h} \frac{\partial \mathrm{WB}}{\partial \mathrm{z}} d z=\left.W B\right|_{h}-\left.W B\right|_{\eta}
$$

where $W_{h}=\frac{\partial h}{\partial t}+U_{h} \frac{\partial h}{\partial x}$ 


$$
W_{\eta}=\frac{\partial \eta}{\partial t}+U_{\eta} \frac{\partial \eta}{\partial x}
$$

Combining these terms together, the free surface equation becomes:

$$
\frac{\partial}{\partial x} \int_{\eta}^{h} U B d z-\left.\frac{\partial h}{\partial x} U B\right|_{h}+\left.\frac{\partial \eta}{\partial x} U B\right|_{\eta}+U_{h} B_{h} \frac{\partial h}{\partial t}+U_{h} B_{h} \frac{\partial h}{\partial x}-B_{\eta} \frac{\partial \eta}{\partial t}-B_{\eta} U_{\eta} \frac{\partial \eta}{\partial x}=\int_{\eta}^{h} q B d z
$$

Canceling out terms and applying the no-slip boundary condition that $\mathrm{U}_{\mathrm{h}}$ is zero:

$$
\frac{\partial}{\partial x} \int_{\eta}^{h} U B d z-B_{\eta} \frac{\partial \eta}{\partial t}=\int_{\eta}^{h} q B d z
$$

or

$$
B_{\eta} \frac{\partial \eta}{\partial t}=\frac{\partial}{\partial x} \int_{\eta}^{h} U B d z-\int_{\eta}^{h} q B d z
$$

where $B_{\eta}$ is the width at the surface.

\section{Equation of State}

The density must be known for solution of the momentum equations. The equation of state is an equation that relates density to temperature and concentration of dissolved substances and is given as follows:

$\rho=\mathrm{f}\left(\mathrm{T}_{\mathrm{w}}, \Phi_{\mathrm{TDS}}, \Phi_{\mathrm{ss}}\right)$

where $f\left(T_{w}, \Phi_{T D S}, \Phi_{s s}\right)=$ density function dependent upon temperature, total dissolved solids or salinity, and suspended solids.

Hence, the temperature, total dissolved solids, and suspended solids must be known and are determined from the water quality model.

\section{Summary of Governing Equations}

Table 1 shows the governing equations after lateral averaging for a channel slope of zero (original model formulation) and for an arbitrary channel slope. Parameters used in Table 1 are illustrated in Figure 17. 
Table 1. Comparison of governing equations for W2 with and without channel slope.

\begin{tabular}{|c|c|c|}
\hline Equation & $\begin{array}{l}\text { Existing governing equation assuming no channel } \\
\text { slope }\end{array}$ & Governing equation assuming an arbitrary channel slope \\
\hline $\begin{array}{l}\mathrm{x}- \\
\text { momentum }\end{array}$ & $\begin{array}{l}\frac{\partial \mathrm{UB}}{\partial \mathrm{t}}+\frac{\partial \mathrm{UUB}}{\partial \mathrm{x}}+\frac{\partial \mathrm{WUB}}{\partial \mathrm{z}}= \\
g B \frac{\partial \eta}{\partial x}-\frac{g B}{\rho} \int_{\eta}^{\bar{j}} \frac{\partial \rho}{\partial x} d z+ \\
\frac{1}{\rho} \frac{\partial B \tau_{\mathrm{xr}}}{\partial \mathrm{x}}+\frac{1}{\rho} \frac{\partial \mathrm{B} \tau_{\mathrm{x} z}}{\partial \mathrm{z}}\end{array}$ & $\begin{array}{l}\frac{\partial \mathrm{UB}}{\partial \mathrm{t}}+\frac{\partial \mathrm{UUB}}{\partial \mathrm{x}}+\frac{\partial \mathrm{WUB}}{\partial \mathrm{z}}= \\
g B \sin \alpha+g \cos \alpha B \frac{\partial \eta}{\partial x}-\frac{g \cos \alpha B}{\rho} \int_{\eta}^{\bar{\rho}} \frac{\partial \rho}{\partial x} d z+ \\
\frac{1}{\rho} \frac{\partial B \tau_{\mathrm{xx}}}{\partial \mathrm{x}}+\frac{1}{\rho} \frac{\partial \mathrm{B} \tau_{\mathrm{x} z}}{\partial \mathrm{z}}\end{array}$ \\
\hline z-momentum & $0=g-\frac{1}{\rho} \frac{\partial P}{\partial z}$ & $0=g \cos \alpha-\frac{1}{\rho} \frac{\partial P}{\partial z}$ \\
\hline $\begin{array}{l}\text { free surface } \\
\text { equation }\end{array}$ & $B_{\eta} \frac{\partial \eta}{\partial t}=\frac{\partial}{\partial x} \int_{\eta}^{h} U B d z-\int_{\eta}^{h} q B d z$ & $B_{\eta} \frac{\partial \eta}{\partial t}=\frac{\partial}{\partial x} \int_{\eta}^{h} U B d z-\int_{\eta}^{h} q B d z$ \\
\hline
\end{tabular}

Note: U,W: horizontal and vertical velocity

B: channel width

P: pressure

$\mathrm{g}$ : acceleration due to gravity

$\tau_{\mathrm{x}}, \tau_{\mathrm{z}}$ : lateral average shear stress in $\mathrm{x}$ and $\mathrm{z}$

$\rho:$ density

$\eta$ : water surface

$\alpha$ : channel angle



Figure 18. Definition sketch for channel slope (exaggerated slope). 


\section{Determination of Turbulent Shear Stresses}

In order to solve the equations above, the following terms must also be evaluated:

- shear stress at water surface from wind

- shear stress at boundary (boundary shear)

- algorithm for transmitting shear stress vertically, $\tau_{x z}$

- algorithm for transmitting shear stress longitudinally, $\tau_{x x}$

\section{Surface shear stress}

The shear stress at the water surface is defined as:

$\tau_{s}=C_{D} \rho_{a}\left(W_{h}-u_{s}\right)^{2} \cong C_{D} \rho_{a}\left(W_{h}\right)^{2}$

where $\tau_{\mathrm{s}}$ : surface shear stress at water surface

$\mathrm{u}_{\mathrm{s}}$ : surface velocity in water

$\mathrm{W}_{\mathrm{h}}$ : wind velocity measured at a distance $\mathrm{h}$ above water surface in direction of shear

$\mathrm{C}_{\mathrm{D}}$ : drag coefficient

$\rho_{\mathrm{a}}$ : air density

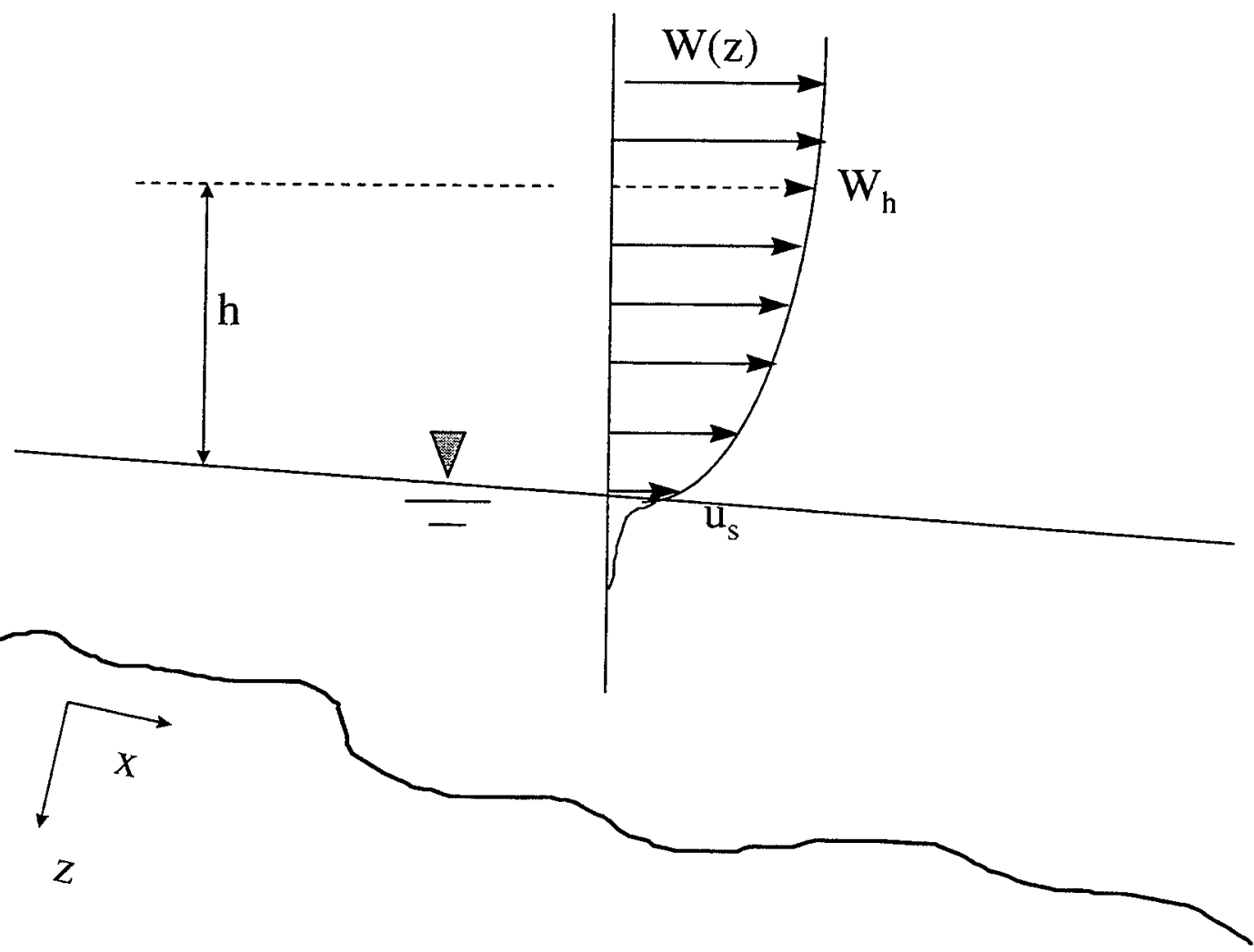

Figure 19. Wind stress on the water surface. 
Note that this relationship leads to the " $3 \%$ rule" for surface currents:

$\tau_{s}=\underbrace{C_{D} \rho_{a}\left(W_{h}-u_{s}\right)^{2}}_{\text {air }}=\underbrace{C_{D} \rho_{W} u_{s}^{2}}_{\text {water }}\}$ if $C_{D_{\text {air }}} \sim C_{D_{\text {water }}}$, then $\underbrace{u_{s} \sim 0.03 W_{h}}_{3 \% \text { rule }}$

Usually the drag coefficient is a function of the measurement height, $h$, above the water surface. Most drag coefficient formulae have been determined based on a $10 \mathrm{~m}$ wind speed measurement height. If wind speeds are taken at other measurement heights, for the shear stress calculation, these should be corrected to $10 \mathrm{~m}$.

The windspeed is a function of measurement height. To correct the measurement height to an elevation $\mathrm{z}$, the following approach is used.

Assuming a logarithmic boundary layer:

$$
\frac{W_{z}}{W_{z_{I}}}=\frac{\ln \left(\frac{z}{z_{0}}\right)}{\ln \left(\frac{z_{l}}{z_{0}}\right)}
$$

where $\mathrm{W}_{\mathrm{z}}$ : desired wind speed at elevation $\mathrm{z}$

$\mathrm{W}_{\mathrm{z}}$ : known wind speed at height $\mathrm{z}_{1}$

$\mathrm{z}_{0}$ : wind roughness height (assume $0.003 \mathrm{ft}$ for wind $<5 \mathrm{mph}$ and 0.015 for wind $>5$

mph, range 0.0005 to $0.03 \mathrm{ft}$ )

This term can then be used to compute the surface stress in the direction of the x-axis and the crossshear (the cross-shear term will be used in the turbulent shear stress algorithm) as follows:

$$
\begin{aligned}
& \tau_{u x} \cong C_{D} \rho_{a} W_{h}^{2} \cos \left(\Theta_{1}-\Theta_{2}\right) \\
& \tau_{w y} \cong C_{D} \rho_{a} W_{h}^{2} \sin \left(\Theta_{1}-\Theta_{2}\right)
\end{aligned}
$$

where $\tau_{\mathrm{wx}}$ : surface shear stress along $\mathrm{x}$-axis due to wind

$\tau_{\mathrm{wy}}:$ surface shear stress along lateral direction due to wind

$\Theta_{1}$ : wind orientation relative to North, radians

$\Theta_{2}$ : segment orientation relative to North, radians 


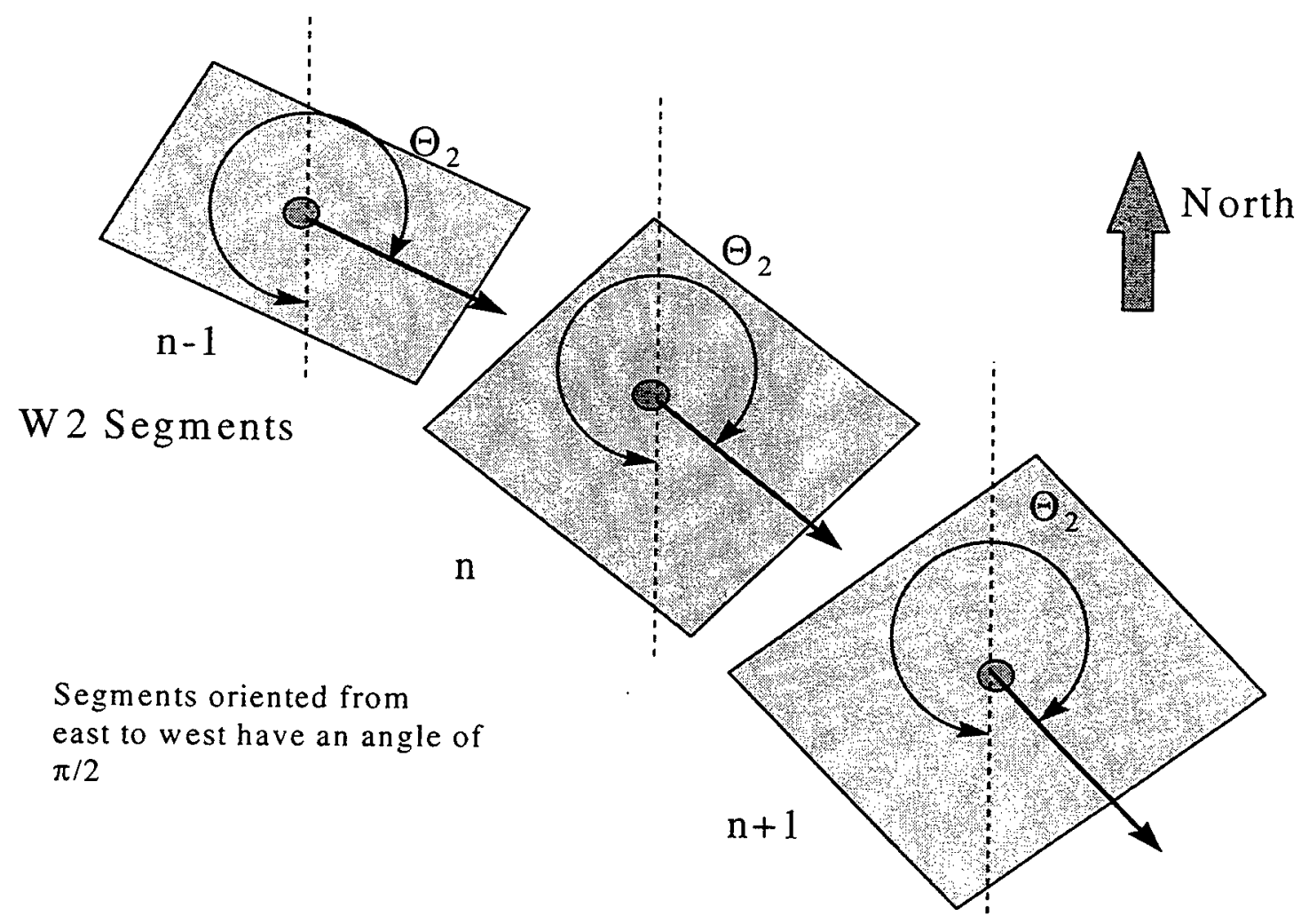

Figure 20. Orientation of W2 segments relative to N.

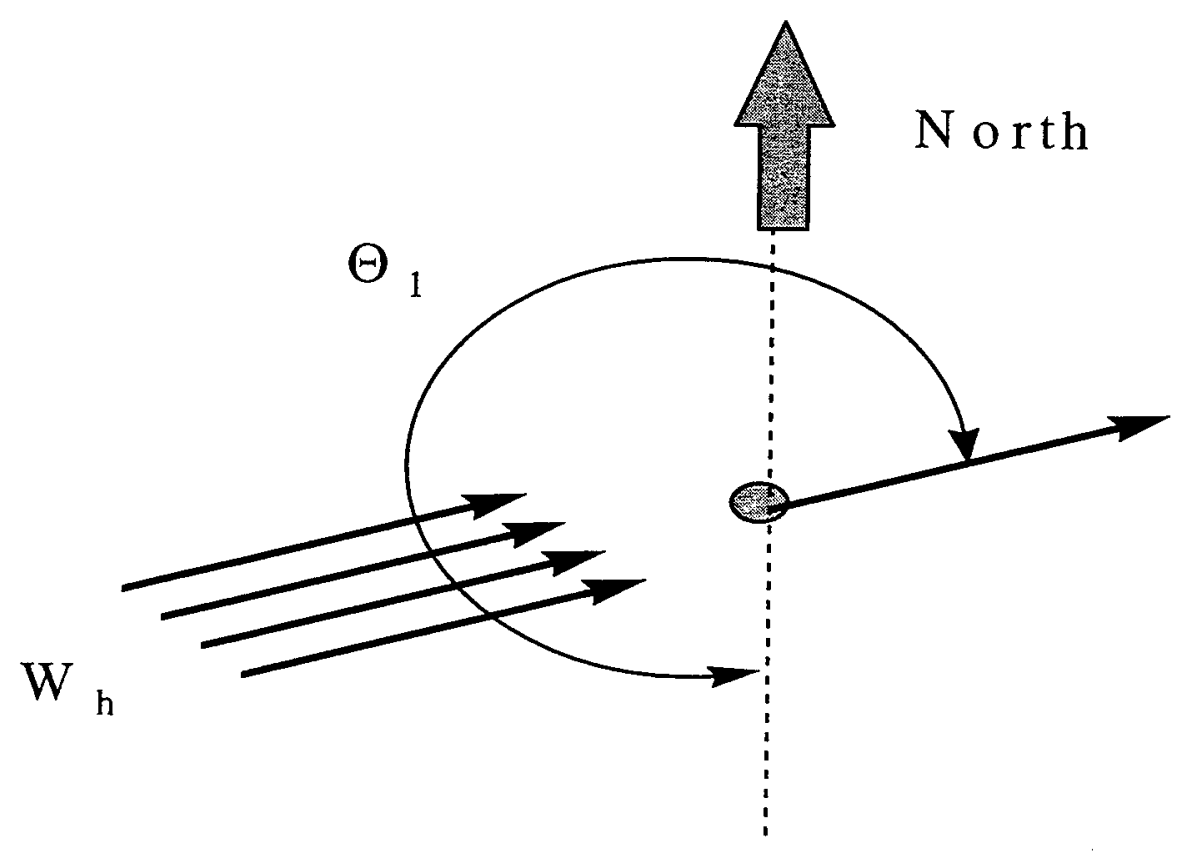

Hence, a w ind from the $\mathrm{N}$ would have an angle of 0 , a wind from east to west would be $\pi / 2$.

Figure 21 . Orientation of wind velocity relative to North. 
The drag coefficient, $\mathrm{C}_{\mathrm{D}}$, is defined in $\mathrm{W} 2$ as:

For $\mathrm{W}_{\mathrm{h}}<1 \mathrm{~m} / \mathrm{s}, \mathrm{C}_{\mathrm{D}}=0.0$

For $1 \leq \mathrm{W}_{\mathrm{h}}<15 \mathrm{~m} / \mathrm{s}, \mathrm{C}_{\mathrm{D}}=0.0005\left(\mathrm{~W}_{\mathrm{h}}\right)^{0.5}$

For $\mathrm{W}_{\mathrm{h}} \geq 15 \mathrm{~m} / \mathrm{s}, \mathrm{C}_{\mathrm{D}}=0.0026$

These formulae are based on a $10 \mathrm{~m}$ measurement height. Note that for a river basin model, the wind speed may vary significantly over the study area. This issue is discussed in the section on Variability in Meteorological Forcing.

\section{Bottom shear stress}

The shear stress is defined along the bottom of each cell or for each cell in contact with side walls or channel bottom as:

$\tau_{b}=\frac{\rho_{w} g}{C^{2}} U|U|$

where $C$ is the Chezy friction coefficient

$\mathrm{U}$ is the longitudinal velocity

$\rho_{w}$ is the density of water

The Chezy coefficient is related to the Manning's friction factor as

$C($ for SI units only $)=(1 / n) R^{1 / 6}$

where $\mathrm{n}$ : Manning's friction factor

$\mathrm{R}$ : hydraulic radius

The shear stress for bottom friction will be more important for sloping river channels since the primary balance is between gravity and bottom friction. The bottom friction coefficient will be variable segment by segment.

\section{Vertical shear stress}

Vertical shear stress in W2 is defined as:

$$
\frac{\tau_{x z}}{\rho}=v_{\text {turhulent }} \frac{\partial U}{\partial z}=A_{z} \frac{\partial U}{\partial z}
$$

This shear stress term also includes the contribution to the shear stress from surface waves induced by the wind. The wind can produce waves that produce decaying motions with depth (Lighthill, 1978) as shown in Figure 22. 


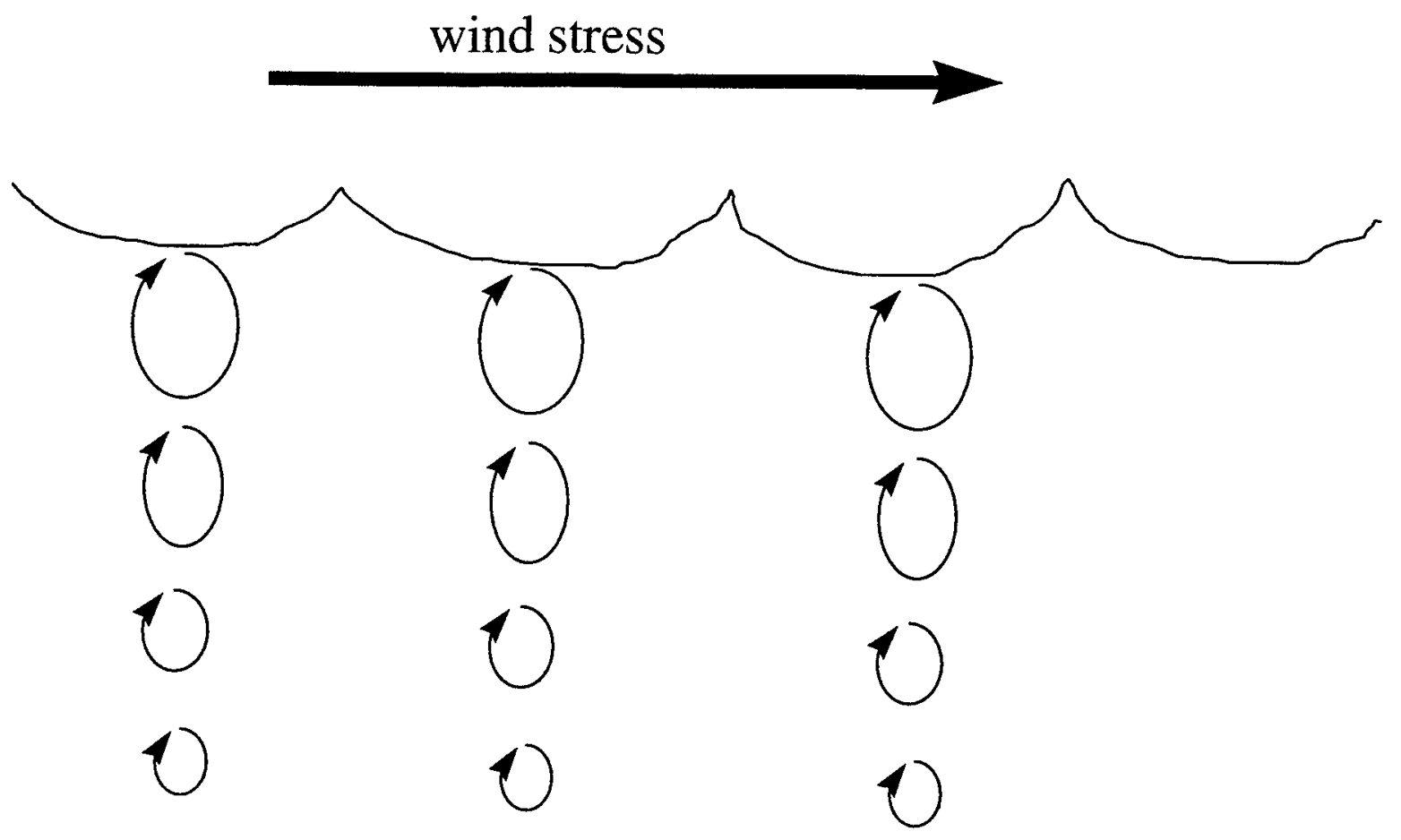

Figure 22. Decay of wind shear with depth.

This addition has been critiqued by some (Chapman, 1989) as being unnecessary since the expressions for the wind shear stress implicitly account for the effect of wave induced stress by the wind shear.

Regardless, the total longitudinal shear stress for a layer is defined in W2 as having contributions from interfacial velocity shear, wind wave generated shear, and friction shear along boundaries:

$$
\frac{\tau_{x z}}{\rho}=A_{z} \frac{\partial U}{\partial z}+\frac{\tau_{w x x}}{\rho} e^{-2 k z}+\frac{\tau_{b}}{\rho}
$$

where $\tau_{\mathrm{wx}}$ is the longitudinal wind shear at the surface (see above)

$\mathrm{k}=$ wave number $=\frac{4 \pi^{2}}{g T_{w}^{2}}$

$\mathrm{T}_{\mathrm{w}}=$ wind wave period (empirical) $=6.95 E-2 \quad F^{0.233}|W|^{0.534}$

$\mathrm{F}=$ fetch length, $\mathrm{m}$.

\section{Vertical eddy viscosity}

The turbulent eddy viscosity was conceptualized by Prandtl as:

$$
v_{\text {turbulent }}=\ell^{2}\left|\frac{d U}{d z}\right|
$$


where $\ell$ is defined as the mixing length and can be interpreted as being proportional to the average size of large eddies or the length scale of a turbulent eddy. This length is a function of distance from a boundary or wall since the eddy sizes vary as a function of distance from a boundary. The goal in most turbulence models is the determination of the mixing length as a function of position in the fluid.

In the formulation in $\mathrm{W} 2$, the mechanism for transporting the wind stress at the surface is based on:

$\mathrm{A}_{2}=$ vertical eddy viscosity $=\kappa \frac{l^{2}}{2}\left[\left(\frac{\partial U}{\partial z}\right)^{2}+\left(\frac{\partial V}{\partial z}\right)^{2}\right]^{1 / 2} e^{-C R i}$

where: Ri: Richardson number $=\frac{g \frac{\partial \rho}{\partial z}}{\rho\left(\frac{\partial U}{\partial z}\right)^{2}}$

$\kappa$ is the von Karman constant $=0.4$

$\mathrm{C}$ is an empirical constant taken as 1.5

1 , a vertical length scale, is chosen as vertical cell thickness.

Hence, this formulation is a mixing length formulation that is decreased or increased based on the Richardson number. The Richardson number accounts for the impact of density stratification on transfer of momentum between fluid parcels. In regions where there is no stratification, $R \mathbf{i}=0$, and the exponential term is 1 . For regions where there is strong stratification (or as $\frac{d \rho}{d z} \rightarrow \infty$ ), the Richardson number becomes large and the exponential term approaches 0 .

The term in the above formulation uses the lateral velocity because even winds blowing at right angles to the model cell may cause vertical transfer of momentum, or mixing between fluid layers. Hence, this term allows for increasing the transfer of stress vertically in the fluid as a result of lateral currents.

In the longitudinal-vertical model, the lateral velocity, $\mathrm{V}$, and its gradient, $\partial \mathrm{V} / \partial \mathrm{z}$, are due to the lateral component of wind wave motion and are assumed to be zero when averaged laterally, but not necessarily the term $(\partial \mathrm{V} / \partial \mathrm{z})^{2}$. It is assumed that cross wind shear $\tau_{w y}$ generates lateral wave components and decays exponentially with depth, $\mathrm{z}$, such that

$\tau_{\mathrm{yz}}=\tau_{\mathrm{wy}} \exp (-2 \mathrm{kz})$

where $\tau_{\mathrm{wy}}$ is the lateral wind shear at the surface defined above. 
Then using

$$
\frac{\tau_{y z}}{\rho}=A_{z} \frac{\partial V}{\partial z}
$$

the lateral velocity gradient squared becomes

$$
\left(\frac{\partial V}{\partial z}\right)^{2}=\left[\frac{\tau_{w y} \exp (-2 k z)}{\rho A_{z}}\right]
$$

The final equation for the vertical eddy viscosity is then

$$
\mathrm{A}_{z}=\kappa\left(\frac{l^{2}}{2}\right) \sqrt{\left(\frac{\partial \mathrm{U}}{\partial z}\right)^{2}+\left(\frac{\tau_{\mathrm{wy}} \mathrm{e}^{-2 \mathrm{kz}}}{\rho \mathrm{A}_{\mathrm{z}}}\right)^{2}} \mathrm{e}^{\left(-\mathrm{CR}_{\mathrm{i}}\right)}
$$

The above equation is implicit. In the model, this equation is explicit since the value of $A_{z}$ in the lateral wind shear term is used from the previous time step. $A_{z}$ is never less than the molecular kinematic viscosity for water. This formulation is subject to further research and discussion and is vital in establishing flow patterns within the domain.

In the river basin sections, the above formulation for vertical eddy viscosity may or may not be adequate. Additional formulations for the vertical eddy viscosity for both vertically well-mixed systems and continuously stratified systems will be tested as shown in Tables 2 and 3 . Since these formulations vary significantly, the theory and literature values will be used as a guide to determine the appropriate function after model testing (this follows the recommendation of Shanahan and Harleman, 1982). Numerical results of the velocity field will be compared to analytical solutions for 2-D open channel flow at steady-state with simple turbulence closure hypotheses. The code will be tested for stability and robustness of the solution scheme.

Table 2. Typical vertical eddy viscosity $\left(A_{v}\right)$ formulations for shallow systems that are vertically well-mixed where $\tau_{z}=A_{v} \frac{\partial u}{\partial z}$.

\begin{tabular}{|l|l|l|l|}
\hline $\begin{array}{l}\text { Equation } \\
\text { number }\end{array}$ & Equation & Comments & Reference \\
\hline 1 & $A_{v}=A_{v,}\left(\frac{(h-z-0.1)}{h}\right)^{3 / 4}$ & $\begin{array}{l}\text { Avv is the eddy viscosity at the } \\
\text { surface. zero at bottom. } \\
\text { maximum at surface }\end{array}$ & $\begin{array}{l}\text { Fjeldstad in Neumann } \\
\text { and Pierson (1966) }\end{array}$ \\
\hline 2 & $A_{v}=\kappa u_{*} z\left(1-\frac{z}{h}\right)$ & $\begin{array}{l}\text { parabolic shape (zero at top } \\
\text { and bottom) }\end{array}$ & Engelund (1978) \\
\hline 3 & $A_{v}=\kappa u_{*}(1-z)\left(\frac{z}{h}\right)$ & $\begin{array}{l}\text { parabolic shape (zero at top } \\
\text { and bottom) }\end{array}$ & Koutitas (1978) \\
\hline 4 & $A_{v}=\left(A_{v,}-A_{v / h}\right)\left(\frac{1-z}{h}\right)^{1 / 2}+A_{v / h}$ & $\begin{array}{l}\text { minimum value at bottom. } \\
\text { maximum at water surface }\end{array}$ & Liggetr (1970) \\
\hline
\end{tabular}




\begin{tabular}{|c|c|c|c|}
\hline $\begin{array}{l}\text { Equation } \\
\text { number }\end{array}$ & Equation & Comments & Reference \\
\hline 5 & $\begin{array}{l}A_{v}=\kappa u_{*} z \quad \text { for near-surface } \\
A_{v}=\kappa u_{* b}(h-z) \quad \text { for near-bottom }\end{array}$ & $\begin{array}{l}\text { U*b is the bottom shear } \\
\text { velocity, zero at surface and } \\
\text { bottom }\end{array}$ & Madsen (1977) \\
\hline 6 & $A_{v}=A_{v o} \exp \left(\frac{-2.7 z}{h}\right)$ & $\begin{array}{l}\text { minimum at bottom and } \\
\text { maximum at surface }\end{array}$ & $\begin{array}{l}\text { Witten and Thomas } \\
(1976)\end{array}$ \\
\hline 7 & $A_{v}=\kappa u_{*} h\left(1-\frac{z}{h}\right)$ & $\begin{array}{l}\text { maximum at surface and zero } \\
\text { at bottom, } A_{v_{0}} \text { is } k u * h\end{array}$ & Thomas (1975) \\
\hline 8 & $A_{v}=A_{v o}\left(1-w \frac{z}{h}\right)^{2}$ & $\begin{array}{l}\text { Maximum at surface and } \\
\text { minimum at } z=h, A_{v v}=c_{1} \text { wh, } \\
\left.w=1-\left(A_{v v} / A_{v o}\right)\right)^{10.5}, c_{1} \text { is a } \\
\text { constant }\end{array}$ & Lindijer (1979) \\
\hline
\end{tabular}

Note: $\mathrm{z}$ is zero at the surface and is positive downwards, hence at the bottom $\mathrm{z}=\mathrm{h}$, where $\mathrm{h}$ is the total depth. $u_{*}$ is the shear velocity, $\kappa$ is von Karman constant. $A_{v h}$ is the bottom value of eddy viscosity.

Table 3. Typical vertical eddy viscosity $\left(A_{v}\right)$ formulations for systems that are continuously stratified where $\tau_{z}=A_{v} \frac{\partial u}{\partial z}$.

\begin{tabular}{|c|c|c|c|}
\hline $\begin{array}{l}\text { Equation } \\
\text { number }\end{array}$ & Equation & Comments & Reference \\
\hline 1 & $A_{v}=A_{v o}(1+\beta R i)^{\alpha}$ & $\begin{array}{l}\mathrm{A}_{\mathrm{vo}} \text { is the eddy viscosity at the surface, } \\
\mathrm{Ri} \text { is the Richardson number, } \\
R i=\frac{\partial \frac{\partial \rho}{\partial z}}{\rho\left(\frac{\partial u}{\partial z}\right)^{2}}, \alpha \text { and } \beta \text { were } \\
\text { empirical coefficients* }\end{array}$ & Munk and Anderson (1948) \\
\hline 2 & $A_{v}=\beta_{1}\left(\frac{A_{v o}}{1+R_{o}}\right)^{\alpha_{1}}$ & $\begin{array}{l}A_{\mathrm{v},} \text { is the eddy viscosity at the surface, } \\
\text { Ro is defined as } R_{0}=\frac{g h \Delta \rho}{\rho u_{*}^{2}}, \alpha_{1} \\
\text { and } \beta_{1} \text { were empirical coefficients }\end{array}$ & French (1979) \\
\hline 3 & $A_{v}=A_{v o} \exp \left(-\beta_{2} R i\right)$ & $\begin{array}{l}A_{v 0} \text { is the eddy viscosity at the surface, } \\
\beta_{2} \text { is an empirical coefficient* }\end{array}$ & $\begin{array}{l}\text { Mamayev as quoted in French } \\
\text { (1985) }\end{array}$ \\
\hline
\end{tabular}

The range of coefficients values are shown from French (1985) to be: for $\alpha=-1, \beta$ ranges from 2.5 to $30.3 ; \alpha=-2, \beta=9.8 ; \alpha=1, \beta=-3.3 ; \alpha=-0.5, \beta$ ranges from 10 to $30 ; \alpha_{1}=0.747, \beta_{1}=0.31 ; \alpha_{1}=0.379$, $\beta_{1}=0.062 ;$ and for model $3, \beta_{2}=0.4$;

\section{Longitudinal turbulent shear stress}

The longitudinal turbulent shear stress is defined as:

$$
\frac{\tau_{x x}}{\rho}=v_{\text {turbulent }} \frac{\partial U}{\partial x}=A_{x} \frac{\partial U}{\partial x}
$$


where $\quad A_{x}=v_{\text {turbulent }}$ and is the longitudinal turbulent viscosity or the longitudinal eddy viscosity. $A_{x}$ is a user-defined constant in the model.

This turbulence closure approximation is termed a zero-order closure model since no further equations are necessary to solve for the transmission of longitudinal shear stress within the fluid. This term is usually of very low magnitude except in areas near boundaries, like at the face of a dam, where the longitudinal velocity goes to zero.

\section{Validation of Velocity Field}

The velocity predicted by W2 in river channels with sloping bottoms will be compared to the following theoretical approaches for open-channel flow:

- steady-state, depth averaged velocity will be compared to Chezy or Manning's Equation, i.e.,

$$
\frac{1}{(h-\eta)} \int_{\eta}^{h} U d z=C \sqrt{R S}=\frac{1}{n} R^{2 / 3} S^{1 / 2}
$$

where $C$ is the Chezy coefficient

$\mathbf{n}$ is the Manning's friction factor

$\mathrm{S}$ is the channel longitudinal slope

$R$ is the hydraulic radius

The model will be run at steady-state and the predictions of velocity will be compared to the Chezy and Manning's Equation

- assuming a turbulent vertical eddy viscosity of $A_{v}=\kappa U_{*} z\left(1-\frac{z}{h-\eta}\right)$, the velocity profile varies vertically as $U(z)=\frac{U_{*}}{\kappa}\left(1+\ln \frac{z}{h-\eta}\right)$

where $U^{*}$ is the shear velocity $\kappa$ is the von Karman constant

This also is a steady-state model of the vertical variation of velocity in a sloping channel. The W2 model results will be compared with this formulation, as well as others derived for different assumed functional distributions of $A_{v}$.

\section{Variability in Meteorological Forcing}

The river basin model will be extended over large spatial scales that will probably include significant meteorological data variability. The model currently requires the following meteorological data: 
- air temperature

- dew point temperature (or relative humidity)

- wind speed and direction

- cloud cover (or measured solar radiation and a back-computed cloud cover)

Because of the implications of spatially variable meteorological data, the following aspects will be evaluated:

- allowance for different meteorological input files for different model branches

- in river basins and in some reservoir systems, shading by canyons or vegetation in parts of upper river basins may also be important. The inclusion of a simple segment-bysegment shading function that only adjusts short-wave solar radiation should be included. If a canopy formed over the segment, then adjustments would also have to be made on atmospheric radiation inputs. As a first approximation, this latter case will be neglected.

- if one meteorological file is provided with the elevation of the meteorological station, the air and dew-point temperature and short-wave solar radiation would be adjusted according to elevation of the system within the model and then allow the user to make branch-by-branch adjustments to wind sheltering and cloud cover

\section{Air temperature}

The adjustments to air temperature would follow the approach of Singh (1992), where the average temperature (dry bulb) decreases with altitude (assuming an adiabatic process) at $0.7^{\circ} \mathrm{C}$ per $100 \mathrm{~m}$. For example, in a modeling study of Wahiawa Reservoir (Wells and Berger, 1997), the reservoir was located at an elevation of $256.6 \mathrm{~m} \mathrm{NGVD}$ and the airport meteorological data were at an elevation of $2.1 \mathrm{~m}$ NGVD. The air temperature difference between the stations would then be about $1.8^{\circ} \mathrm{C}$. A correlation study of air temperatures was performed between Honolulu and Kunia and verified that this temperature correction was correct within $0.1^{\circ} \mathrm{C}$.

\section{Dew-point temperature}

The air temperature, though, is not the only meteorological data parameter that is affected by changes in altitude. The dew point temperature also is a function of the air temperature and relative humidity. The following correlation between air temperature, dew point temperature, and relative humidity from Singh (1992) was used to estimate the reduction in dew point temperature between different locations:

$$
T-T_{d e w} \cong(14.55+0.114 T)(1-R H)+(2.5+0.007 T)(1-R H)^{3}+(15.9+0.117 T)(1-R H)^{14}
$$

where $\mathrm{T}$ : air temperature in $\operatorname{deg} \mathrm{C}$

$\mathrm{T}_{\text {dew }}$ : dew point temperature in deg $\mathrm{C}$

RH: relative humidity as a fraction

With a known relative humidity and a known air temperature at the new elevation, the dew point temperature at the new elevation can be determined. This equation generally leads to a dew-point 
temperature reduction that is of the same magnitude as the dry bulb temperature, but somewhat less based on relative humidity.

\section{Alternative solar radiation calculation}

The current short-wave solar radiation algorithm in W2 does not correct for altitude of the water body nor for atmospheric conditions. A different algorithm can be included as a model option that incorporates short-wave solar radiation changes with elevation, as well as with atmospheric turbidity. This algorithm has been used by Brown and Barnwell (1987) in QUAL2E and the Environmental Laboratory (1986) in CE-QUAL-R1. This algorithm includes an additional tuning factor called the atmospheric attenuation factor, TURB. This factor accounts for scattering of shortwave solar radiation by atmospheric dust and moisture.

To illustrate the differences in the two algorithms, Figure 23 shows a comparison of the current W2 solar radiation formulation and the algorithm used in QUAL2E and CE-QUAL-R1 at various elevations for an atmospheric attenuation factor of 0.25 and a dew-point temperature of $15^{\circ} \mathrm{C}$.

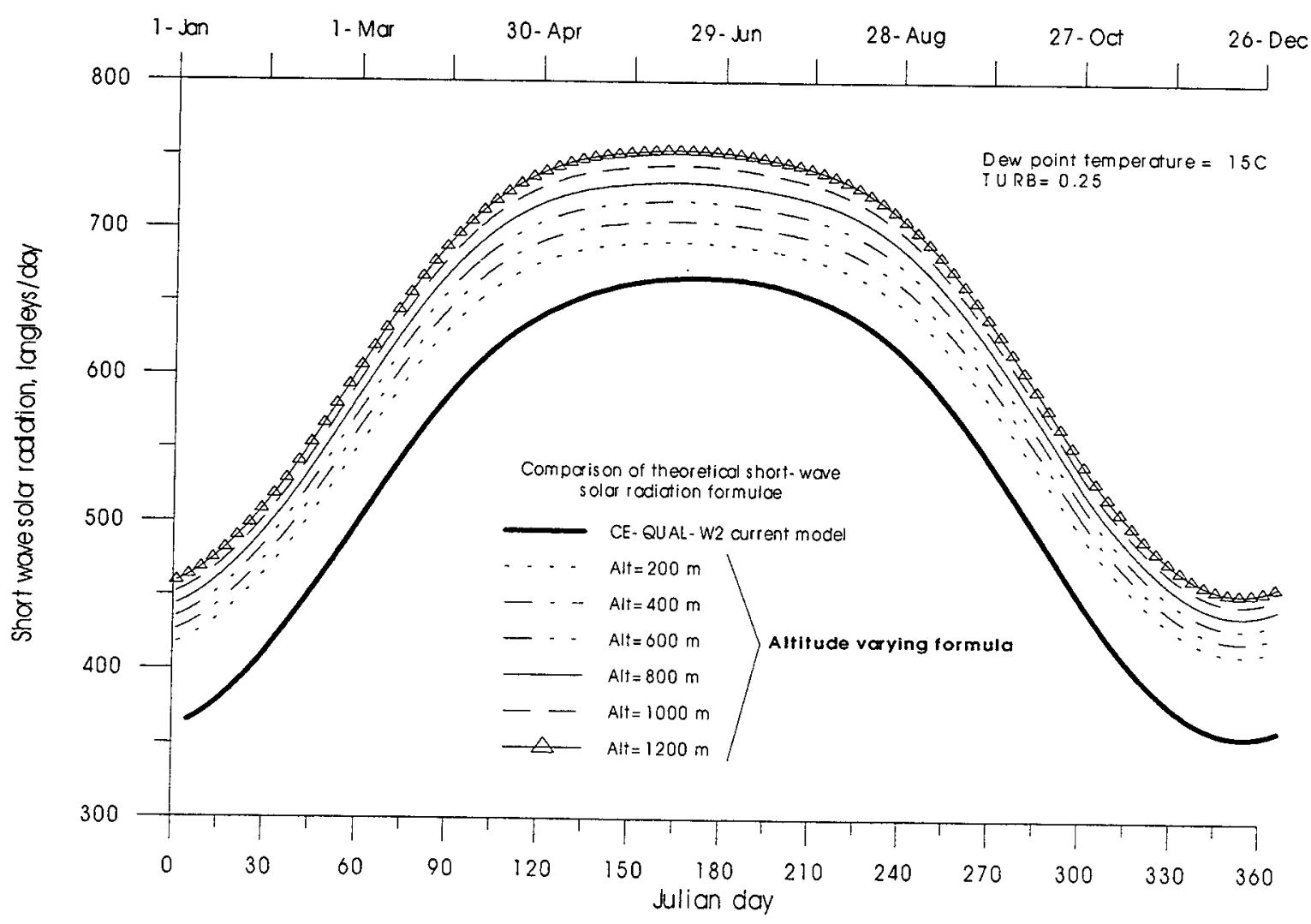

Figure 23. Comparison of solar radiation formulae for daily average clear-sky conditions using current W2 model equation and those used in QUAL2E and CE-QUAL-R1. 


\section{Variability in Reaeration Formulae}

Since the river basin model will encompass areas that are dependent on boundary shear or on wind stress for turbulence, the reaeration formula for these systems must be variable. In the following two sections, formulae for reaeration as a function of wind speed and as a function of boundary shear are presented.

\section{Theoretical reaeration formulae as function of wind speed}

Theoretical reaeration formulae for wind speed formulations in units of day ${ }^{-1}$ for $K_{a}$ and $m /$ day for $\mathrm{K}_{\mathrm{L}}$ are shown in Table 4.

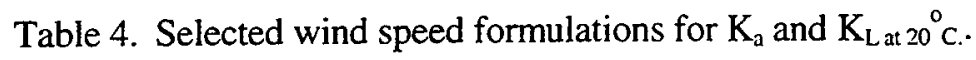

\begin{tabular}{|c|c|c|}
\hline Equation & Comments & Reference \\
\hline$K_{a}=\frac{K_{L}}{H}=\frac{0.864 W}{H}$ & $\begin{array}{l}\mathrm{W} \text { is in } \mathrm{m} / \mathrm{s} \text { measured at } 10 \mathrm{~m} \text { above } \\
\text { water surface. } \mathrm{H} \text { depth in } \mathrm{m}\end{array}$ & $\begin{array}{l}\text { Broecker et al } \\
\text { (1978) }\end{array}$ \\
\hline$K_{a}=\frac{K_{L}}{H}=\frac{\alpha W^{\beta}}{H}$ & $\begin{array}{l}\alpha=0.2, \beta=1.0 \text { for } W<3.5 \mathrm{~m} / \mathrm{s}: \alpha=0.057 \text {. } \\
\beta=2.0 \text { for } W>3.5 \mathrm{~m} / \mathrm{s} ; \text { where } W \text { is a } \\
\text { daily averaged wind speed }\end{array}$ & Gelda et al (1996) \\
\hline$K_{u}=\frac{K_{L}}{H}=\frac{0.728 W^{0.5}-0.317 W+0.0372 W^{2}}{H}$ & & $\begin{array}{l}\text { Banks and } \\
\text { Herrera (1977) }\end{array}$ \\
\hline$K_{a}=\frac{K_{L}}{H}=\frac{0.0986 W^{1.64}}{H}$ & & $\begin{array}{l}\text { Wanninkhof et al. } \\
\text { (1991) }\end{array}$ \\
\hline $\begin{array}{l}K_{a}=\frac{K_{L}}{H}=\frac{0.728 W^{0.5}-0.317 W+0.0372 W^{2}}{H} \\
+3.93 \frac{\sqrt{U}}{H^{1.5}}\end{array}$ & $\begin{array}{l}U \text { is the mean estuary tidal velocity in } \\
\mathrm{m} / \mathrm{s} \text {, this formula combines the effect of } \\
\text { wind from Banks and Herrera (1977) } \\
\text { and estuary tidal flow }\end{array}$ & $\begin{array}{l}\text { Thomann and } \\
\text { Fitzpatrick (1982) }\end{array}$ \\
\hline$K_{a}=\frac{K_{L}}{H}=\frac{\frac{D_{n 2}}{\left(200-60 W^{0.5}\right) 10^{-6}}}{H}$ & $\begin{array}{l}\mathrm{D}_{02} \text { is the molecular diffusivity of } \\
\text { oxygen (at } 20^{\circ} \mathrm{C} \text { is } 2.1 \mathrm{E}-9 \mathrm{~m}^{2} / \mathrm{s}\end{array}$ & Chen \\
\hline $\begin{array}{l}K_{a}=\frac{K_{L}}{H}=\frac{0.362 \sqrt{W}}{H} \quad W<5.5 \mathrm{~m} / \mathrm{s} \\
K_{a}=\frac{K_{L}}{H}=\frac{0.0277 W^{2}}{H} \quad W>5.5 \mathrm{~m} / \mathrm{s}\end{array}$ & & Banks (1975) \\
\hline$K_{a}=\frac{K_{L}}{H}=\frac{a+b W}{H}$ & $\begin{array}{l}\mathrm{W} \text { in m/day, a from } 0.005 \text { to } 0.01 \mathrm{~m} / \mathrm{day} \text {, } \\
\mathrm{b} \text { from } 1 \mathrm{E}-6 \text { to } 1 \mathrm{E}-5 \mathrm{~m}^{-1}\end{array}$ & $\begin{array}{l}\text { Baca and Amett } \\
\text { (1976) }\end{array}$ \\
\hline$K_{a}=\frac{K_{L}}{H}=\frac{0.64+0.128 W^{2}}{H}$ & recommended form for WQRSS model & Smith (1978) \\
\hline
\end{tabular}




\begin{tabular}{|c|c|c|}
\hline Equation & Comments & Reference \\
\hline $\begin{array}{l}K_{a}=\frac{K_{L}}{H}=\frac{0.156 W^{0.63}}{H} \quad W \leq 4.1 \mathrm{~m} / \mathrm{s} \\
K_{a}=\frac{K_{L}}{H}=\frac{0.0269 W^{1.9}}{H} \quad W>4.1 \mathrm{~m} / \mathrm{s}\end{array}$ & & Liss (1973) \\
\hline$K_{a}=\frac{K_{L}}{H}=\frac{0.0276 W^{2}}{H}$ & & $\begin{array}{l}\text { Downing and } \\
\text { Truesdale (1955) }\end{array}$ \\
\hline$K_{a}=\frac{K_{L}}{H}=\frac{0.0432 W^{2}}{H}$ & & Kanwisher (1963) \\
\hline$K_{a}=\frac{K_{L}}{H}=\frac{0.319 W}{H}$ & & $\begin{array}{l}\text { Yu. Tuffy, and } \\
\text { Lee (1977) }\end{array}$ \\
\hline $\begin{array}{l}K_{a}=\frac{K_{L}}{H}=\frac{0.398}{H} W<1.6 \mathrm{~m} / \mathrm{s} \\
K_{a}=\frac{K_{L}}{H}=\frac{0.155 W^{2}}{H} \quad W \geq 1.6 \mathrm{~m} / \mathrm{s}\end{array}$ & & Weiler (1974) \\
\hline$K_{a}=\frac{K_{L}}{H}=\frac{0.5+0.05 W^{2}}{H}$ & as used in current $\mathrm{W} 2$ model & $\begin{array}{l}\text { Cole and Buchak } \\
\text { (1995) }\end{array}$ \\
\hline
\end{tabular}

Figure 24 shows how some of these formulations vary with wind speed in the range of the winter wind velocities for Portland. 







\section{Theoretical formulae as a function of boundary shear}

Table 5 shows some of the more common reaeration formulae as a function of boundary shear.

Table 5. Reaeration formulae as a function of boundary shear at $20^{\circ} \mathrm{C}$.

\begin{tabular}{|c|c|c|c|}
\hline $\begin{array}{c}\text { Equation } \\
\text { number }\end{array}$ & Equation & Comments & Reference \\
\hline 1 & $K_{a}=\frac{K_{L}}{H}=\frac{\left(D_{O_{2}} U\right)^{1 / 2}}{H^{3 / 2}}$ & $\begin{array}{l}\mathrm{D}_{\mathrm{O} 2} \text { is the molccular diffusion } \\
\text { coefficient for water at } 20 \mathrm{oC} \text { it is } \\
8.1 \mathrm{E}^{-5} \mathrm{ft}^{2} / \mathrm{hr}, \mathrm{U} \text { and } \mathrm{H} \text { are average } \\
\text { velocity and depth of channel; } \\
\mathrm{D}_{\mathrm{O} 2}=1.91 \mathrm{E} 3(1.037)^{\mathrm{T}-20} \text { where } \mathrm{D} \text { is } \\
\text { in } \mathrm{ft}^{2} / \text { day }\end{array}$ & $\begin{array}{l}\text { O'Connor and Dobbins } \\
(1958)\end{array}$ \\
\hline 2 & $K_{a}=\frac{K_{L}}{H}=\frac{11.6 U}{H^{1.67}}$ & $\mathrm{U}$ in $\mathrm{fps}$ and $\mathrm{H}$ in $\mathrm{ft}$ and $\mathrm{K}_{\mathrm{a}}$ in day ${ }^{-1}$ & $\begin{array}{l}\text { Churchill, Elmore and } \\
\text { Buckingham (1962) }\end{array}$ \\
\hline 3 & $\begin{array}{l}K_{a}=0.88 U S \text { for } 10<Q<300 c f s \\
K_{a}=1.8 U S \text { for } 1<Q<10 c f s\end{array}$ & $\begin{array}{l}S \text { is slope in } \mathrm{ft}^{\prime} \text { mile, } \mathrm{U} \text { is velocity in } \\
\mathrm{fps}, \mathrm{K}_{\mathrm{a}} \text { is in day } \mathrm{y}^{-1}\end{array}$ & $\begin{array}{l}\text { Tsivoglou and Wallace } \\
\text { (1972) }\end{array}$ \\
\hline 4 & $K_{a}=\frac{K_{L}}{H}=\frac{21.6 U^{0.67}}{H^{1.85}}$ & $\mathrm{U}$ in $\mathrm{fps}, \mathrm{H}$ in $\mathrm{ft}$ & Owens et al. (1964) \\
\hline 5 & $K_{a}=\frac{K_{L}}{H}=\frac{25 u^{*}}{H}\left(1+F^{0.5}\right)$ & $\begin{array}{l}\mathrm{u}^{*} \text { is the shear velocity }\left[(\mathrm{HSg})^{0.5}\right], \mathrm{S} \\
\text { is the slope of encrgy grade line, F } \\
\text { is Froude number }\left[\mathrm{u}^{*} /(\mathrm{gH})^{0.5}\right]\end{array}$ & $\begin{array}{l}\text { Thackston and Krenkel } \\
\text { (1966) }\end{array}$ \\
\hline 6 & $K_{a}=\frac{K_{L}}{H}=\frac{7.62 U}{H^{1.33}}$ & $\mathrm{U}$ is in $\mathrm{fps}$ and $\mathrm{H}$ is in $\mathrm{ft}$ & Langbien and Durum (1967) \\
\hline
\end{tabular}

\section{Temperature dependence of reaeration formulae}

Many authors use the Arrhenius concept where

$$
K_{T}=K_{20} \Theta^{T-20}
$$

where $\Theta$ is 1.024 . Alternatively, as in the case of those reaeration formulae that use the molecular diffusivity of oxygen, a relationship such as:

$D_{O 2}\left(m^{2} / s\right)=4.58 E-11 \cdot T+1.2 E-9$

where $\mathrm{T}$ is the temperature in $\mathrm{C}$, has been used. These two relationships yield almost identical results as shown in Figure 25.

Upon further examination in the current code of $\mathrm{W} 2$, no temperature correction was made to the calculated value of $\mathrm{K}_{\mathrm{L}}$. This will be changed in the new code. 
Variation of KL with Temperature

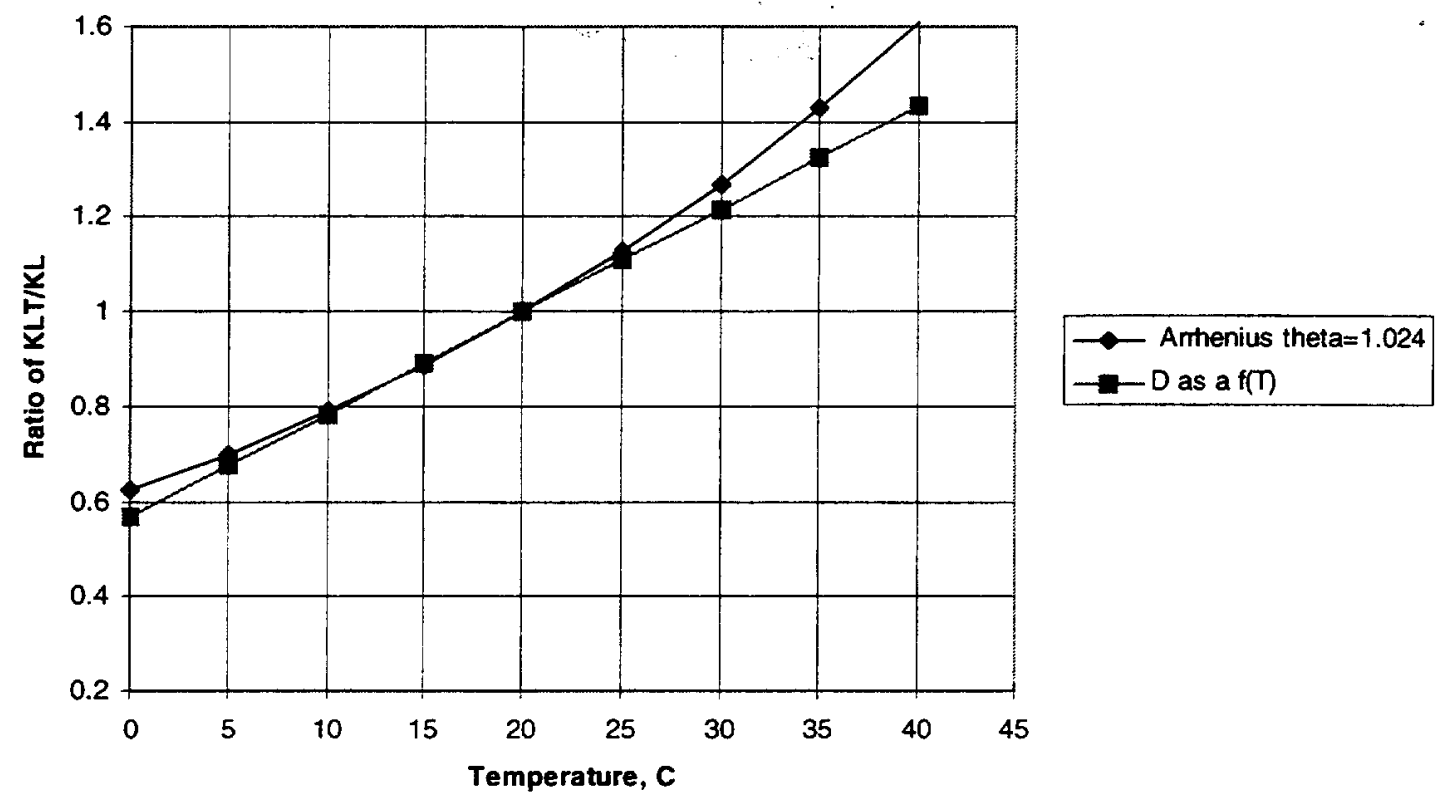

Figure 25. Variation of $\mathrm{K}_{\mathrm{LT}} / \mathrm{K}_{\mathrm{L} 20}$ as a function of temperature.

\section{Linkage of Branches with Internal Head Boundary Conditions}

\section{Linkage of mainstem branches}

One issue in the development of the river basin model is the linkage of branches of different channel slope orientation. This was shown earlier in Figure 4. Figure 26 shows in detail some of the variable definitions with the current sloped channel scheme. 


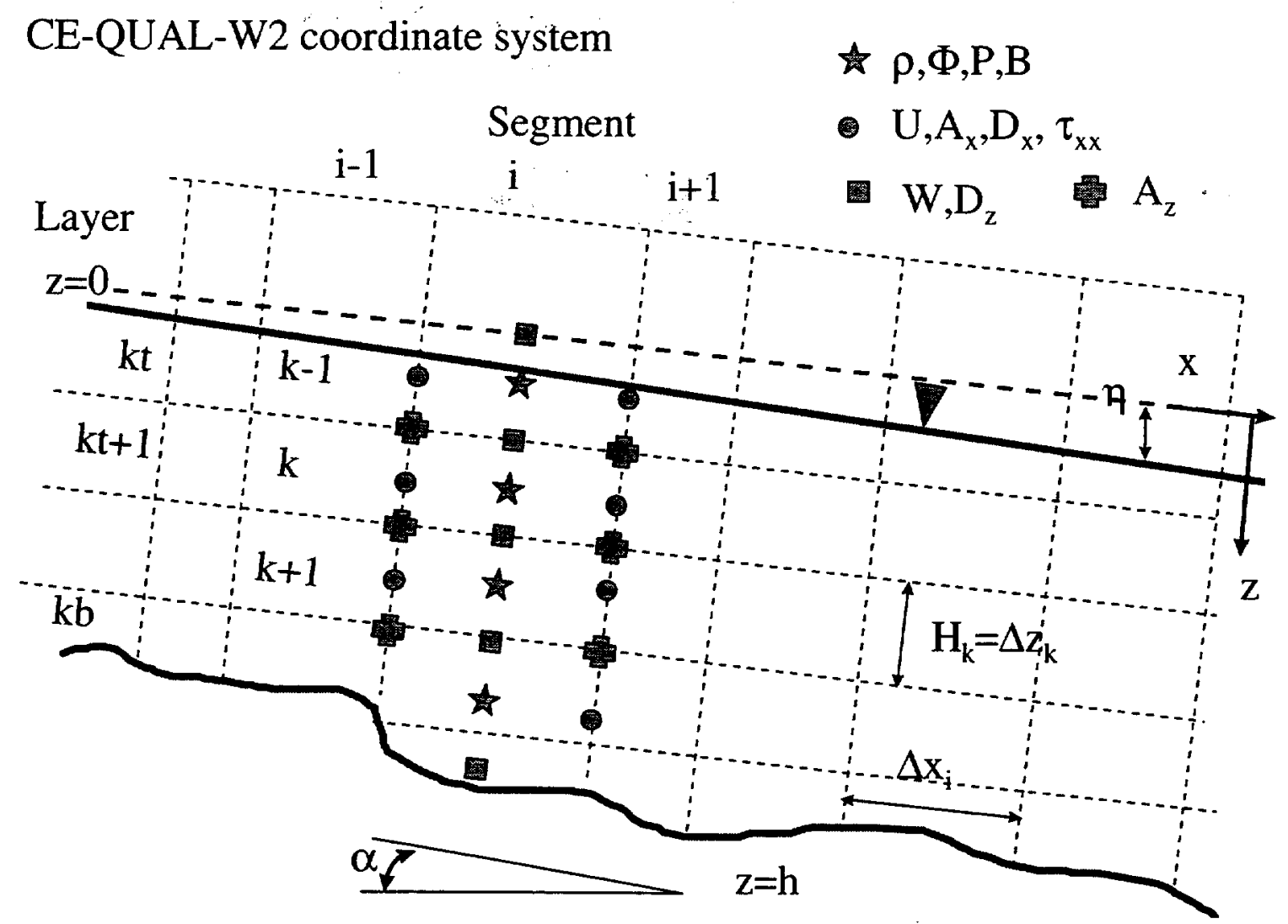

Figure 26. Variable definitions for W2 model with arbitrary channel slope.

At an internal junction between two branches where the slope changes, how should the velocity field and concentration field be mapped from the upstream grid to the downstream grid? A first order approach for the velocity vectors could be to assume that the angle orientation of the branch does not affect the stream lines, since they will bend to the shape of the channel bottom (Figure 27). This is no different than how W2 handles the transition between segments now (Figure 28).

\section{Branch transition}



Figure 27. Branch transition vertically. 


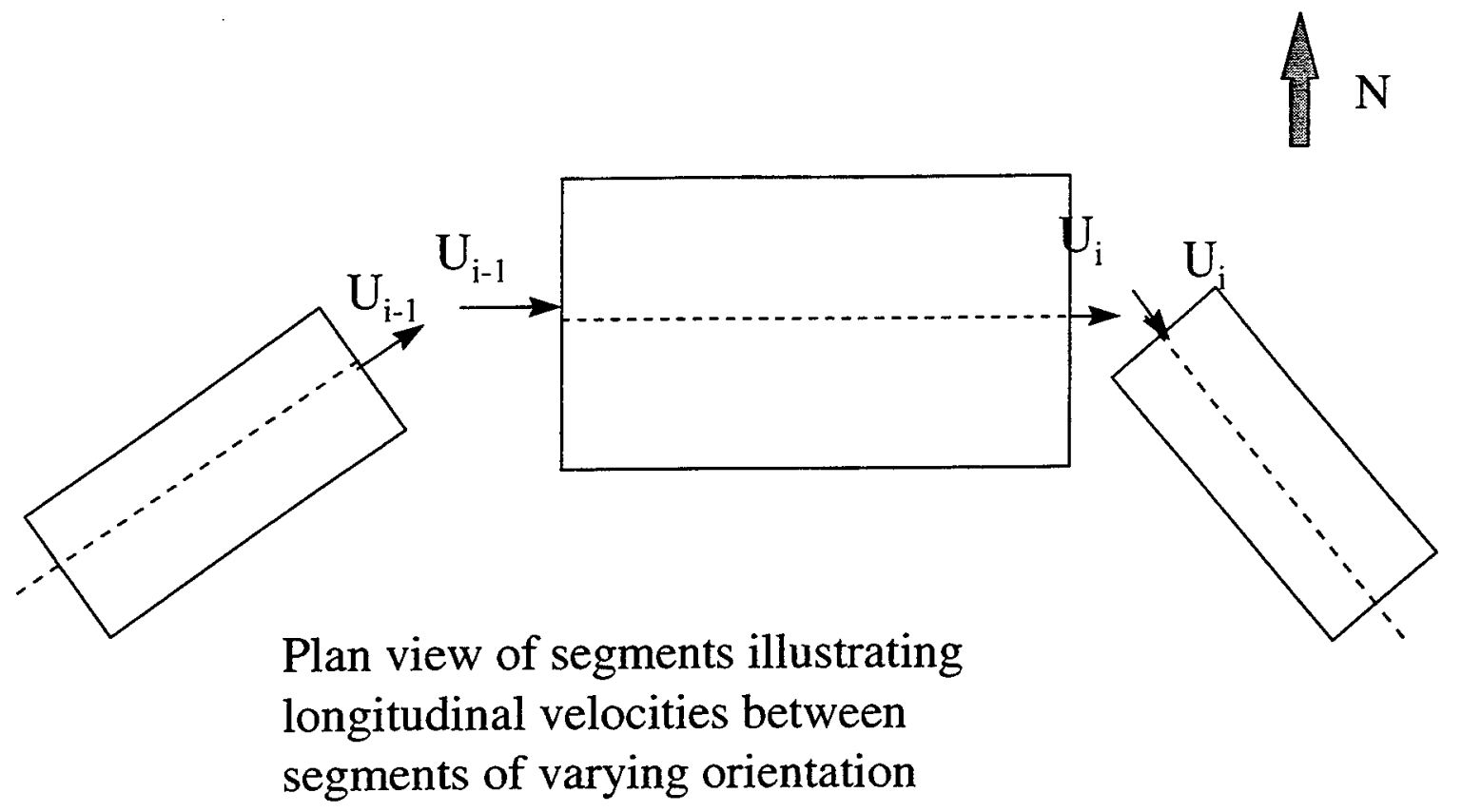

Figure 28. Variation of longitudinal velocity between segments.

In contrast to variation of the flow horizontally, the vertical and longitudinal components of the branch may be important for plunging flows. This will be deduced from numerical evaluation. In the case of preserving the $\mathrm{x}$ and $\mathrm{z}$ components of the velocity, the transition could be illustrated as in Figure 29.

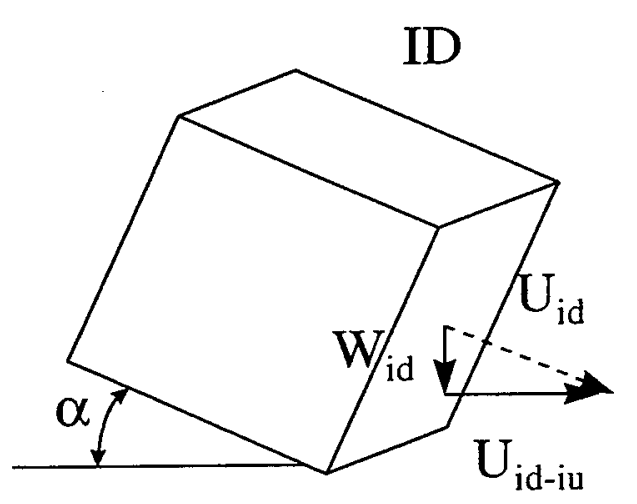

\section{Branch transition}

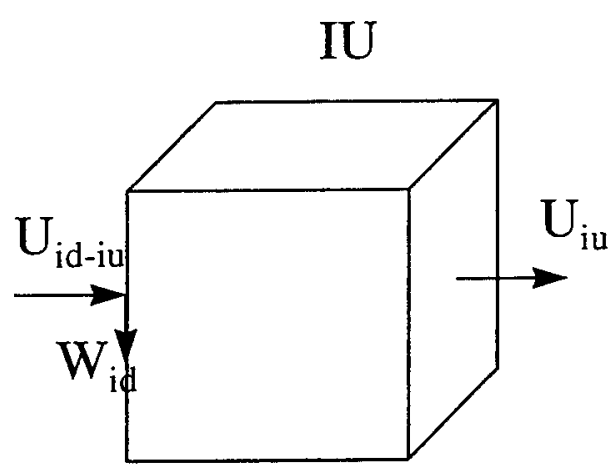

$$
\mathrm{U}_{\mathrm{id}-\mathrm{iu}}=\cos \alpha \mathrm{U}_{\mathrm{id}} \quad \mathrm{W}_{\mathrm{id}}=\sin \alpha \mathrm{U}_{\mathrm{id}}
$$

Figure 29. Illustration of branch transition.

However, the vertical velocity of a cell is not determined at the side edge of a segment, but at the bottom of the segment. In order for all the volume to be passed from one cell to another, all the 
flow from the downstream segment (ID) should be transferred to the upstream segment (IU). Since the model does not assume strong vertical accelerations, we may be forced to neglect the vertical component of velocity at this transition and assume that the longitudinal velocity entering segment $\mathrm{IU}$ is $\mathrm{U}_{\mathrm{ID}}$. Calculations and numerical testing will be performed to verify this assumption.

Another issue is the linkage between branches when the grid sizes are different between the upstream grid and the downstream grid. Flow and mass will be conserved at the linkage and will be computed internally. This spatial averaging of the flow (and velocity), heat and mass to preserve flow and constituent mass between branches is illustrated conceptually in Figure 30.



Figure 30. Transfer of mass and momentum between main stem branches with unequal grid spacing.

\section{Linkage of tributary branches}

The existing W2 model assumes all tributary branches come in at right angles to the main channel. In many cases, this is appropriate. This orientation (Figure 31) allows volume exchange, but no momentum exchange between branches. The CE-QUAL-RIV1 (Environmental Laboratory, 1995) and the EPA DYNHYD models (Ambrose, et al., 1988) also neglect momentum effects of lateral tributary inflows. For branches with arbitrary channel orientation (as in Figure 32), code changes will be made to allow momentum, in addition to volume (this is accounted for in the free surface equation as q), to be exchanged between branches.

In this section, the linking of these tributary branches with the main stem and preserving momentum between them will be discussed. 




Figure 31. Linkage of tributary branches with existing W2 model.

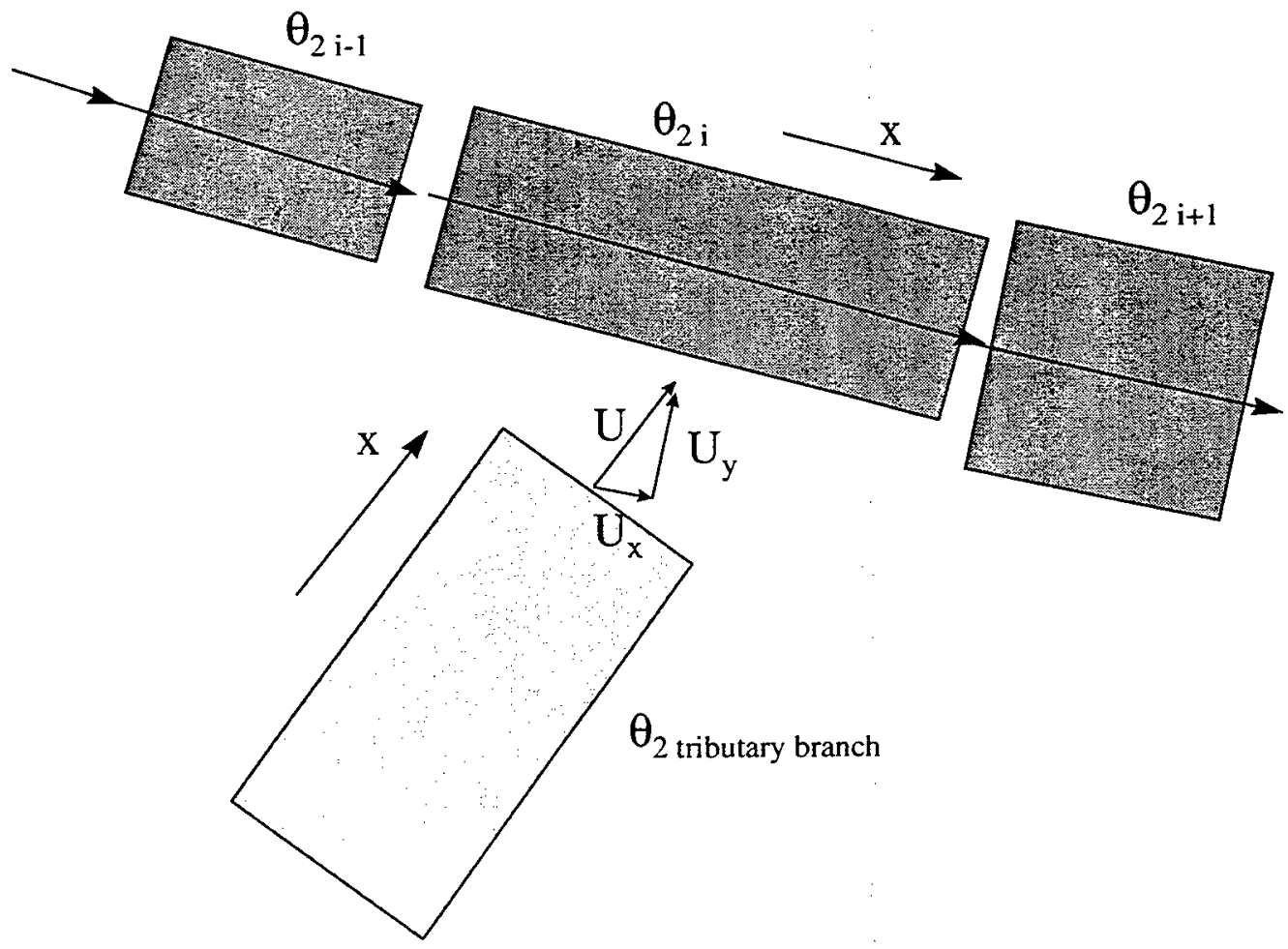

Figure 32. Linkage of tributary branch coming in at an angle to main branch. 
The tributary inflow can create shear stress along both the longitudinal axis of the main stem branch and along the $y$-axis of the segment. In the current model, this cross-shear term is neglected and does not impact vertical mixing. The only vertical mixing as a result of cross-shear is from the wind component in the lateral direction. For this new formulation, the cross-shear mixing will be added to the cross-shear wind stress for the computation involving the vertical eddy viscosity and vertical diffusivity. This involves determining the $y$ and $x$ velocity components of the entering branch as shown in Figure 33.
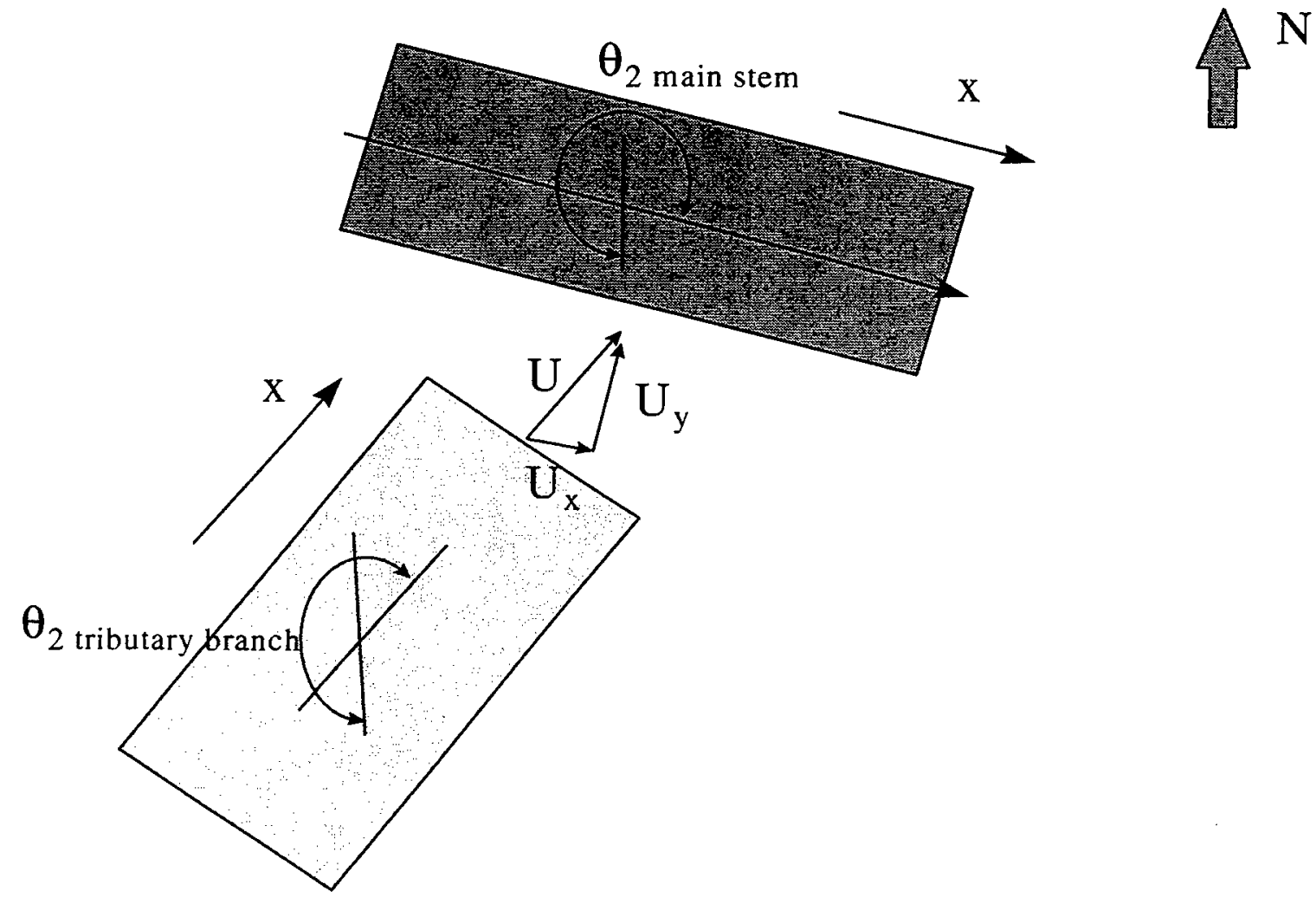

Figure 33. Schematic of branch connection.

\section{Longitudinal momentum}

The vector component of velocity in the $x$-direction of the main channel, $U_{x}$, can be computed by analysis of the channel orientations. This component in the $x$-direction would be: $U_{x}=U \cos \beta$ where $\mathrm{U}$ is the longitudinal velocity of the tributary at segment $\mathrm{ID}$ for the tributary branch and $\beta$ is the difference in the angle between the main stem and tributary segments (see Figure 34). 




Figure 34. Schematic of computation of $x$ and $y$ velocity components.

The conservation of momentum about a control volume, the main stem segment, would result in an additional source of momentum. Lai (1986) shows that the correction to the $\mathrm{x}$-momentum equation would be:

$q B U_{x}$

where $\mathrm{q}$ is the lateral inflow per unit length.

This arises from re-deriving the momentum equations and assuming that all the fluid (q) entering the segment is moving at the velocity $U_{x}$. This correction to the $x$-momentum equation would be:

$$
\begin{aligned}
& \frac{\partial \mathrm{UB}}{\partial \mathrm{t}}+\frac{\partial \mathrm{UUB}}{\partial \mathrm{x}}+\frac{\partial \mathrm{WUB}}{\partial \mathrm{z}}=g B \sin \alpha+g \cos \alpha B \frac{\partial \eta}{\partial x}-\frac{g \cos \alpha B}{\rho} \int_{\eta}^{z} \frac{\partial \rho}{\partial x} d z+ \\
& \frac{1}{\rho} \frac{\partial B \tau_{x x}}{\partial \mathrm{x}}+\frac{1}{\rho} \frac{\partial \mathrm{B} \tau_{\mathrm{x} z}}{\partial \mathrm{z}}+\underbrace{q B U_{x}}_{\text {momentum from side tributaries }}
\end{aligned}
$$

\section{Cross-shear of tributary inflow}

The $y$-velocity coming into a reservoir also may contribute significantly to vertical mixing. The $y$ component of a tributary inflow is (see Figure 33): $U_{y}=U \sin \beta$. Since there is no $y$-momentum equation, the only mechanism for mixing energy with the present formulation of the vertical shear stress is the cross-shear stress from the wind given earlier as $\tau_{w y} \cong C_{D} \rho_{a} W_{h}^{2} \sin \left(\Theta_{1}-\Theta_{2}\right)$. 
This cross-shear stress accounts for the shear stress and mixing that results from wind blowing across the $y$-axis of the segment. The lateral branch inflow at a velocity, $U_{y}$, could be thought of as an additional component of that stress under the current context of the turbulence closure approximations.

Assuming that the water in the y-direction has zero velocity, the additional shear stress could be parameterized as an interfacial shear:

$$
\tau_{\text {yributary }} \cong \rho \frac{f}{8} U_{y}^{2}
$$

where $f$ is an interfacial friction factor. For two-layer flow systems, $f$ has been found to be of order 0.01 . The value of $f$ for this non-ideal approach could be determined by numerical computation. Hence, the value of the cross-shear term would be increased by a lateral tributary inflow. This will be evaluated by numerical experiments computing the magnitude of the cross-shear term from wind and from lateral inflow. A more robust theoretical approach may be needed to account for this increase in lateral shear, but that may be necessary only if the model includes the y-momentum equation. 


\section{Additional River Basin Model Issues}

Since W2 will be applied to river basins, additional factors may need to be addressed in the model. Some of these potential factors may be:

- impact of river meanders on transport (see Holley and Jirka, 1986)

- impact of shallow embayments - shallow embayments may be necessary for the continuity balance but may not really fully participate in momentum transport. This issue is also necessary to be addressed in reservoir systems. In W2 currently, one can specify a lateral branch with an angle $90^{\circ}$ to the main stem to account for this. Alternatively, one could follow the approach of CE-QUAL-RIV1, where storage areas are added to a segment that participate in water quality and volume balance, but not in the momentum balance.

- evaluation of revising the W2 bathymetry layout for river channels - this would include allowing the user to define a one-layer cell that has a changing cross-sectional area with depth. For example in CE-QUAL-RIV1, the user can input a rectangular, triangular, trapezoidal, parabolic, or ellipsoidal cross-section. In W2, the user would have to input several vertical layers to have the same shape as the CE-QUAL-RIV1 one-layer model. In order to improve the efficiency of the code, efforts will be made to allow W2 to also have one-layer with an arbitrary channel shape.

- impact of constrictions in the river channel - in river systems, the impact of bridge piers or other obstacles in the fluid may be significant. The $\mathrm{x}$-momentum equation may need to reflect the additional frictional resistance. 


\section{Summary}

The following tasks will be performed to implement the above points:

- alter the x-momentum equation for a general channel slope within the Version 3 code

- alter the input of data for a sloping channel by adding the channel slope and explaining how the channel geometry will be entered

- allow for a branch to be associated with a given meteorological file or allow the option for altitude dependent meteorological terms to be adjusted

- allow for cell variable or branch variable friction and wind sheltering coefficient

- alter the code to allow for internal head boundary conditions between a main stem and a tributary branch to transfer momentum properly (both longitudinal momentum and the additional cross-shear terms)

- alter the code to allow a transition between main stem branches when the channel slope and the cell layers are different

Once these tasks are complete, the code will be tested for test cases in order to evaluate the impact of the various model changes. Numerous vertical eddy viscosity formulations will be used to compare model predictions to theory. 
Ambrose, R. B.; Wool, T.; Connolly, J. P.; and Schanz, R. W. (1988) "WASP4, A Hydrodynamic and Water Quality Model: Model Theory, User's Manual, and Programmer's Guide," Environmnetal Reserach Laboratory, Environmental Protection Agency, EPA 600/3-87/039, Athens, Ga.

ASCE (1988) "Turbulence Modeling of Surface Water Flow and Transport," Journal of Hydraulic Engineering, ASCE Committee on Turbulence Models in Hydraulic Computations, 114(9),9701073.

Batchelor, G. K. (1967) An Introduction to Fluid Dynamics, Cambridge University Press, NY.

Berger, C. and Wells, S. A. (1995) "Effects of Management Strategies to Improve Water Quality in the Tualatin River, Oregon," in Water Resources Engineering, Vol. 2, ed. by W, Espey Jr. and P. Combs, ASCE, 1360-1364.

Brown, L. C. and Barnwell, T. O. (1987) "The Enhanced Stream water Quality Models QUAL2E and QUAL2E-UNCAS: Documentation and User Manual," Environmental Research Laboratory, EPA/600/3-87/007, Athens, Ga.

Chapman, R. (1989) "Review and Recommendation of Estuarine Mixing Parameterizations, with Specific Reference to Vertical Mixing in Multi-Dimensional Boxes," Report prepared for USACE, Waterways Experiments Station, Vicksburg, MS.

Cushman-Roisin, B. (1994) Introduction to Geophysical Fluid Dynamics, Prentice-Hall, Englewood Cliffs, NJ.

Cole, T. and Buchak, E. (1995) CE-QUAL-W2: A Two-Dimensional, Laterally Averaged, Hydrodynamic and Water Quality Model, Version 2.0, Technical Report El-95-May 1995,

Waterways Experiments Station, Vicksburg, MS.

Engelund, F. 1978. Effect of Lateral Wind on Uniform Channel Flow. Progress Report 45, Inst. of Hydrodynamic and Hydraulic Engr., Tech. Univ. of Denmark.

Environmental Laboratory (1986)"CE-QUAL-R1: A Numerical One-Diemnsional Model of Reservoir Water Quality; User's Manual," Instruction Report EL-82-1, USACE Waterways Experiments Station, Vicksburg, Ms.

Environmental Laboratory (1995) "CE-QUAL-RIV1: A Dynamic, One-Dimensional (Longitudinal) Water Quality Model for Streams: User's Manual," Instruction Report EL-95-2, USACE Waterways Experiments Station, Vicksburg, Ms. 
Fischer, H. B.; E. List; R. Koh; J. Imberger; N. Brooks (1979) Mixing in Inland and Coastal Waters, Academic Press, NY.

French, R. H. (1985) Open-Channel Hydraulics, McGraw-Hill, New York.

Holley, E. R. and Jirka, G. (1986) "Mixing in Rivers," Technical Report E-86-11, US Army Engineer Waterways Experiment Station, Vicksburg, MS.

Koutitas, C. G. 1978. Numerical Solution of the Complete Equations for Nearly Horizontal Flows. Advances in Water Resources, 1(4), 213.

Libby, P. A. (1996) Introduction to Turbulence, Taylor and Francis, Washington D.C.

Lighthill, J. (1978) Waves in Fluids, Cambridge University Press, NY.

Liggett, J. A. 1970. Cell Method for Computing Lake Circulation. Journal of the Hydraulics Div., ASCE, 96(HY3), 725.

Lindijer, G. H. 1979. Three-Dimensional Circulation Models for Shallow Lakes and Seas; SemiAnalytical Steady-State Analysis of Wind-Driven Current Including the effect of Depth-Dependent Turbulent Exchange Coefficient. Report R 900-11, Delft Hydraulics Laboratory, Netherlands.

Madsen, O. S. 1977. A Realistic Model of the Wind-Induced Ekman Boundary Layer. J. Physical Oceanography, 7(2), 248.

Munk, W. H. and Anderson, E. R. (1948) "Notes on the Theory of the Thermocline," Journal of Marine Research, Vol 1, p.276.

Neumann, G. and Pierson, W. J. 1966. Principles of Physical Oceanography. Prentice-Hall Inc. Englewood Cliffs, N. J.

Sabersky, R.; A. Acosta, E. Haupmann (1989) Fluid Flow A First Course in Fluid Mechanics, Macmillan Publishing Co., NY.

Shanahan, P. and Harleman, D. (1982) "Linked Hydrodynamic and Biogeochemical Models of Water Quality in Shallow Lakes," Technical Report 268, R. M. Parson Laboratory, MIT, Cambridge, MA.

Thomas, J. H. 1975. A Theory of Steady Wind-Driven Current in Shallow Water with Variable Eddy Viscosity, J. Physical Oceanography, 5(1), 136.

Wells, S. A. and Berger, C. J. 1995. "Hydraulic and Water Quality Modeling of Wahiawa Reservoir," prepared for R. M. Towill Corporation, Honolulu, Ha.

Witten, A. J. and J. H. Thomas 1976. Steady Wind-Driven Currents in a Large Lake with Depth Dependent Eddy Viscosity, J. Physical Oceanography, 6(1), 85. 
Banks, R.B. 1975. Some features of wind action on shallow lakes, ASCE, J. Env. Engmg. Div., 101(EE3), pp. 489-504.

Baca, R.G. and R.C. Arnett. 1976. A limnological model for eutrophic lakes and impoundments, Batelle Inc., Pacific Northwest Laboratories, Richland, Washington.

Banks, R. B. and Herrera, F. F. 1977. Effect of Wind and Rain on Surface Reaeration. J. Envir. Engr. Div. ASCE 101(EE5):813-827.

Broecker, H. C., Petermann, J., and Siems, W. 1978. The Influence of Wind on $\mathrm{CO}_{2}$ Exchange in a Wind-Wave Tunnel, J. Marine Res., 36(4):595-610.

Gelda, R. K., Auer, M. T., Effler, S. W., Chapra, S. C., and Storey, M. L. 1996. Determination of Reaeration Coefficients: A Whole Lake Approach. J. Envir. Engr. ASCE.

Smith, D.J. 1978. WQRRS, Generalized computer program for River-Reservoir systems. USACE Hydrologic Engineering Center (HEC), Davis, California.User's Manual 401-100, 100A, 210 pp.

Liss, P.S. 1973. Processes of gas exchange across an air-water interface. Deep Sea Research, Vol. 20, pp 221-238.

Downing, A.L., and G.A. Truesdale. 1955. Some factors affecting the rates of solution of oxygen in water. Journal of Applied Chemistry, Vol. 5, pp.570-581.

Kanwisher, J. 1963. On exchange of gases between the atmosphere and the sea. Deep Sea Research, Vol. 10, pp. 195-207.

Thomann, R. V. and Fitzpartrick, J. F. 1982. Calibration and Verification of a Mathematical Model of the Eutrophication of the Potomac Estuary, report by HydroQual, Inc. Mahwah, NJ, to DES, District of Columbia.

Yu, S.L., T.J. Tuffy, and D.S. Lee. 1977. Atmosphere reaeration in a lake. Office of Water Resources and Technology, U.S. Department of the Interior.

Wannikof, R., Ledwell, J. R., and Crusius, J. 1991. Gas Transfer Velocities on Lakes measured with Sulfur Hexafluoride. In Symposium Volume of the Second International Conference on Gas Transfer at Water Surfaces, S. C. Wilhelms and J. S. Gulliver, eds., Minneapolis, Mn.

Weiler, R.R. 1974. Carbon dioxide exchange between water and atmosphere.Journal of Fisheries research, Board Committee, Vol. 31, pp. 329-332. 


\section{REPORT DOCUMENTATION PAGE}

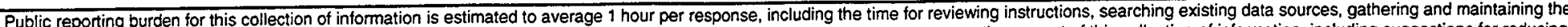

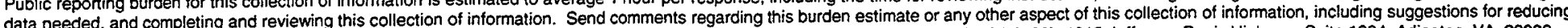

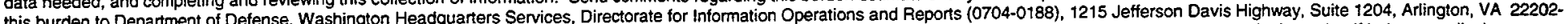

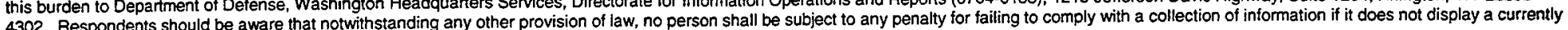
4302. Respondents should be aware that notwithstanding any other provision of law, no person shall
1. REPORT DATE (DD-MM-YYYY)
2. REPORT TYPE

August 2000

Final report

4. TITLE AND SUBTITLE

Theoretical Basis for the CE-QUAL-W2 River Basin Model

5b. GRANT NUMBER

5c. PROGRAM ELEMENT NUMBER

6. AUTHOR(S)

Scott A. Wells, Thomas M. Cole

5d. PROJECT NUMBER

5e. TASK NUMBER

5f. WORK UNIT NUMBER

33251

7. PERFORMING ORGANIZATION NAME(S) AND ADDRESS(ES)

8. PERFORMING ORGANIZATION REPORT NUMBER

Department of Civil Engineering

Portland State University

Portland, OR 97207-0751
U.S. Army Engineer Research and Development Center

Environmental Laboratory

3909 Halls Ferry Road

Vicksburg, MS 39180-6199
ERDC/EL TR-00-7

10. SPONSOR/MONITOR'S ACRONYM(S)

11. SPONSOR/MONITOR'S REPORT NUMBER(S)

\section{DISTRIBUTION / AVAILABILITY STATEMENT}

Approved for public release, distribution unlimited.

\section{SUPPLEMENTARY NOTES}

\section{ABSTRACT}

This report describes the theoretical development for CE-QUAL-W2, Version 3, that will allow the application of the model to entire water basins including multiple reservoirs, steeply sloping rivers, and estuaries. The governing equations are rederived to include the ability to model steeply sloping rivers. Numerous auxiliary issues including turbulence schemes and reaeration more appropriate for rivers are also explored.

\section{SUBJECT TERMS}

Hydrodynamic model, River basin model, Water quality model

16. SECURITY CLASSIFICATION OF:

a. REPORT

UNCLASSIFIED

b. ABSTRACT
UNCLASSIFIED

c. THIS PAGE

UNCLASSIFIED

\begin{tabular}{l|c|}
\hline $\begin{array}{l}\text { 17. LIMITATION } \\
\text { OF ABSTRACT }\end{array}$ & $\begin{array}{c}\text { 18. NUMBER } \\
\text { OF PAGES }\end{array}$ \\
& 62 \\
\hline
\end{tabular}

62 19a. NAME OF RESPONSIBLE PERSON

19b. TELEPHONE NUMBER (include area code) 